\title{
Alexandra Sayuri Watanabe
}

Perfil clínico e laboratorial de pacientes com anafilaxia à ferroada de formigas (Solenopsis sp) sob tratamento com imunoterapia específica

Tese apresentada à Faculdade de Medicina da Universidade de São Paulo para obtenção do título de Doutora em Ciências

Programa de Alergia e Imunopatologia

Orientador: Prof. Dr. Fabio Fernandes Morato Castro

São Paulo 


\section{Alexandra Sayuri Watanabe}

Perfil clínico e laboratorial de pacientes com anafilaxia à ferroada de formigas (Solenopsis sp) sob tratamento com imunoterapia específica

Tese apresentada à Faculdade de Medicina da Universidade de São Paulo para obtenção do título de Doutora em Ciências

Programa de Alergia e Imunopatologia

Orientador: Prof. Dr. Fabio Fernandes Morato Castro

São Paulo 


\section{FICHA CATALOGRÁFICA}

Dados Internacionais de Catalogaçäo na Publicação (CIP)

Preparada pela Biblioteca da

Faculdade de Medicina da Universidade de São Paulo

Creprodução autorizada pelo autor

Watanabe, Alexandra Sayuri

Perfil clínico e laboratorial de pacientes com anafilaxia à ferroada de formigas (Solenopsis $\mathrm{sp}$ )

sob tratamento com imunoterapia especifica

Alexandra Sayuri Watanabe. -- São Paulo, 2020.

Tese (doutorado)--Faculdade de Medicina da

Universidade de São Paulo.

Programa de Alergia e Imunopatologia.

Orientador: Fabio Fernandes Morato Castro.

Descritores: 1.Himenópteros 2.Anafilaxia .Venenos de formiga 4.Dessensibilização imunológica 5.Hipersensibilidade

$\mathrm{USP} / \mathrm{FM} / \mathrm{DBD}-238 / 20$

Responsável: Erinalva da Conceição Batista, CRB-8 6755 


\section{DEDICATÓRIA}

Dedico esta tese a meus pais, que mesmo já com 81 e 85 anos sempre tentam até hoje dar o melhor para seus filhos. Dedico a meu marido, Fabio Y., aos meus filhos, Léo e Bia. $\mathrm{O}$ amor por eles me faz lutar para ser uma pessoa melhor todos os dias! Dedico a meus irmãos e sobrinhos, sempre estaremos unidos, sempre nos ajudando... 


\section{AGRADECIMENTOS}

Agradeço a Faculdade de Medicina da USP que faço parte desde aluna, na Turma 83 até agora. Ao Prof Jorge Kalil, por me acolher no Serviço e que nos ensina que a ciência de qualidade pode ser realizada no Brasil. Ao Dr Luiz Augusto Marcondes Fonseca, que me orientou no mestrado. Ao Prof Dr Fabio Fernandes Morato Castro, com sua capacidade enorme de acreditar nas pessoas, de mostrar que a difusão do conhecimento é fundamental e que só beneficia os pacientes! Com ele aprendi não somente esse assunto da tese, mas o olhar voltado para doenças alérgicas. Nos passa segurança, que estamos no caminho certo e que podemos contar com seu apoio em qualquer situação. A Prof Keity Souza Santos, com seu conhecimento profundo, prático e com sua didática nos ensina além da bancada; além de ser uma grande amiga. A Ariana, que me ensinou que a palavra SORTE não é adequada para se referir a uma pessoa. Dedicação, profissionalismo e estudo são palavras mais adequadas. Ao Clóvis, sempre com frases fortes e seguras; a Ana Paula, com sorriso confortante e palavras na hora certa; a Elaine, com frases maduras e alegres; Isaura, sempre preocupada com o outro, Fabi: com voz suave, mas de personalidade; ao Martti e Cynthia: gêmeos com corações enormes e energia que não acaba! Aos meus amigos de infância, de colégio Etapa (Henri e Celina: me ajudaram com os extratos, eternos amigos), de faculdade, de HC, de Oshiman, aos amigos que encontrei pela vida, fui me moldando e me tornando a pessoa que sou hoje pelo convívio com eles. À diretoria do LIM 60 (Dra Cristina Kokron e Dr Edécio C. Neto) e todos funcionários que lá atuam e que me ajudaram muito. À Dra Myrthes, que me ajudou a estar nesse Serviço há muitos anos atrás,... À Rosana Coutinho, minha parceira nas terças de manhã, uma pessoa que merece tudo de bom nessa vida. Aos sempre presentes: Serafim, Junior e Maurício! À secretaria: Tania, Sonia e Cris meu muito obrigada! A Eleni Arruda que sempre me salvou nesses anos! A todos assistentes do HC-FMUSP, que mostram a força do conhecimento desse Serviço! As alunas da Prof Keity, aos residentes e estagiários! Muitos passam por lá, e deixam saudades! E a Nossa Senhora Aparecida (me casei na igreja de Nossa Senhora Aparecida), que ela sempre cubra com seu manto as pessoas que estão comigo e proteja de todos males! 
"Aprender é a única coisa de que a mente nunca se cansa, nunca tem medo e nunca se arrepende"

(Leonardo da Vinci) 


\section{NORMATIZAÇÃO ADOTADA}

Esta dissertação ou tese está de acordo com as seguintes normas, em vigor no momento desta publicação:

Referências: adaptado de International Committee of Medical Journals Editors (Vancouver).

Universidade de São Paulo. Faculdade de Medicina. Divisão de Biblioteca e Documentação. Guia de apresentação de dissertações, teses e monografias. Elaborado por Anneliese Carneiro da Cunha, Maria Julia de A. L. Freddi, Maria F. Crestana, Marinalva de Souza Aragão, Suely Campos Cardoso, Valéria Vilhena. 3a ed. São Paulo: Divisão de Biblioteca e Documentação; 2011.

Abreviaturas dos títulos dos periódicos de acordo com List of Journals Indexed in Index Medicus. 


\section{SUMÁRIO}

\section{Lista de abreviaturas, siglas e símbolos}

\section{Lista de figuras}

\section{Lista de tabelas}

RESUMO

SUMMARY

1 INTRODUÇÃO

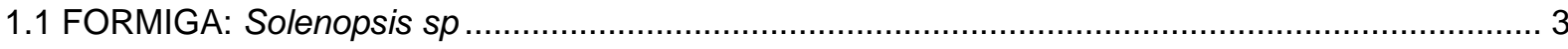

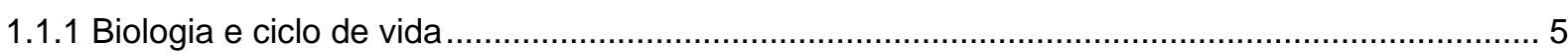

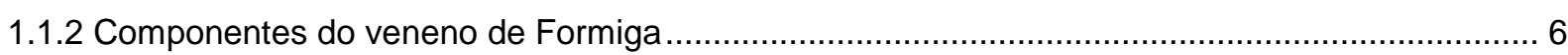

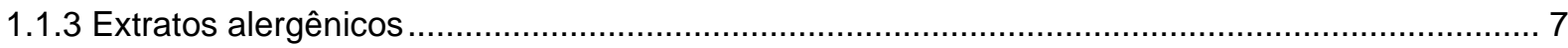

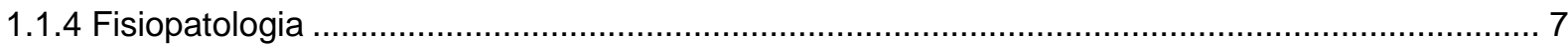

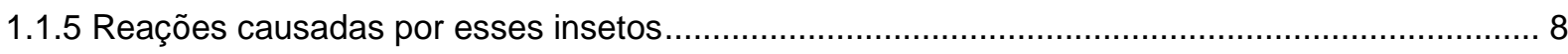

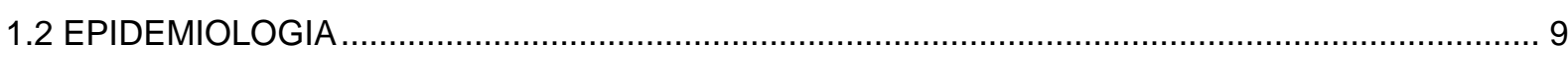

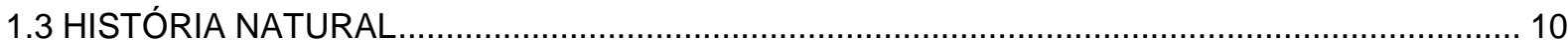

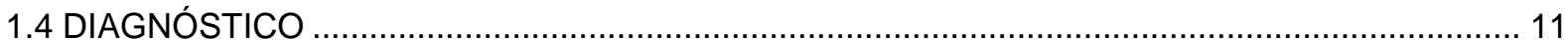

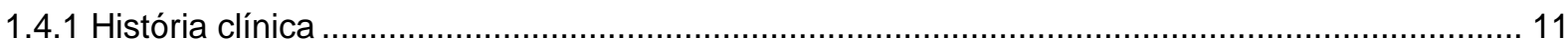

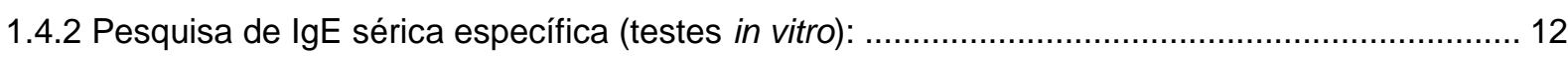

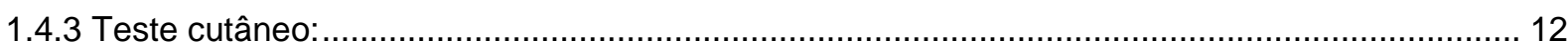

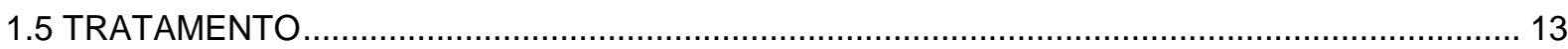

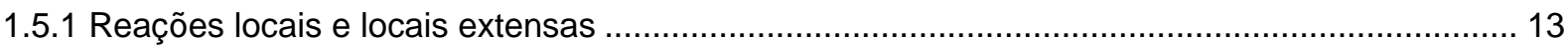

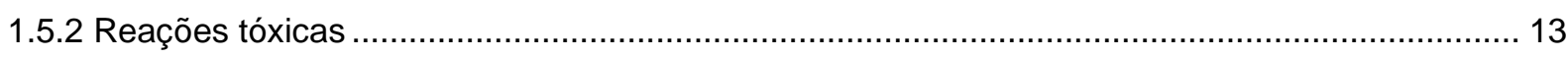

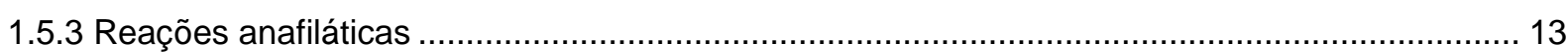

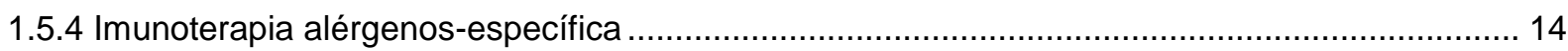

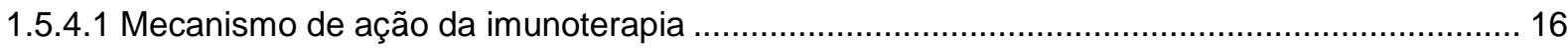

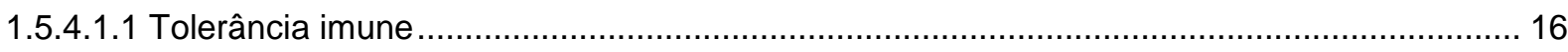

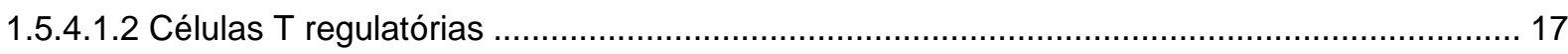

1.5.4.1.3 Células B regulatórias e tolerância imune ................................................................... 18

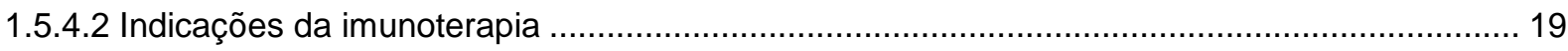

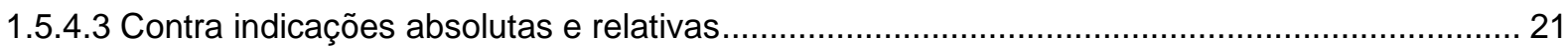

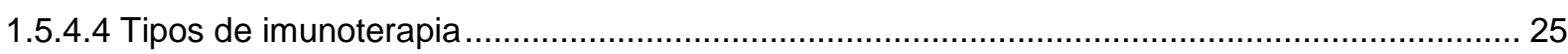

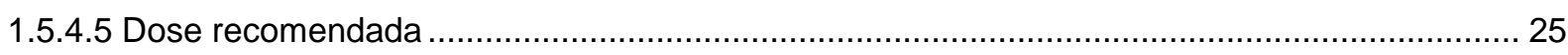

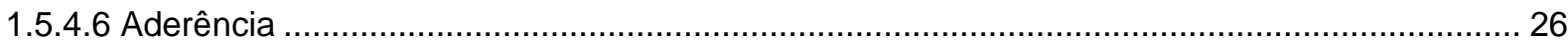

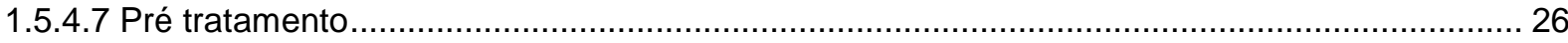




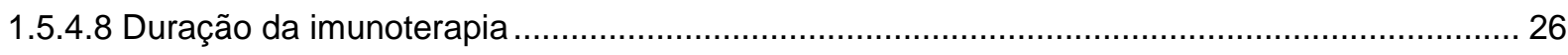

1.5.4.9 Fatores de risco para reações adversas durante a imunoterapia ....................................... 27

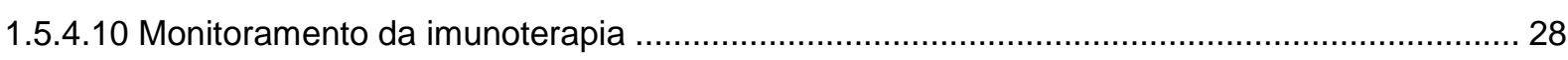

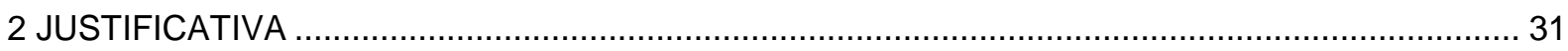

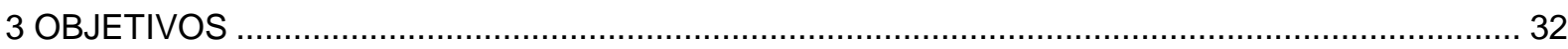

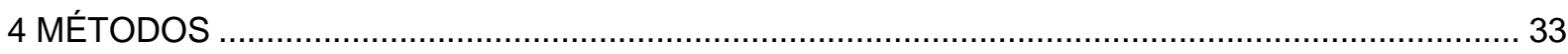

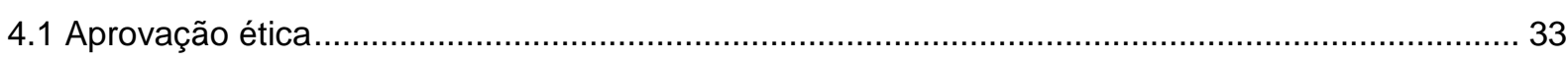

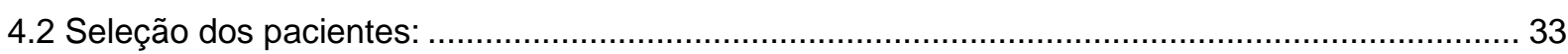

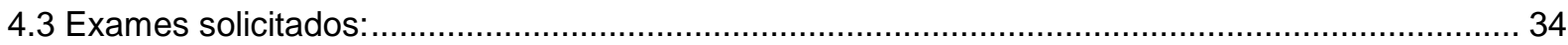

4.3.1 Pesquisa de IgE e IgG4 específica in vitro (ImmunoCap®, Thermofisher, Brasil): ..................... 34

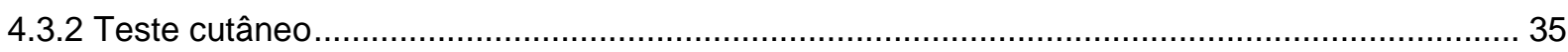

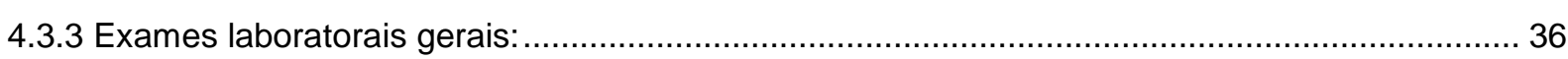

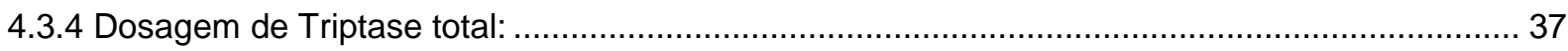

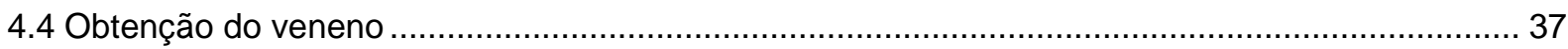

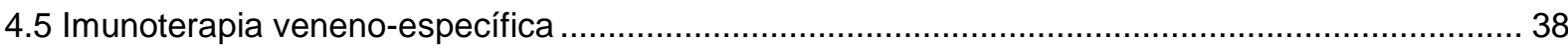

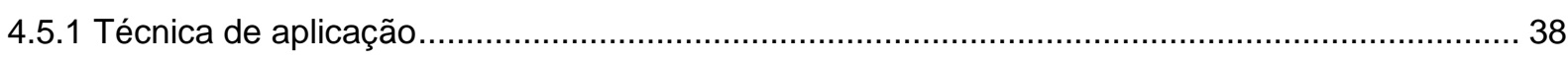

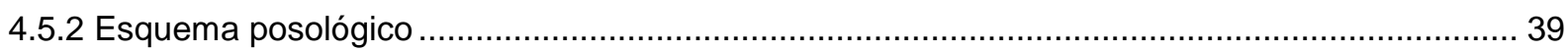

4.5.3 Protocolo de reinício e interrupção da imunoterapia ............................................................. 40

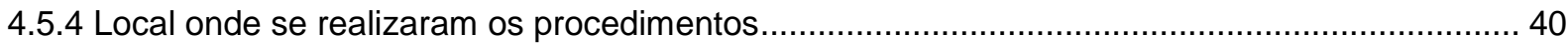

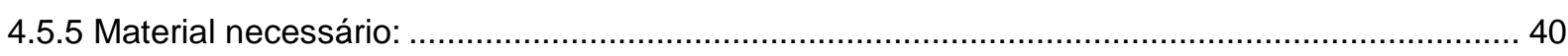

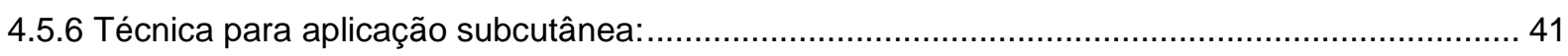

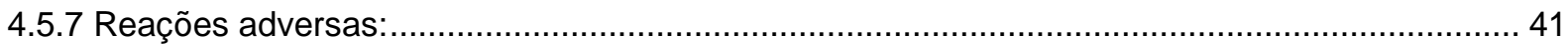

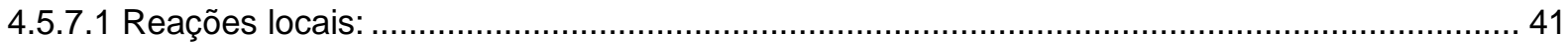

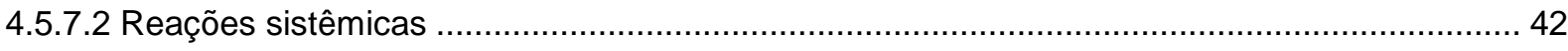

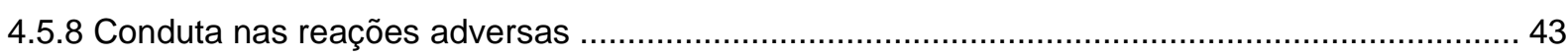

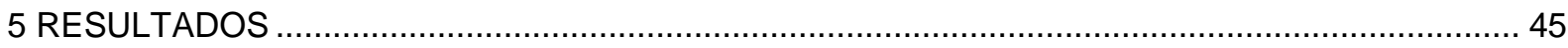

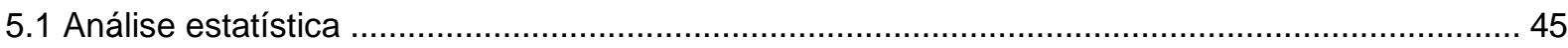

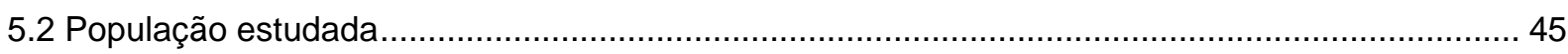

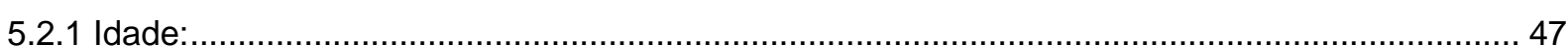

5.2.2 Gênero:

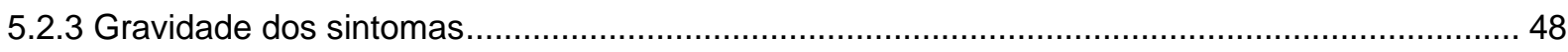

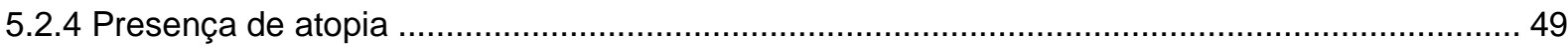

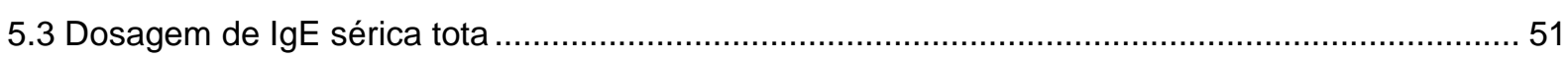

5.4 Dosagens de IgE séricas específicas ao veneno de formiga (Immunocap i70®) …......................53

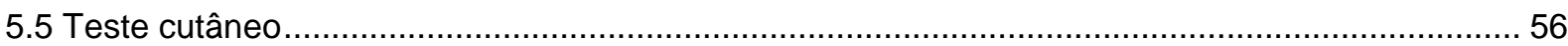

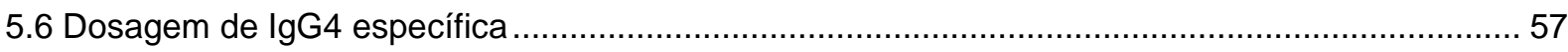

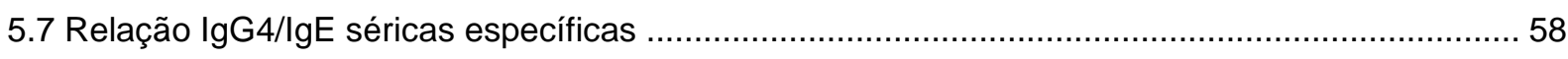

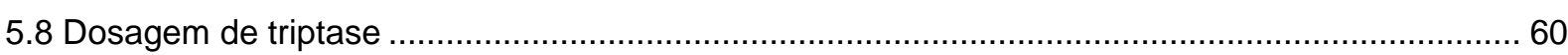




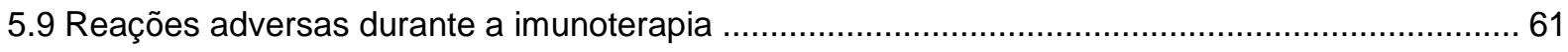

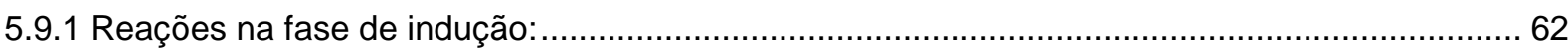

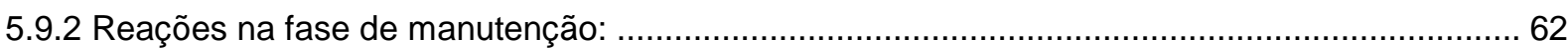

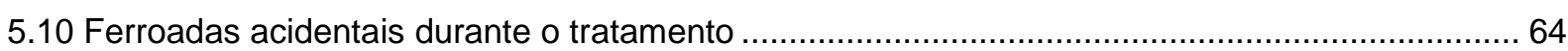

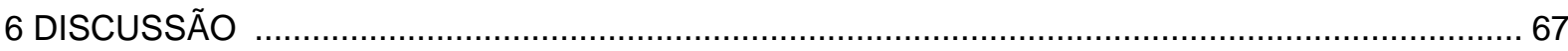

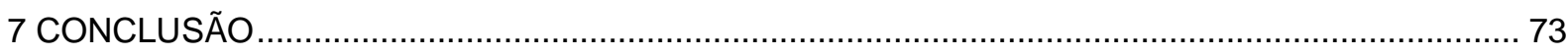

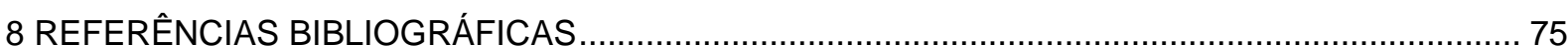




\section{Lista de figuras}

Figura 1: pústulas estéreis formadas após ataque de formigas de fogo

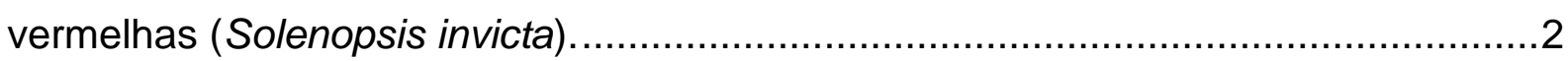

Figura 2: formigas mais comuns causadoras de reações alérgicas ${ }^{15}$........................

Figura 3: Formigas lava-pés se apresentam de tamanho variado (esquerda). A

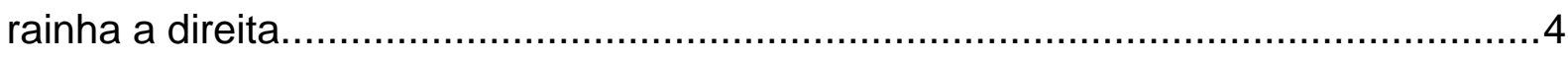

Figura 4: ninho de formigas lava-pés. .......................................................... 4

Figura 5: Mecanismos de imunoterapia veneno específica....................................19

Figura 6: indicações da imunoterapia segundo a gravidade da reação alérgica ${ }^{116}$ 20

Figura 7: testes cutâneos positivos dos pacientes do estudo (A: positividade no teste intradérmico; B: positividade no prick teste)

Figura 8: Gravidade de reação e modificação da dose (adaptado de Tanskerley et al. $\left.{ }^{66}\right)$.

Figura 9: classificação das reações sistêmicas a imunoterapia subcutânea..............42

Figura 10: distribuição dos pacientes conforme a idade

Figura 11: porcentagem dos pacientes distribuídos de acordo com a gravidade da reação anterior

Figura 12: dosagens da IgE total de cada paciente (linha vermelha: valor de referência) .52

Figura 13: valores de IgE sérica basal para veneno de formiga (i70) nos

pacientes com reação grau III .54

Figura 14: valores de IgE sérica basal para veneno de formiga (i70) nos pacientes com reação grau IV 54

Figura 15: porcentagem de positividade dos testes cutâneos.

Figura 16: Dosagens de lgG4 específica basal e após 12 meses do início da fase de manutenção por paciente

Figura 17: comparativo da razão das dosagens de lgG4/lgE específicas basais e após 12 meses da fase de manutenção da imunoterapia

Figura 18: porcentagem das reações adversas ocorridas durante a fase de indução da imunoterapia 
Figura 19: porcentagem das reações adversas ocorridas durante a fase de manutenção da imunoterapia .63

Figura 20: número de reações adversas (por injeção) durante a imunoterapia de acordo com a fase e tipo de reação

Figura 21: Distribuição das ferroadas acidentais por paciente durante a fase de indução e de manutenção de acordo com a gravidade de reação 


\section{Lista de tabelas}

Tabela 1: esquema do protocolo utilizado exemplificando o aumento das concentrações semanalmente. 39

Tabela 2: dosagens de imunoglobulinas de cada paciente 46

Tabela 3: dados epidemiológicos e gravidade de reação dos pacientes incluídos

Tabela 4: presença de atopia segundo a gravidade de reação em cada paciente

Tabela 5: valores de IgE total de cada paciente.

Tabela 6: valores de IgE sérica para veneno de formiga (i70) no período basal e após 1 ano da fase de manutanção em cada paciente 56

Tabela 7: dosagens de IgG4 específicas ao veneno de formiga no período basal e após 1 ano do início da fase de manutenção .59

Tabela 8: dosagens de triptase de cada paciente.

Tabela 9: número de ferroadas e sintomas após ferroada acidental durante a fase de indução em cada paciente

Tabela 10: número de ferroadas e sintomas após ferroada acidental durante a fase de manutenção em cada paciente 


\section{Lista de abreviaturas, símbolos e siglas}

\begin{tabular}{|c|c|}
\hline AAAAI & $\begin{array}{l}\text { The American Academy of Allergy, Asthma ano } \\
\text { Immunology }\end{array}$ \\
\hline APC & Célula apresentadora de antígenos \\
\hline Breg & Célula $B$ reguladora \\
\hline CAPPesq & Comissão de Ética para Análise de Projetos de Pesquisa \\
\hline EAACI & European Academy of Allergy and Clinical Immunology \\
\hline ELISA & Enzyme-Linked Immunosorbent Assay \\
\hline EUA & Estados Unidos da América \\
\hline FMUSP & Faculdade de Medicina da Universidade de São Paulo \\
\hline $\mathrm{FC} \varepsilon \mathrm{RI}$ & Receptores de alta afinidade a $\lg \mathrm{E}$ \\
\hline $\lg A$ & Imunoglobulina A \\
\hline $\lg E$ & Imunoglobulina E \\
\hline $\lg G$ & Imunoglobulina G \\
\hline $\lg M$ & Imunoglobulina M \\
\hline $\lg G 4$ & Subclasse de imunoglobulina $G$ \\
\hline IL & Interleucinas \\
\hline IM & Intramuscular \\
\hline IT & Imunoterapia \\
\hline LIM & Laboratórios de Investigação Médica \\
\hline $\mathrm{Mg}$ & Miligrama \\
\hline $\mathrm{MHC}$ & Major compatibility Complex \\
\hline Ml & Mililitro \\
\hline $\mathrm{Mm}$ & Milímetro \\
\hline$\%$ & Porcento \\
\hline Th1 & Thelper 1 \\
\hline Th2 & Thelper 2 \\
\hline Treg & Células $\mathrm{T}$ regulatórias \\
\hline TCLE & Termo de Consentimento Livre e Esclarecido \\
\hline VEF1 & Volume expiratório forçado no $1 \mathrm{~s}$ \\
\hline (B) & Marca registrada \\
\hline$\mu g$ & Micrograma \\
\hline
\end{tabular}




\section{RESUMO}

Watanabe AS. Perfil clínico e laboratorial de pacientes com anafilaxia à ferroada de formigas (Solenopsis sp) sob tratamento com imunoterapia específica [tese]. São Paulo: Faculdade de Medicina, Universidade de São Paulo; 2020.

Resumo: veneno de formiga (Solenopsis sp) é uma causa importante de anafilaxia após ferroada desses insetos. Ocorre principalmente em crianças e são poucos dados na literatura sobre tratamento específico. Objetivo: avaliamos as características clínicas e laboratoriais dos pacientes submetidos a imunoterapia com veneno de formigas (Solenopsis sp) após 1 ano da fase de manutenção. Métodos: pacientes que foram atendidos com anafilaxia por veneno de Solenopsis SP no ambulatório de Alergia e Imunologia Clínica do Hospital das Clínicas da FMUSP e foram submetidos à imunoterapia veneno específica. Esses pacientes foram avaliados no período basal e após 1 ano da fase de manutenção em relação aos seguintes parâmetros: avaliação das características clínicas; idade; atopia; gênero; reações prévias; teste cutâneo; determinação sérica de IgE e IgG4 específicas; triptase; reações adversas a Imunoterapia; exposição natural às ferroadas durante 0 tratamento. Resultados: 33 pacientes que apresentaram reação anafilática grave (grau III e IV de Muller) foram incluídos. A maioria morava em zona urbana e $75,9 \%$ dos pacientes tinham menos de 20 anos de idade. Não houve relação da gravidade da reação com gênero, dosagem de triptase, atopia, qualquer reação prévia, concentração do extrato alergênico no teste cutâneo ou nível de lgE específica. Houve diferença estatística significante na razão $\operatorname{lgG} 4 / \mathrm{lgE}$ específicas no período basal e durante a imunoterapia. A maioria das reações foram locais e apenas duas reações sistêmicas ocorreram pela imunoterapia, porém foram leves e durante a fase de indução. Vinte pacientes foram ferroados acidentalmente durante $o$ tratamento e apenas 3 apresentaram reações sistêmicas leves (urticária): 1 na fase de indução e 2 no início da fase de manutenção, não houve necessidade de uso de adrenalina intramuscular nessas reações, com melhora após antihistamínicos por via oral. Conclusões: poucos estudos no mundo avaliaram pacientes submetidos à imunoterapia com veneno de Solenopsis sp e esse estudo é inédito na avaliação de dados clínicos e laboratoriais no tratamento com veneno dessas formigas. As lições aprendidas nesse estudo nos ajudaram a entender a tanto a eficácia quanto a manutenção da tolerância ao veneno de formiga induzida pela imunoterapia específica. Seria interessante novos estudos sobre comportamento das células T específicas durante a imunoterapia com veneno de formiga.

Descritores: Himenópteros; Anafilaxia; Venenos de formiga; Dessensibilização imunológica; Hipersensibilidade. 


\begin{abstract}
Watanabe AS. Clinical and laboratory profile of patients with anaphylaxis to fire ant venom (Solenopsis sp) under specific subcutaneous immunotherapy [thesis]. São Paulo: "Faculdade de Medicina, Universidade de São Paulo"; 2020.
\end{abstract}

Background: Anaphylaxis to fire ant venoms (Solenopsis $s p$ ) is a significant cause of systemic allergic reaction caused by Hymenoptera stings in children. There are only few reports about safety and efficacy of specific immunotherapy. Objective: Evaluate clinical characteristics, IgE and IgG4 specific responses of patients undergoing immunotherapy with a whole-body extract of Solenopsis $s p$ after one year of the maintenance phase. Materials and methods: Thirty-three patients were enrolled due to anaphylaxis by fire ant venom (Solenopsis sp) and underwent specific venom immunotherapy. They were assessed at baseline and one year after the beginning of the maintenance phase for: skin test; specific IgE and IgG4 antibodies to fire ant venom; tryptase. Results: All patients included presented severe anaphylactic reaction. Although two patients $(6.25 \%)$ presented a tryptase level higher than $11.4 \mathrm{ug} / \mathrm{ml}$, systemic mastocytosis was ruled out. There was no relationship between the severity of the reaction with gender, tryptase level, atopy, previous reactions, concentration of the allergen in the skin test or specific $\operatorname{lgE}$ level. There was an increase of the specific IgG4/IgE ratio between the two timepoints. Reactions were local with only two mild systemic reactions during the build-up phase. Twenty patients had accidental stings during immunotherapy with 3 presenting only urticaria. Conclusions: This study is unprecedented in the evaluation of clinical and laboratory data in the fire ant immunotherapy. Our results show that after one year of maintenance phase patients do not developed any severe reaction with only few mild reactions and presented a significant production of specific lgG4.

Descriptors: Hymenoptera, Anaphylaxis, Ant venoms, Desensitization, immunologic, Hypersensitivity 


\section{INTRODUÇÃO}

O termo "anafilaxia" foi usado pela primeira vez em 1901, quando Richet e Portier observaram uma reação que era "oposta" (ana) a proteção (profilaxia) que eles estavam tentando realizar: imunizar cachorros contra os toxinas de anêmonas do mar' ${ }^{1}$.

Observaram que, à medida que injetavam a toxina em um grupo de cães, alguns deles apresentavam uma forte reação e morriam imediatamente, descrevendo então o fenônemo da anafilaxia, e à medida que os medicamentos foram sendo cada vez mais utilizados, as reações anafiláticas foram mais frequentemente observadas em humanos ${ }^{2}$.

No passado, as reações eram classificadas como anafiláticas quando mediadas por anticorpos lgE ou anafilactóides, quando não mediadas por $\lg \mathrm{E}^{3,4}$.

Esse conceito e o termo "anafilactóide" caíram em desuso, no entanto, novos consensos definiram e classificaram a anafilaxia, bem como houve uma maior compreensão das várias vias fisiopatológicas desempenhando um papel na anafilaxia ${ }^{5}$.

Desse modo, hoje, anafilaxia é uma reação alérgica sistêmica aguda e com risco de vida associada aos diferentes mecanismos, gatilhos, apresentações clínicas e gravidade ${ }^{6}$.

Medicamentos e ferroadas de insetos são os principais causas em adultos; e alimentos e ferroada de insetos as mais frequentemente implicadas em crianças e adolescentes ${ }^{7,8,9}$.

A alergia alimentar afeta $8 \%$ a $11 \%$ das crianças e adultos nos Estados Unidos ${ }^{10,11,12}$, enquanto as reações adversas a medicamentos afetam até $10 \%$ da população e $20 \%$ dos pacientes hospitalizados, sendo que as reações de hipersensibilidade a medicamentos são responsáveis por $10 \%$ de todas as reações adversas ${ }^{13}$. 
Segundo o Registro Europeu de Anafilaxia $^{14}$, a anafilaxia por venenos de himenópteros é a principal causa de reação sistêmica em adultos $(48,2 \%)$, e $20,2 \%$ dos casos de anafilaxia em pacientes pediátricos.

A alergia a insetos é descrita desde a antiguidade, com desenhos na tumba do Faráo Menès do Egito, sugerindo que a causa de sua morte tenha sido uma ferroada de vespa em $2641 \mathrm{AC}^{15}$.

As ferroadas de himenópteros são causadas porque injeta o ferrão na pele, um ovipositor modificado; portanto, apenas fêmeas da espécie têm a capacidade de ferroar. O conteúdo do saco do veneno pode variar de acordo com a geografia e a estação, parcialmente explicando a variabilidade das reações alérgicas com episódios distintos de ferroada. A maioria das proteínas nos venenos são enzimas, ou inibidores de enzimas, como fosfolipases, hialuronidase e melitina (nas abelhas) e várias proteínas de função desconhecida, como o antígeno 5 (vespas) e pilosulina (formigas), ou seja, são moléculas grandes e complexas. O veneno das formigas de fogo (Solenopsis) é composto principalmente de uma mistura de alcalóides complexos com proteínas misturadas. $\mathrm{O} \mathrm{pH}$ alcalino é responsável pela formação de uma pústula típica que identifica a ferroada deste inseto ${ }^{15}$.

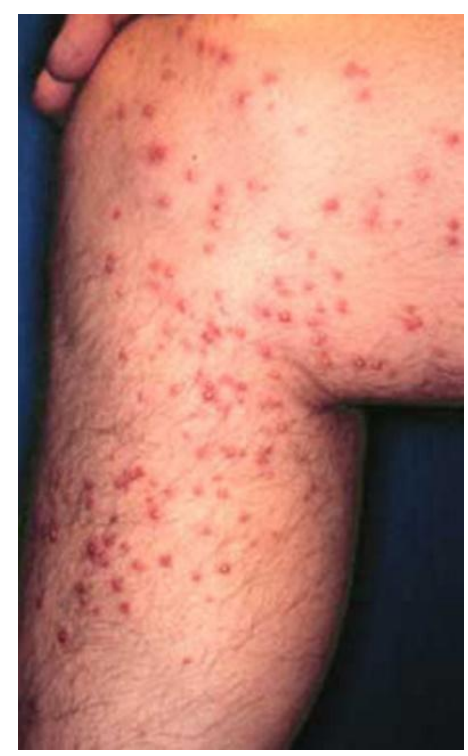

Figura 1: pústulas estéreis formadas após ataque de formigas de fogo vermelhas (Solenopsis invicta).

Fonte: Foto: Sanford D. Porter, USDA, Gainesville, FL. 
Os himenópteros mais estudados, com extratos comerciais purificados de venenos para testes e tratamento nos Estados Unidos, são as abelhas e as vespas. As formigas são muito biodiversas, com 22 subfamílias reconhecidas, aproximadamente 300 gêneros e mais de 14.000 espécies. Dezesseis subfamílias de formigas, com 1900 espécies existentes, têm um aparelho de ferroar e injetam o veneno para defesa, predação e interação social. No entanto, apenas um pequeno número dessas formigas pode causar reações alérgicas em humanos, incluindo a espécie que temos no Brasil: Solenopsis sp16 (Figura 2).

\begin{tabular}{|l|l|l|}
\hline Família e subfamília & Nome científico & Nome comum \\
\hline Formicidae & Solenopsis invicta & $\begin{array}{l}\text { Formiga de fogo ou } \\
\text { lava-pés }\end{array}$ \\
\cline { 2 - 3 } & Myrmecia spp & Jack jumper (Austrália) \\
\cline { 2 - 3 } & Pogonomyrmex spp. & $\begin{array}{l}\text { Harvester ant (Sudeste } \\
\text { dos EUA) }\end{array}$ \\
\cline { 2 - 3 } & Pachycondyla spp. & $\begin{array}{l}\text { Chinese needle ant } \\
\text { (sudeste da Ásia) }\end{array}$ \\
\cline { 2 - 3 } & Rhytidoponera metallica & Green-head ant \\
& (Australia) \\
\hline
\end{tabular}

Figura 2: formigas mais comuns causadoras de reações alérgicas ${ }^{15}$

\section{$1.1 \quad$ FORMIGA: Solenopsis sp}

Pertencem à subfamília Myrmicinae, chamadas de formigas-de-fogo ou lava-pés. As espécies mais importantes são a Solenopsis invicta (lava pés vermelha), originária das regiões Sudeste e Centro Oeste (pantanal matogrossense) e Solenopsis richteri (lava pés preta), originária do Rio Grande do Sul, Argentina e Uruguai. A maioria possui de 1,8 a $6 \mathrm{~mm}$ de tamanho, 
sendo que a rainha pode atingir até $1 \mathrm{~cm}$ (Figura 3). A rainha tem asas, utilizadas para o voo nupcial. Outra característica importante é que as formigas prendem-se com suas mandíbulas à pele e podem ferroar repetidamente 0 indivíduo ${ }^{17,18}$.

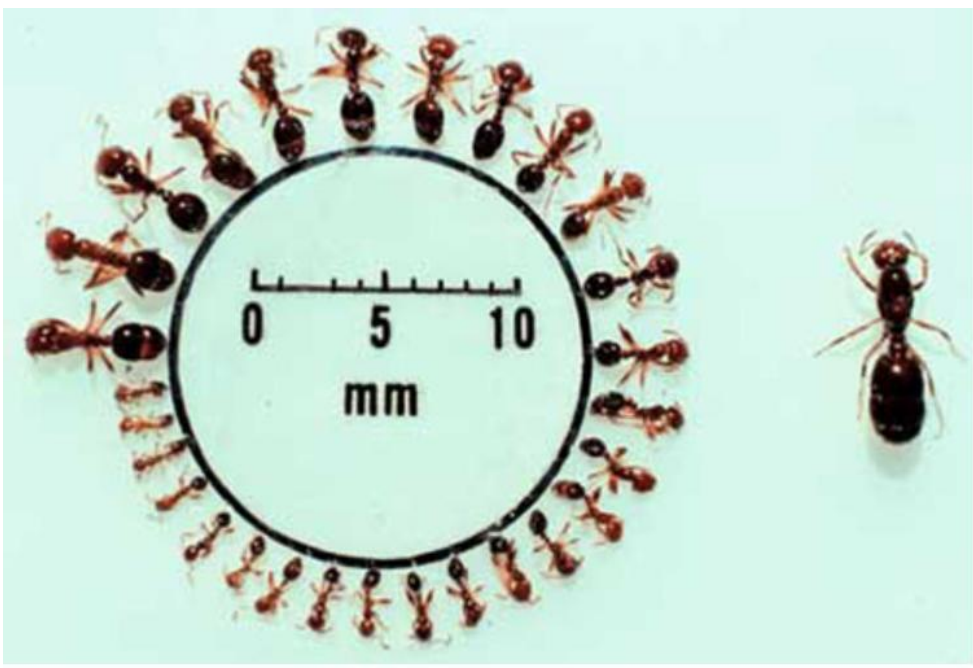

Figura 3: Formigas lava-pés se apresentam de tamanho variado (esquerda). A rainha a direita.

Fonte: Foto feita por Sanford D. Porter, Gainesville, FI.

Ninhos são construídos no solo e raramente têm mais de $46 \mathrm{~cm}$ de diâmetro. Quando um formigueiro é perturbado, as formigas emergem agressivamente para morder e ferroar o intruso ${ }^{19}$. (Figura 4)

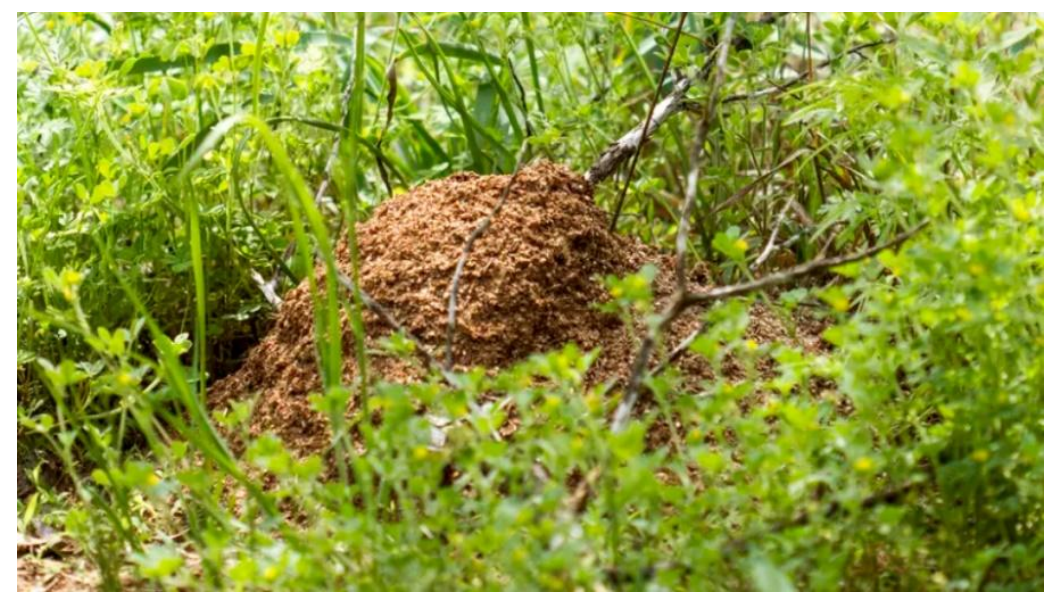

Figura 4: ninho de formigas lava-pés.

Fonte: Foto: Alex Wild/ University of Texas/Insects Unlocked/Wikimedia Commons. 
As ferroadas dessas formigas se tornaram um grande problema médico em grande parte do sudeste dos EUA ${ }^{20,21,22}$.

Além do risco para as pessoas, as formigas ameaçam a fauna natural e o gado doméstico, e seus ninhos representam problemas para a agricultura e as estradas ${ }^{23,24,25}$.

As formigas de fogo contêm magnetita, que funciona como uma bússola para orientá-las no eixo norte-sul; além disso, a magnetita detecta outros campos magnéticos e elétricos, atraindo as formigas para as linhas de energia subterrâneas ${ }^{25}$.

\subsubsection{Biologia e ciclo de vida}

A vida útil das formigas operárias depende do seu tamanho. Trabalhadores menores podem viver de 30 a 60 dias, trabalhadores de tamanho médio de 60 a 90 dias, e trabalhadores principais de 90 a 180 dias. A rainha pode viver de dois a seis anos. O ciclo de vida completo do ovo ao adulto leva entre 22 e 38 dias $^{26}$.

O voo de acasalamento é o principal meio de propagação de colônias; secundariamente, pode ocorrer brotamento no qual uma porção de uma colônia se torna uma unidade autônoma. Os voos de acasalamento ocorrem entre a primavera e o outono ${ }^{27}$.

Os voos de acasalamento geralmente ocorrem ao meio-dia em dias quentes $\left(>24^{\circ} \mathrm{C}\right)$, ou em dias ensolarados após a chuva ${ }^{28}$. O acasalamento ocorre durante o voo e os machos morrem logo após o acasalamento com as fêmeas. No sul dos Estados Unidos, 97.000 rainhas podem ser produzidas por hectare de terra infestada por ano e são frequentemente atraídas para piscinas onde os proprietários podem encontrar milhares de formigas aladas presas na superfície da água ${ }^{28}$.

A rainha é a única produtora de ovos e é capaz de produzir até 1.500 ovos por dia. As colônias de formigas maduras podem conter até 240.000 operárias, com uma colônia típica composta por $80.000^{7}$. 
As formigas operárias grudam na pele usando suas mandíbulas e, posteriormente, abaixam a ponta do abdômen para injetar o ferrão na vítima. Desse modo, as formigas de fogo mordem e ferroam, mas apenas a ferroada é responsável pela dor e pústula ${ }^{21}$.

\subsubsection{Componentes do veneno de Formiga}

As formigas operárias ferroam agarrando a pele com suas mandíbulas, inserindo o ferrão na pele e injetando lentamente o veneno. As ferroadas são muito mais lentas do que as de abelhas e vespas, e não são imediatamente dolorosas. Elas podem ferroar repetidamente, muitas vezes girando em um padrão circular, enquanto mantêm suas mandíbulas presas na pele. Cada ferroada injeta apenas um volume muito pequeno, geralmente nanolitros contendo 10 a 100 ng de proteína ${ }^{29}$.

Estudos sobre a composição do veneno de lavapés foram limitados por muitos anos pela incapacidade de obter quantidades significativas de veneno puro. O método original usado para obter veneno era fazer com que as formigas ferroassem tubos de microcapilares. Entretanto, como as formigas de fogo ferroam lentamente e como apenas uma única formiga pode ser processada ao mesmo tempo, esse método é extremamente trabalhoso e apenas pequenas quantidades podem ser coletadas, por isso utiliza-se até hoje comercialmente o extrato de corpo total ${ }^{29}$.

Os alcalóides são o principal componente do veneno das formigas de fogo e as proteínas presentes no veneno compõem apenas uma pequena fração do total ${ }^{30}$.

A fase aquosa do veneno de Solenopsis invicta contém quatro componentes principais de proteínas alergênicas ${ }^{29}$.

O alérgeno Sol i2 compreende cerca de metade a dois terços da proteína no veneno. É um homodímero ligado a uma cadeia dissulfeto com 119 aminoácidos, cada um contendo sete resíduos de cisteína ${ }^{31}$. Sua estrutura não é relacionada a nenhuma outra proteína procurada nas bases de dados. 
Sol i 4 é uma proteína de cadeia única com 117 aminoácidos, apresentando 35\% de identidade com Sol i2 e compreende cerca de 8 a $10 \%$ da proteína do veneno ${ }^{29}$.

Sol i 3 representa cerca de 15 a 25\% da proteína do veneno. É uma molécula de cadeia única com 212 aminoácidos. Possui cerca de 44-50\% de identidade com as moléculas do antígeno 5 de vespas ${ }^{32}$.

Embora Sol i 1 compreenda apenas 2-4\% da proteína do veneno ${ }^{29}$, é uma molécula particularmente interessante e importante. Os anticorpos IgE de muitos soros de pacientes sensíveis ao veneno de vespa se ligam ao Sol i 1 nos estudos RAST e imunoblot, pois essa fração possui atividades de fosfolipase $A$ e $B^{32}$.

\subsubsection{Extratos alergênicos}

Extratos comerciais de formigas lava-pés são todos extratos de corpo total. O veneno purificado ainda não foi desenvolvido para venda como produto comercial. Foram relatados muitos estudos que comparam vários extratos comerciais com várias preparações de "veneno", com atividade alergênica significativa demonstrada através de testes cutâneos ${ }^{33,34,35,36} \mathrm{e}$ testes in vitro $33,36,37,38,39,40,41$.

\subsubsection{Fisiopatologia}

As reações alérgicas são direcionadas contra os constituintes alergênicos proteicos presentes nos venenos. $O$ fator mais importante nessas reações alérgicas é a presença de anticorpos $\lg E$ veneno-específico. Nos pacientes alérgicos, há uma preferência na produção de interleucinas com perfil Th2 com a capacidade de induzirem a formação de $\lg \mathrm{E}$. As células ativadas na presença de IL 4 e IL 13 causam a seleção de isotipos de lgE durante a maturação das células $B$ ativadas com subsequente produção de $\lg E$ específica ao veneno. As moléculas de $\lg E$ ligam-se a mastócitos e basófilos através de receptores de alta afinidade (FcERI), mantendo-os em um estado de 
prontidão ou estado de sensibilização. Em um próximo contato com o mesmo alérgeno, ocorre a ligação deste a pelo menos duas moléculas de $\operatorname{lgE}$ fixadas à superfície de mastócitos, levando à desgranulação de mediadores químicos com as mais variadas atividades biológicas ${ }^{42}$.

\subsubsection{Reações causadas por esses insetos}

Além de ser uma importante praga agrícola e urbana, causando danos ambientais, as formigas também são importantes causadoras de danos médicos.

As reações a ferroadas desses insetos podem ser classificadas como $^{43}$ : reação tóxica e reação alérgica.

As reações tóxicas podem ser: reação local ou reação generalizada; já as reações alérgicas podem ser: locais extensas ou anafiláticas.

A reação tóxica local apresenta uma área de edema, calor local, eritema e dor no local da ferroada; resolvendo em poucas horas. Como citado acima, ferroadas de formigas de fogo vermelhas apresentam características peculiares, pois nos locais há formação de pústulas dentro de 24 horas.

Por outro lado, reações tóxicas sistêmicas são causadas pelos efeitos fisiológicos de grande quantidade de veneno injetada após múltiplas ferroadas, simulando reações anafiláticas. Os sintomas são geralmente gastrointestinais: vômitos, diarreia e dores abdominais, podendo ser acompanhados por cefaleia, febre, espasmos musculares, convulsão e até mesmo em morte.

As reações locais extensas caracterizam-se por uma área maior de eritema e edema ao redor do sítio da ferroada, que podem persistir por 48 horas ou mais, chegando até a uma ou mais semanas. A infecção secundária, nesses casos, não é incomum.

As reações anafiláticas podem ser subdivididas, segundo a intensidade dos sintomas, em (critérios de Mueller modificados) ${ }^{44}$ : 
Grau I: urticária, prurido, mal estar, ansiedade.

Grau II: um dos sintomas anteriores e dois ou mais dos seguintes: broncoconstrição leve, náuseas, vômitos, dor abdominal, diarreia e angioedema. Este último pode ser considerado grau II quando aparecer isoladamente.

Grau III: um dos anteriores e dois ou mais dos seguintes: dispneia, sibilos, estridor (esses três já são considerados grau III quando aparecem isoladamente), disfagia, disartria, rouquidão, fraqueza, confusão mental e sensação de morte eminente.

Grau IV: um dos anteriores e dois ou mais dos seguintes: queda de pressão arterial, colapso, perda de consciência, incontinência urinária e cianose.

As reações tardias de hipersensibilidade citotóxica e por imunocomplexos são pouco frequentes, talvez por falhas no diagnóstico etiológico, pois é extremamente difícil a correlação entre causa e efeito; podendo manifestar-se por: distúrbios renais, encefalopatias, neurites, miocardites, vasculites, anemias hemolíticas e pela doença do soro.

Outras complicações incluem ${ }^{43}$ : Síndrome de Guillain-Barré, púrpura de Henoch-Schönlein, Síndrome de Reye-like, infarto do miocárdio, arritmia cardíaca e morte.

\subsection{EPIDEMIOLOGIA}

O risco de uma pessoa ser ferroada em área endêmica é de $30 \%$ a $60 \%^{20,45}$, com $0,16 \%$ a $16 \%$ de risco de apresentar reações sistêmicas graves $^{46,47}$.

No Brasil temos somente dados obtidos do Centro de Vigilância Epidemiológica do Estado de São Paulo ${ }^{48}$, sendo que entre os anos de 1998 a fevereiro de 2020, foram registrados 41.545 acidentes causados por abelhas (somente há notificação para abelha, não há dados com acidentes por vespa 
ou formiga), sendo notificados 73 óbitos. No ambulatório de reações a venenos de insetos do Serviço de Imunologia Clínica e Alergia do Hospital das Clínicas da Faculdade de Medicina da Universidade de São Paulo (HC-FMUSP) observamos que $73,8 \%$ dos pacientes que apresentaram reações ao veneno de formiga tinham menos de 20 anos e mais de $50 \%$ dos pacientes que apresentaram reações aos venenos de abelha e vespa eram adultos.

\subsection{HISTÓRIA NATURAL}

Estudos conduzidos para se avaliar a história natural são importantes para orientar médicos e pacientes quanto a ferroadas futuras. $\mathrm{O}$ paciente que apresentar uma reação anafilática grave não significa que numa ferroada subsequente desenvolverá a mesma reação ou mais grave. Estudos retrospectivos ${ }^{49}$ com venenos de abelhas e vespas mostram que a simples presença de anticorpos lgE veneno-específicos constituem risco de reações sistêmicas futuras, porém não há parâmetros identificados que possam predizer quais indivíduos sensibilizados apresentarão reações sistêmicas. Desde que uma reação alérgica a ferroada tenha ocorrido, o risco de uma nova reação é maior, e está relacionado também com a idade do paciente ${ }^{49}$.

- Reação local extensa:

Quando o paciente apresenta uma reação local extensa, geralmente, a chance de se repetir a mesma reação é grande, porém com risco de $10 \%$ de ocorrer reação anafilática em ferroadas subsequentes, permanecendo nesse mesmo valor após 10 a 20 anos.

- Reação cutânea:

Para os que desenvolveram uma reação cutânea, em crianças, o risco de reações mais graves em futuras ferroadas é de aproximadamente $10 \%$ 
e em adultos esse risco é de $20 \%$. Após 10 a 20 anos esse risco em crianças cai para $5 \%$ e em adultos, $10 \%$.

- Reação sistêmica grave:

Para os que desenvolveram uma reação sistêmica, em crianças o risco de desenvolver uma reação sistêmica grave em ferroadas futuras é de $40 \%$ e em adultos, o risco é de aproximadamente $60 \%$ de reações sistêmicas graves. Após 10 a 20 anos, em crianças diminui para $30 \%$ e em adultos diminui para $40 \%$.

\subsection{DIAGNÓSTICO}

O diagnóstico de anafilaxia ao veneno de formiga é baseado na história clínica, pesquisa de anticorpos $\lg \mathrm{E}$ específicos ao veneno e testes cutâneos, após pelo menos 3 a 4 semanas depois do evento agudo para reduzir a probabilidade de resultado falso-negativo. Estes testes não apenas confirmam o diagnóstico, mas também identificam o veneno adequado para ser utilizado na imunoterapia ${ }^{50}$.

\subsubsection{História clínica}

O paciente ou responsável deve ser questionado sobre ${ }^{51}$ :

- sintomas e evolução da reação: descrever sintomas apresentados logo após a ferroada e como progrediu a reação evoluindo ou não para uma reação sistêmica (sintomas cutâneos, respiratórios, neurológicos, gastrointestinais ou cardiológicos) e como foi o atendimento, necessitando ou não de serviço de emergência. Em pacientes com reações pouco claras, um relatório do médico responsável pelo tratamento da reação aguda ou quaisquer registros da reação e tratamento devem ser solicitados e revisados.

- número de ferroadas e local do corpo acometido

- descrição do inseto responsável: tamanho, cor, se voava ou não, se deixou ferrão no local 
- localização geográfica: se estava em um sítio, ou cidade, jardim ou parques

- história anterior de ferroadas e tipo da reação.

- cofatores que pudessem estar envolvidos (período menstrual, atividade física extenuante, stress, infecção, uso de medicações)

- fatores de risco individuais:

- Na população geral: adultos jovens, gênero masculino (2 homens : 1 mulher) e o tipo de inseto envolvido (ferroadas por abelhas na literatura demonstram maior gravidade de reações ${ }^{52,53}$.

Adultos têm maior probabilidade de apresentar reações ao serem ferroados novamente do que crianças. O risco aumenta com a idade, pois está particularmente relacionado a co-morbidades, especialmente a presença de doenças cardiovasculares e pacientes que fazem tratamento com betabloqueadores e inibidores da enzima de conversão da angiotensina (iECA $)^{53}$.

Pacientes que apresentam mastocitose, mesmo sendo pacientes não alérgicos, sabidamente são pessoas predispostas a reações graves após ferroada desses insetos ${ }^{53}$. A possibilidade da atopia ser fator de risco para reações alérgicas tem sido bastante estudada e aceita por vários autores ${ }^{54}$.

\subsubsection{Pesquisa de IgE sérica específica (testes in vitro):}

A determinação de anticorpos IgE veneno-específicos ao veneno de formiga pode ser realizada no soro, podendo ser utilizados radioimunoensaios, métodos enzimáticos e quimioluminescência para essa detecção. Aproximadamente $10 \%$ a $15 \%$ dos pacientes com testes cutâneos positivos podem apresentar pesquisa de lgE sérica específica negativa ou baix ${ }^{50}$.

\subsubsection{Teste cutâneo:}

O teste cutâneo é realizado com extrato de corpo total da formiga (Solenopsis $s p$ ). Realiza-se primeiro um prick test (teste de puntura) com 
diluições crescentes e, caso este seja negativo, faz-se o teste intradérmico. $O$ teste positivo indica apenas sensibilização prévia, sendo incapaz de predizer se haverá reação na próxima exposição e a gravidade da reação.

\subsection{TRATAMENTO}

\subsubsection{Reações locais e locais extensas}

Para a maioria dessas reações, a aplicação de gelo, compressa fria, analgésicos e antihistamínicos são suficientes para melhorar o edema e o desconforto local. A maioria dessas reações resolve dentro de poucas horas da ferroada. Para as reações locais extensas, procede-se como citado acima e podem ser acrescentados corticóides tópicos e orais ${ }^{55}$.

\subsubsection{Reações tóxicas}

As reações tóxicas requerem estabilização do paciente com reposição de fluidos, corticóides e monitorização cardíaca, pulmonar, hematológica e renal por alguns dias ${ }^{55}$.

\subsubsection{Reações anafiláticas}

Como a maioria das mortes por reações anafiláticas ocorre dentro de uma hora após a ferroada, a monitorização agressiva precoce, tratamento, estabilização e intervenção são mandatórios. A adrenalina é o medicamento de escolha na anafilaxia, na concentração de 1:1000 em solução aquosa, na dose de 0,3 a $0,5 \mathrm{~mL}$ (dose de adulto) e $0,01 \mathrm{~mL} / \mathrm{kg}$ até o máximo de $0,3 \mathrm{~mL}$ (dose para crianças), em intervalos de 15 a 30 minutos. Fluidos intravenosos são cruciais para evitar o colapso vascular, além de manutenção de vias aéras pérveas. Antihistamínicos, $\beta 2$-agonistas e corticóides podem ser utilizados como segunda linha de tratamento ${ }^{56}$. 
Como medidas preventivas, evitar andar com pés descalços em jardins, quintais; procurar andar com botas em áreas rurais. Para as reações graves, orientar plano de ação e utilização de adrenalina auto injetável ${ }^{57}$ (Epipen $\AA$ adulto ou júnior; AnaPen $\AA$, Adrenaclick $\AA$, Jext $\AA$, Emerade $\AA$, Penepin®, etc) caso haja necessidade.

\subsubsection{Imunoterapia alérgenos-específica}

A Imunoterapia alérgeno-específica é o único tratamento específico e modificador da doença e da evolução natural. É a única terapia que demonstrou a capacidade não apenas de melhorar os sintomas e reduzir a necessidade de medicamentos, mas também por induzir tolerância e prevenir o desenvolvimento de novas condições alérgicas. A imunoterapia alérgenosespecífica em crianças pode ser indicada em rinite, asma alérgica, alguns alimentos e venenos de insetos himenópteros ${ }^{58}$.

A eficácia relatada para os pacientes tratados com veneno de abelha é de $77-84 \%$, e de $91-96 \%$ nos pacientes que recebem veneno de vespa ${ }^{59,60}$.

Triplett $^{61}$ primeiro relatou imunoterapia bem-sucedida com extratos de corpo total para alergia ao veneno de formiga de fogo em 1973, sendo que nos EUA é amplamente utilizada por alergistas ${ }^{62}$.

Não havia estudos sistemáticos da eficácia da imunoterapia com extrato de corpo total de formigas de fogo até que Freeman et al. em $1992^{63}$, utilizaram testes de provocação após término da imunoterapia para avaliar a eficácia. Eles mostraram que a imunoterapia com extratos totais proporcionou um alto grau de proteção a quase todos os pacientes. Apenas um deles apresentou uma reação séria no grupo tratado com imunoterapia, enquanto houveram duas reações cutâneas e quatro reações graves generalizadas em uma população que não foi tratada.

Quando os testes de provocação com o inseto ou ferroadas em campo são utilizados para monitorar eficácia da imunoterapia, demonstrou-se um estado de proteção a longo prazo ${ }^{64,65}$, por vários anos após a 
descontinuação da imunoterapia com extrato de corpo total, com eficácia alta de $97 \%$ verificado no estudo de Tankersley et $a^{66}$.

A segurança e a eficácia de protocolos cluster, rush e ultra rush para imunoterapia com formiga de fogo foram relatados anteriormente. A maioria dos estudos tem um número limitado de pacientes e o objetivo desses estudos era determinar se o pré-tratamento profilático com anti-histamínicos e esteróides reduziriam a taxa de reação sistêmica ${ }^{66,67,68,69,70,71,72}$.

Adams et al. ${ }^{69}$ ilustrou a segurança e eficácia da imunoterapia rush com veneno de formiga de fogo em três pacientes. Beveridge e cols. ${ }^{70}$ descreveram um relato de caso de imunoterapia cluster em um homem de 66 anos. Dietrich e cols. ${ }^{71}$ incluíram 37 pacientes submetidos ao protocolo rush de 1 dia. Dos 22 testes de provocação com a formiga, em 21 resultaram em nenhum sinal ou sintoma de reação sistêmica, com uma taxa de eficácia na prevenção de reações sistêmicas de $95,5 \%$ para o protocolo rush.

Arseneau e cols. ${ }^{72}$ avaliaram a segurança e eficácia da imunoterapia rush de 1 dia com extrato de corpo total de formiga de fogo $(0,5 \mathrm{~mL}$ 1:100 (peso/vol) - dose de manutenção), com teste de provocação aproximadamente no dia 22 em 53 pacientes, resultando em sintomas de rinite leve (eficácia de $98,1 \%)$.

Brown e cols. ${ }^{73}$ avaliam a eficácia de outra espécie de formiga, com imunoterapia com veneno de $M$. pilosula (jack jumper) na prevenção da anafilaxia com risco de vida. Foi muito eficaz na prevenção de novas reações sistêmicas e poderia beneficiar a população em áreas do sudeste da Austrália, onde ocorrem ferroadas de formigas da espécie Myrmecia.

Para avaliar a prescrição de imunoterapia com corpo total de formigas, Waulters ${ }^{74}$ et al demonstrou uma melhora significativa na eficácia com 0,5 mL 1:100 peso/volume como a dose de tratamento predominante.

Além da imunoterapia de corpo total para formigas ser eficaz na redução de reações sistêmicas subsequentes em crianças e adultos, essa 
modalidade de tratamento pode ter um impacto benéfico significativo na qualidade de vida desses pacientes ${ }^{75}$.

\subsubsection{Mecanismo de ação da imunoterapia}

\subsection{Tolerância imune}

A indução a longo prazo de não responsividade aos alérgenos, seja em ambientes de exposição natural ou em provocações in vivo é um status ativo de resposta imune formado por uma complexa rede de células imunes, tecidos e mediadores. Na tolerância imunológica, alterações na resposta de células $T$ e células $B$ alérgeno específicas de memória fazem com que haja diminuição da $\lg E$, assim como aumento na produção de lgG4 por células $B$, e ocorre também downregulation do limiar de ativação de mastócitos e basófilos que terminam por suprimir sintomas alérgicos ${ }^{76}$.

Diferentes mecanismos imunes mediados por células $\mathrm{T}$ foram propostos serem a base da tolerância a alérgenos. Como a resposta é lgE mediada, movida por células TH2, é sugerido que a imunoterapia específica leva a uma mudança de resposta imune $\mathrm{TH} 2$ para $\mathrm{TH} 1^{77,78,79}$.

De fato, há um estudo já citado $\operatorname{acima}^{76}$ que mostra perda de reatividade celular $\mathrm{TH} 2$ específica de Bet $\mathrm{v} 1 \mathrm{em}$ pacientes tratados com imunoterapia após o primeiro ano do tratamento, mas isso não foi acompanhado por um aumento no número de células TH1 específicas de alérgenos. Dados mais recentes apontam para as células Treg como peças chave no estabelecimento da tolerância a alérgenos ${ }^{80,81}$, com foco particular nas células Tr1 secretando IL-10, que são induzidas precocemente durante a imunoterapia alérgeno específica ${ }^{82,83,84}$. Entretanto, nesse estudo ${ }^{76}$ quando se analisou tanto a frequência de células TR1 alérgeno específicas quanto a secreção de IL-10 pelas PBMCs por mais de 5 anos após o início da imunoterapia, os dados sugeriram que a ativação da célula TR1 específica da Bet $v 1$ foi um evento transitório. Isso pode ser explicado pelo fato que células 
TR1 específicas podem ter se deslocado para órgãos efetores para mediar a tolerância a alérgenos localmente e não sistemicamente ${ }^{85,86}$.

\subsection{Células T regulatórias}

Os dados obtidos em estudos com humanos e ratos revelaram importantes contribuições das células Treg na indução e manutenção da tolerância imunológica ${ }^{87,88,89}$.

O aumento de células Treg alérgenos específicas e a redução na frequência de células Th2 durante a imunoterapia também foram vistos em estudos de exposições naturais, como nos apicultores ${ }^{90}$.

As células Treg formam um subconjunto específico de células $T$ CD4+ e são mais conhecidas por sua propriedade de supressão pela produção de citocinas como IL-10 e TGF- $\beta$ e também pela utilização de moléculas de superfície inibitórias, como CTLA4 e PD1 ${ }^{91,92,93,94,95}$.

A resposta celular Treg induzida pela imunoterapia pode ser importante para o início do tratamento, mas não para a manutenção da tolerância a alérgenos, como mostram outros estudos que evidenciaram que a frequência de células Treg CD4+CD25+Foxp3+, expressão de IL-10 ou ambos aumentam precocemente durante a imunoterapia com aeroalérgenos ${ }^{82,96,97}$ ou com dessensibilização oral com amendoins ${ }^{98}$. Entretanto, após um tempo diminuíam e, principalmente, retornavam aos níveis de pré-tratamento, embora houve persistência da melhora clínica ${ }^{82,96}$.

O desaparecimento da reatividade de células $T$ específicas a determinados alérgenos sugerem que a preservação a longo prazo da tolerância não deve ser devida somente pela contribuição ativa das células $T$, mas sim devido a respostas diminuídas dessas células específicas aos alérgenos em geral ${ }^{81,99,100,101}$.

Diferentes mecanismos podem ser responsáveis por isso, como depleção de células $T$ induzida pela imunoterapia, indução de anergia de células T, ou desenvolvimento de "ignorância" de alérgenos ${ }^{79,102,103,104,105}$. 
Ao bloquear a ligação de alérgenos a lgE, anticorpos lgG específicos induzidos pela imunoterapia podem impedir a ligação facilitada de antígenos para células T e, portanto, a propagação adicional de respostas específicas de células $\mathrm{T}^{106}$.

\subsection{Células B regulatórias e tolerância imune}

Além das células Treg, a contribuição de outros subconjuntos de células para o estabelecimento e manutenção da tolerância imunológica vem sendo estudado hoje em dia. As células supressoras B produtoras de IL-10 foram denominadas células $B$ reguladoras (Breg) e contribuem para a proteção contra condições inflamatórias crônicas pela produção de IL-10, TGFß e IL-35. Um papel potencial das células Breg na indução de tolerância durante a imunoterapia foi atribuída à diminuição da $\lg E$ e aumento da produção de $\lg G 4$, juntamente com aumento da produção de IL-10 a partir de células T e B alérgeno-específicas ${ }^{107,108,109}$.

A fração naive CD27+ das células Breg produtoras de IL-10 é especificamente confinada à produção de $\lg G 4^{107}$. Essas populações reguladoras de células formam um meio supressor, que acaba com uma diminuição lenta na produção de $\lg E$ alérgeno específico e troca precoce de células B para produzir lgG4 e consequentemente, aumento desses anticorpos. Devido a ambos: predominância de citocinas inibitórias e a uma queda nos níveis de $\lg \mathrm{E}$, há um aumento do limiar de ativação de mastócitos e basófilos para desgranulação, assim chamada dessensibilização precoce. A diminuição de mastócitos e eosinófilos localizados nos tecidos é chamada de dessensibilização tardia ${ }^{110,111}$.

Em resumo (Figura 5), a imunoterapia alérgeno específica resulta em um processo dinâmico tanto de células $\mathrm{T}$ específicas a determinados alérgenos quanto de alterações humorais, não apenas no primeiro ano, mas também durante todo o período de tratamento. A eficácia sustentada atingindo além dos 3 anos de tratamento parece depender de ambos: perda da 
reatividade de células $\mathrm{TH} 2$ alérgeno específicas e persistência de anticorpos IgG com a capacidade de bloquear a interação lgE-alérgeno.

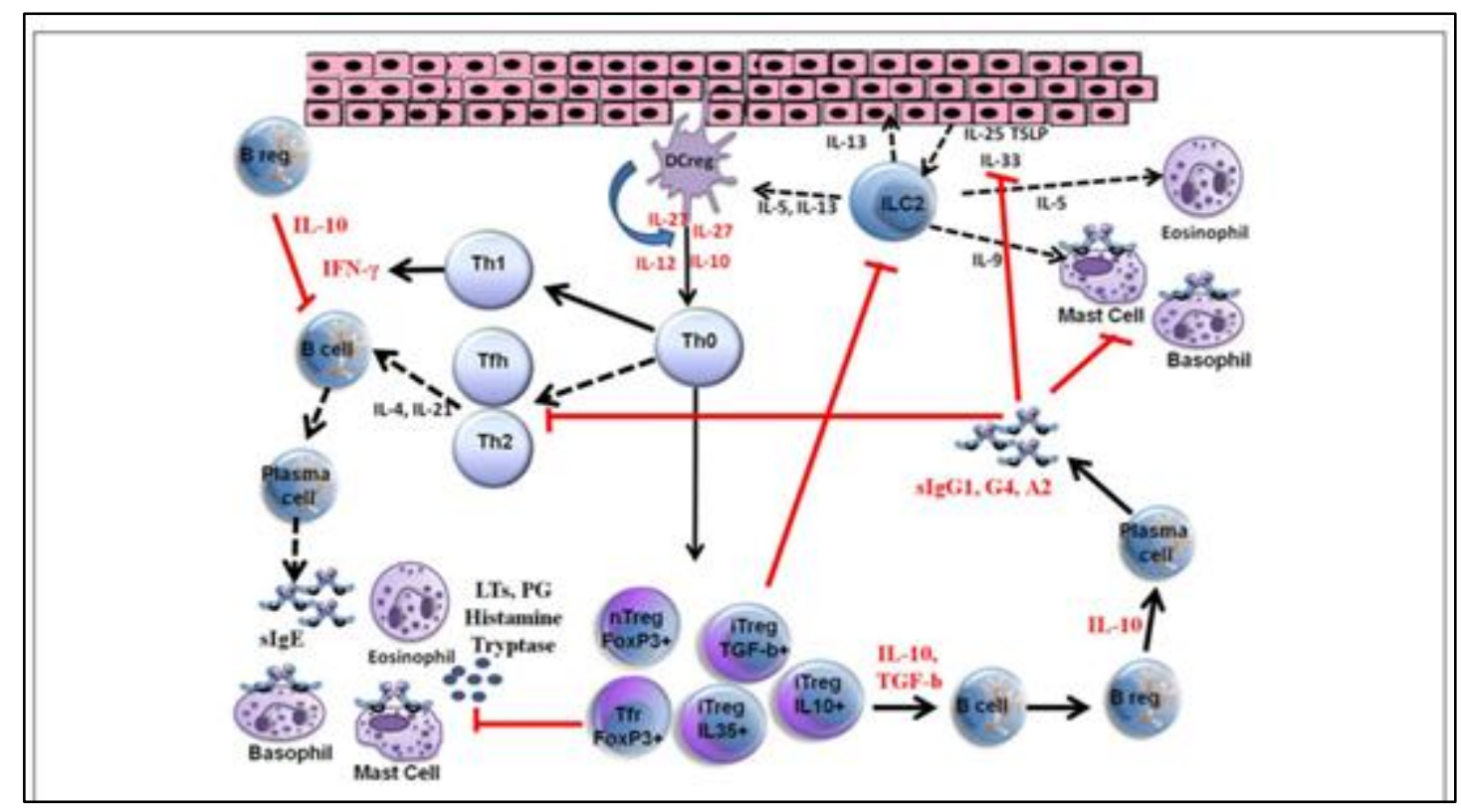

Figura 5: Mecanismos de imunoterapia veneno específica.

Alta dose de veneno de himenópteros estimula as células dendríticas e induzem células Treg e Breg, bem como outros subconjuntos de células B que produzem anticorpos específicos do tipo lgG1, IgG4. Várias citocinas também estão envolvidas na indução de tolerância imunológica e, como resultado, ocorre uma mudança de desvio imunológico do tipo TH2 para TH1. As setas vermelhas mostram a atividade de bloqueio induzida durante a imunoterapia. LTs: Leucotrienos; PG: Prostaglandinas; iTreg: células Tregulatórias induzíveis; $n T r e g:$ células $T$ reguladoras naturais; Tfh: células $T$ foliculares helper; Tfr: células $T$ reguladoras foliculares; Dcreg: células dendríticas reguladoras; TSLP: linfopoetina do estroma tímico.

Adaptado de: Sahiner UM, Durham SR. Hymenoptera Venom Allergy: How Does Venom Immunotherapy Prevent Anaphylaxis From Bee and Wasp Stings? Front Immunol. 2019 Aug 21;10:1959. doi: 10.3389/fimmu.2019.01959. PMID: 31497015; PMCID: PMC6712168. ${ }^{112}$

\subsubsection{Indicações da imunoterapia}

A imunoterapia alérgeno-específica é indicada para crianças e adultos após uma reação alérgica sistêmica que excede os sintomas cutâneos generalizados com uma sensibilização documentada ao veneno do inseto implicado seja por testes cutâneos e/ou dosagem de lgE sérica específica e/ou teste de ativação de basófilos (BAT). Também deve ser considerada apenas para adultos com sintomas de pele, mas com alto risco de reexposição e/ou comprometimento da qualidade de vida ${ }^{113}$. 
Crianças menores de 16 anos que experimentaram somente reações cutâneas, geralmente não é recomendada a imunoterapia, pois os estudos realizados com veneno de abelha e vespa mostraram que as crianças apresentaram uma boa evolução espontânea. As reações sistêmicas nas ferroadas subseqüentes foram mais leves ou semelhantes às originais tanto nas que fizeram imunoterapia, quanto nas que não fizeram ${ }^{114}$.

Quando se consideram crianças menores de 16 anos com hipersensibilidade a veneno de formiga, devem-se avaliar cada caso, pois no Brasil a frequência de exposição é maior nesses pacientes. Além disso não há dados na literatura sobre imunoterapia com veneno desse inseto especificamente em crianças com apenas manifestações cutâneas. Caso a exposição seja muito frequente, considerando hobbies e ocupação do paciente ou em condições de má qualidade de vida avaliada, pode ser possível a indicação da imunoterapia nesses casos (Figura 6) ${ }^{115}$.

\begin{tabular}{|c|c|c|c|}
\hline Criança & $\begin{array}{r}\text { Tipo da reação } \\
\text { grau I ou II }\end{array}$ & Teste cutâneo & Imunoterapia \\
\hline Adulto & $\begin{array}{r}\text { Reação generalizada } \\
\text { grau I ou II }\end{array}$ & Positivo & Sim \\
\hline individualmente \\
$\begin{array}{c}\text { Criança ou } \\
\text { adulto }\end{array}$ & $\begin{array}{c}\text { Reação local extensa } \\
\text { grau III ou IV }\end{array}$ & Positivo ou negativo & Não* \\
\cline { 2 - 4 } & Reneralizada & Positivo & Sim \\
\hline
\end{tabular}

Figura 6: indicações da imunoterapia segundo a gravidade da reação alérgica $^{116}$

*: geralmente não se indica nesses casos porque o risco de novas reações sistêmicas é baixo em pacientes com reação local extensa, sendo de 0,8$7 \%{ }^{117,118}$, mas pode ser indicada para pacientes com reações locais extensas recorrentes, pois verificou-se que a imunoterapia reduz o tamanho e a duração da lesão, especialmente naqueles que estão em alto risco para levar várias ferroadas por causa da ocupação ou da susceptibilidade ${ }^{119}$. 
A imunoterapia não é indicada se não for possível verificar sensibilização ao veneno de insetos. Além disso, um achado de sensibilização ao veneno de insetos em pacientes que não tiveram reações sistêmicas não é uma indicação para a imunoterapia. Também não está indicada em pacientes com reações incomuns que não podem ser atribuídas a reações imediatas do Tipo I, como púrpura trombocitopênica e vasculite, rabdomiólise ou insuficiência renal após múltiplas ferroadas ${ }^{113}$.

\subsubsection{Contra indicações absolutas e relativas}

Em uma pesquisa feita com 520 alergistas principalmente europeus, até $47 \%$ relataram experiência com administração de imunoterapia alérgeno específica em pacientes com condições de risco, como doenças cardiovasculares, IECA ou betabloqueadores, doença maligna em remissão e doença autoimune que anteriormente haviam sido consideradas como contraindicações $^{120}$.

Os problemas eram majoritariamente incomuns, por isso no guideline de $2018^{113}$ os autores reconsideram algumas contraindicações a imunoterapia e algumas recomendações são assim colocadas:

\section{Doença cardiovascular}

Os estudos de mortalidade demonstraram que pacientes particularmente idosos com alergia a veneno de himenópteros e doença cardiovascular preexistente apresentaram um risco aumentado de morrer por ferroada. Portanto, ao contrário das alergias respiratórias, a imunoterapia veneno específica é comumente realizada em pacientes idosos. Com base no perfil de risco/benefício, as doenças cardiovasculares em si não são uma contra-indicação para o tratamento com venenos ${ }^{121}$. 


\section{Uso de betabloqueadores}

Há boas evidências de que a anafilaxia não ocorre com maior frequência em pacientes recebendo betabloqueadores, como resumido recentemente em um documento de posicionamento da $\mathrm{EAACl}^{122}$. No entanto, teoricamente esses pacientes podem estar em risco de maior gravidade da reação sistêmica, e o tratamento de emergência com adrenalina pode ser menos eficaz. Pacientes idosos com alergia a venenos de himenópteros e doença cardiovascular tratados com betabloqueadores são considerados particularmente de alto risco de reação sistêmica grave no caso de ferroada de inseto $^{123}$. Com base no perfil de risco/benefício, não há contraindicação para imunoterapia com venenos em pacientes tratados com betabloqueadores ${ }^{122}$.

\section{$\underline{\text { Inibidores da enzima de conversão da angiotensina (iECA) }}$}

Estudos com grande número de participantes concluíram que o tratamento com iECA não afeta a segurança da imunoterapia veneno específica $^{124,125}$. Um estudo ${ }^{126}$ relatou um risco maior para reação sistêmica grave, no entanto, há uma base crescente de evidências que indicam que os iECAs não aumentam o risco para reação sistêmica grave em pacientes não tratados $^{127,128,129}$. Portanto, o tratamento com inibidores da ECA pode ser mantido durante a imunoterapia, mas o paciente deve ser informado sobre os possíveis riscos.

\section{Neoplasia maligna}

A imunoterapia foi administrada com segurança em pacientes que sofreram concomitantemente de alergia ao veneno de vespa e câncer em estágio menos avançado em uma pequena série de quatro pacientes ${ }^{130}$. Não existem estudos controlados relacionados ao risco ou eficácia da imunoterapia em neoplasias malignas ${ }^{122}$. Portanto, as neoplasias malignas agudas são consideradas uma contraindicação relativa, mesmo se não houver evidências de efeitos desfavoráveis da imunoterapia no crescimento do tumor ou na eficácia da quimioterapia. Os benefícios da imunoterapia devem ser ponderados em relação aos possíveis encargos do tratamento e à atividade da 
doença tumoral. Para concluir, a imunoterapia pode ser recomendada em pacientes alérgicos ao veneno de alto risco quando a doença maligna é estável ou em remissão ${ }^{113}$.

\section{Doença autoimune}

Deve-se tomar cuidado ao prescrever a imunoterapia a pacientes com distúrbios autoimunes de múltiplos órgãos. Devido à falta de dados disponíveis, existe uma contraindicação relativa nos distúrbios autoimunes em remissão e uma contraindicação absoluta nas formas ativas ${ }^{122}$. Distúrbios autoimunes específicos de órgãos, como por exemplo Diabetes Mellitus, tireoidite de Hashimoto, doença de Crohn, colite ulcerativa e artrite reumatóide não são consideradas uma contraindicação quando a doença é estabilizada, mas foram levantadas preocupações de que a medicação imunossupressora possa teoricamente influenciar negativamente a eficácia da imunoterapia ${ }^{131}$. Portanto, a imunoterapia pode ser recomendado em pacientes com distúrbio autoimune de órgão específico quando a doença subjacente está estabilizada $^{113}$.

\section{$\underline{\text { Inibidores da monoaminooxidase (iMAO) }}$}

A prescrição de iMAOs é agora extremamente limitada, devido à grande variedade de interações medicamentosas perigosas ${ }^{132}$. A principal preocupação com seu uso no contexto da imunoterapia é que eles impedem a quebra de drogas simpatomiméticas; portanto, no caso de eventos adversos, o tratamento de emergência com adrenalina pode resultar em hipertensão grave e/ou taquicardia. Para concluir, o tratamento com iMAOs não é uma contraindicação para imunoterapia, mas recomenda-se cautela com o uso de adrenalina $^{122,132}$.

\section{Crianças menores de 5 anos de idade}

Geralmente, a reação sistêmica grave é menos frequente em crianças e parece ser rara em crianças em idade pré-escolar $(<5 \text { anos })^{133}$. No raro evento de uma reação sistêmica, as decisões devem ser tomadas 
individualmente, considerando o risco de futuras reações sistêmicas graves. A imunoterapia veneno específica foi relatada bem sucedida em crianças menores de quatro anos ${ }^{134}$; como o limite de idade de cinco anos é arbitrário, não há preocupações específicas em relação a crianças menores de cinco anos e as mesmas recomendações dos adultos se aplicam ${ }^{113}$.

\section{Gravidez}

A incidência de prematuridade, toxemia, aborto, morte neonatal e malformação congênita parece ser semelhante em pacientes em imunoterapia durante a gravidez em comparação com a população em geral ${ }^{135}$. A imunoterapia parece ser segura em mulheres grávidas, mas os dados são escassos. Portanto, o início do tratamento não é recomendado. Devido ao alto risco de recidiva após o término precoce da imunoterapia ${ }^{136}$ e o baixo risco de eventos adversos ${ }^{124}$, um regime de imunoterapia em andamento bem tolerado durante a gravidez deve ser continuado, usando a dose de manutenção tolerada administrada antes da gravidez ${ }^{138}$.

\section{Mastocitose}

A mastocitose é um fator de risco para o desenvolvimento de anafilaxia a veneno de himenópteros e para reação sistêmica mais grave ${ }^{139}$. A imunoterapia geralmente é bem tolerada pela maioria dos pacientes com mastocitose sistêmica ${ }^{140}$, embora eventos adversos possam ocorrer com mais frequência ${ }^{141}$. Em um estudo sobre pacientes com mastocitose sistêmica confirmada e reações iniciais graves após ferroada (63\% sofreram perda de consciência), foi possível demonstrar que a imunoterapia foi segura e eficaz ${ }^{142}$.

Se os níveis séricos elevados de triptase aumentam o risco de eventos adversos ainda é uma questão debatida e dados robustos são escassos. Geralmente, não há evidências na literatura de que a imunoterapia deva ser realizada indefinidamente em pacientes com mastocitose. No entanto, a imunoterapia pode ser menos protetora em pacientes com reação sistêmica inicial grave e mastocitose e ou triptase sérica elevada ( $>11,4 \mu \mathrm{g} / \mathrm{L}$ ). Portanto, por razões de segurança, deve ser prolongada nesses pacientes ${ }^{143}$. 


\subsubsection{Tipos de imunoterapia}

Desde que os extratos com veneno de insetos para imunoterapia foram introduzidos ${ }^{144}$, muitos protocolos tem sido propostos com o objetivo de maximizar a proteção, minimizar efeitos colaterais e otimizar a conveniência do paciente. O tempo requerido para alcançar uma adequada dose de manutenção de pode variar entre os vários tipos de protocolos ${ }^{145,146}$ :

-Imunoterapia convencional: consiste de uma injeção por semana até completar o período de indução, com duração de dois a três meses

-Imunoterapia "rush": a fase de indução tem duração de 4 a 7 dias

-Imunoterapia "ultra rush": a dose de manutenção é alcançada em um a três dias, portanto o paciente deve ser internado, com aumento das doses no período de indução ocorrendo em horas

-"cluster" (rush modificada, semi rápida): realizado com até quatro injeções diárias do alérgeno no período de indução, com intervalo de 15 a 30minutos e a dose de manutenção é alcançada em aproximadamente 6 semanas.

Como acima citado, os esquemas rush e ultra-rush fornecem proteção mais precoce contra ferroadas futuras do que o protocolo convencional e por isso são mais utilizados em indivíduos que estão altamente expostos tais como os apicultores.

Em relação à fase de manutenção, a maioria dos protocolos sugere um intervalo entre as aplicações de quatro em quatro semanas, podendo ser encontrados na literatura intervalos maiores, de até três meses ${ }^{147}$.

\subsubsection{Dose recomendada}

A partir do end point, que é a concentração que foi positiva no teste cutâneo, podemos estabelecer a concentração a ser utilizada para a imunoterapia: quando for positivo no prick test, dilui-se em 1000 vezes a concentração do extrato. Quando for positivo no intradérmico, dilui-se em 100 
vezes o extrato para o início do tratamento. A dose recomendada na manutenção é de $0,5 \mathrm{ml}$ de uma diluição de 1:100 por peso por volume do extrato comercial disponível ${ }^{148}$.

\subsubsection{Aderência}

A aderência a imunoterapia para venenos é alta, possivelmente devido à percepção dos pacientes de um risco imprevisível de reações com risco de vida. Em um estudo ${ }^{149}, 95 \%$ e $84 \%$ dos pacientes continuaram com a imunoterapia após três e cinco anos, respectivamente.

\subsubsection{Pré tratamento}

Em vários ensaios duplo-cegos ${ }^{150,151,152,153}$, controlados por placebo, foi demonstrado que o pré-tratamento com anti-histamínicos $\mathrm{H} 1$ melhora a tolerabilidade da imunoterapia. É importante ressaltar que a eficácia da imunoterapia não foi influenciada negativamente ${ }^{153,154}$.

Os anti-histamínicos geralmente foram administrados 1-2 horas antes das injeções e em alguns casos, duas vezes ao dia. Em caso de eventos adversos repetidos pela mesma dose, o pré-tratamento com omalizumabe pode ser recomendado ${ }^{155,156}$.

\subsubsection{Duração da imunoterapia}

A duração desse tratamento com veneno desses insetos varia de 3 a 5 anos e, segundo o artigo de parâmetros práticos ${ }^{116}$ sobre venenos de insetos publicado em 2017, deve ser individualizada, considerando a gravidade dos sintomas antes da imunoterapia, a resposta clínica ao tratamento, se há reações sistêmicas durante 0 tratamento $e$ se as reações foram desencadeadas pela ferroada de abelha. A duração de 5 anos é melhor do que 3 anos. O término após aproximadamente um ou dois anos leva a uma taxa de recaída de 22 a $27 \%{ }^{137,158}$.

Alguns estudos concluíram que a imunoterapia por três anos pode ser suficiente, particularmente em pacientes com apenas reações iniciais leves a moderadas ${ }^{159}$. O tratamento mais longo é recomendado nas reações mais 
graves; sendo que 3 anos em imunoterapia pode ser suficiente em crianças. As evidências sugerem que apesar da persistência positiva do teste cutâneo, 80 a $90 \%$ dos pacientes não terão uma reação sistêmica após ferroada do inseto causador quando o tratamento é realizado por 3 a 5 anos $^{116}$. A decisão de interrupção da imunoterapia requer, portanto, uma flexibilidade individual baseada nas evidências clínicas.

A duração ideal da imunoterapia com extrato de formiga, que é menos padronizado, é bem menos definida. Muitos alergistas consideram interromper a imunoterapia após um período que varia de 3 a 5 anos empiricamente, baseando-se na duração para os outros himenópteros, ou quando o teste cutâneo ou quando o teste in vitro torna-se negativo. Até o momento, uma recomendação definitiva sobre a duração da imunoterapia para alergia a ferroada de formiga ainda não está definida ${ }^{160}$.

\subsubsection{Fatores de risco para reações adversas durante a imunoterapia}

A frequência de eventos adversos sistêmicos pela imunoterapia em grandes estudos multicêntricos varia de 8 a $20 \%^{124,138,161}$. A maioria dos estudos inclui apenas um pequeno número de pacientes e fornece dados conflitantes. O fator de risco mais importante é o tratamento com veneno de abelha. Tem sido relatado consistentemente que existe um risco 3,1 a 6,0 vezes maior de eventos adversos sistêmicos devido ao tratamento com veneno de abelhas ${ }^{124,162,163}$.

O rápido aumento da dose durante a fase de indução é um fator de risco baixo, porém estabelecido ${ }^{124,138}$.

A mastocitose e/ou triptase sérica elevada foram inicialmente consideradas como fator de risco para eventos adversos. Um estudo multicêntrico da EAACl encontrou um risco ligeiramente aumentado quando a triptase foi elevada em pacientes alérgicos ao veneno de vespa ${ }^{124}$, enquanto outro estudo realizado em pacientes alérgicos ao veneno de abelha não verificou tal achado ${ }^{164}$. Nós estudamos em nosso Serviço o aumento de triptase 
em pacientes com anafilaxia a venenos de himenópteros e não encontramos qualquer diferença em relação à gravidade (dados não publicados).

Um estudo realizado em pacientes com mastocitose concluiu que a imunoterapia nesses pacientes é segura e eficaz ${ }^{165}$, confirmando dados anteriores $^{140}$.

Embora ainda seja um assunto debatido, os inibidores da ECA e os betabloqueadores não são considerados fatores de risco independentes para eventos adversos ${ }^{124,125,166}$.

É importante ressaltar que reações iniciais graves ${ }^{124,125,161}$, testes cutâneos positivos em baixas concentrações e dosagens altas de anticorpos $\lg \mathrm{E}$ específicos ${ }^{161,164}$ não são considerados fatores de risco para eventos adversos.

\subsubsection{Monitoramento da imunoterapia}

De acordo com um documento realizado pela Academia Européia de Alergia e Imunologia (EAACl) em $2017^{167}$, os biomarcadores potenciais para monitorização da eficácia clínica da imunoterapia alérgeno específica são assim resumidos:

a) dosagem de $\lg E$ ( $\lg E$ total, razão $\lg E$ específica/lgE total)

b) dosagens de subclasses de $\lg G$ (IgG específica para alérgenos, lgG1 e lgG4 específica, razão lgE específica/lgG4)

c) atividade inibidora sérica de $\lg E$ para $\lg E(\lg E F A B)$,

d) ativação de basófilos,

e) quimiocinas e citocinas,

f) marcadores de células Tregs, Bregs

g) biomarcadores in vivo, incluindo testes de provocação. 
A taxa de recaída após a descontinuação do tratamento é de $10 \%$ a $15 \%$; sendo que o risco é maior em pacientes submetidos a tratamento por menos de 5 anos ${ }^{168}$.

No entanto, testes in vitro para identificar pacientes que não toleram ou para identificar os que irão reagir a uma nova ferroada após a descontinuação da imunoterapia não existe, o único método confiável disponível é a provocação com inseto, mas, por questões éticas, não é permitido realizar no Brasil ${ }^{169,170}$.

Um aumento no bloqueio pelos anticorpos $\lg G 4$, uma diminuição nos níveis de anticorpos IgE ou uma diminuição da sensibilidade do teste cutâneo foram marcadores relatados em pacientes submetidos a imunoterapia veneno específica $^{169}$.

Foi levantada a hipótese de que a capacidade de neutralização do antígeno pelos anticorpos $\lg \mathrm{G}$, produzidos durante o tratamento, forneceria uma proteção clínica na maioria dos pacientes ${ }^{171}$.

\section{Dosagem de $\lg G 4$}

A presença da imunoglobulina G4 (lgG4) veneno específica é considerada ser indicador de tolerância em indivíduos alérgicos. Esses anticorpos IgG4 são capazes de inibir a ligação do anticorpo lgE ligado a membrana com alérgeno, evitando as reações imune mediadas ${ }^{77,167}$, sendo observado aumento crescente desse anticorpo durante pelo menos 3 anos de acompanhamento de imunoterapia.

A capacidade de inibir a ligação anticorpo lgE-alérgeno foi confirmada através da determinação da razão entre interações lgE-alérgeno específico medidas na presença e na ausência nos soros de pacientes alérgicos a pólens reunidos em diferentes momentos, mostrando uma relação inversa entre concentrações de IgG específica ao alérgeno induzida pela imunoterapia e concentrações do anticorpo lgE específico ${ }^{77}$.

A evidência in vivo para um potencial papel protetor da lgG específica para alérgenos vem de pacientes com alergia ao veneno de abelha 
que se tornaram tolerantes ao veneno após receberem IgG plasmática de apicultores, que apresentam respostas aumentadas de IgG4 durante a temporada de apicultura ${ }^{172}$.

Um estudo de James e cols. ${ }^{173}$ sugere que a capacidade de bloquear a ligação ao alérgeno lgE deve-se principalmente pela fração lgG4, com a inibição sendo parcialmente abolida pelo esgotamento deste isotipo. Nesse estudo com Bet $v$ 1, o aumento dos níveis de lgG4 específicos foi paralelo a uma crescente capacidade de bloqueio dos soros dos pacientes, o que foi perdido quando a IgG foi removida. Além disso, foi observado uma relação inversa entre concentrações aumentadas de lgG4 específicas e diminuição da reatividade do teste cutâneo ao pólen de bétula como parâmetro clínico. 


\section{JUSTIFICATIVA}

Compreender os mecanismos de regulação imune na imunoterapia veneno específica é um dos tópicos mais importantes em pesquisa básica e clínica. A imunoterapia com veneno de formigas, em especial a espécie Solenopsis sp, muito frequente em nosso meio, em pacientes que apresentaram reações anafiláticas graves após ferroada mostra-se imprescindível e a falta de estudos na literatura que realizaram o seguimento desses pacientes avaliando quanto à eficácia e eventos adversos destacam a importância da realização do presente projeto.

Neste estudo, que foi executado em nosso ambulatório de alergia a venenos de insetos, avaliamos dados clínicos e laboratoriais dos pacientes submetidos à imunoterapia com extrato de corpo total de Solenopsis $s p$ (Solenopsis richteri e Solenopsis invicta) para o tratamento de anafilaxia ao veneno de formiga. Trata-se de um assunto pouco estudado e com nossos resultados esperamos ter contribuído para o diagnóstico e tratamento dessas alergias. 


\section{OBJETIVOS}

Avaliar dados clínicos e laboratoriais dos pacientes submetidos à imunoterapia com corpo total de Solenopsis $s p$ como um tratamento de anafilaxia ao veneno de formiga.

Parâmetros a serem avaliados:

a. Teste cutâneo com extrato de corpo total (período basal)

b. Dosagem de IgE específica ao veneno de formiga (basal e após 12 meses de ter entrado na fase de manutenção do tratamento)

c. Avaliar fatores de risco para reações mais graves (presença de atopia, dosagem de IgE sérica específica, teste cutâneo, reação prévia, dosagem de triptase, gênero)

d. Relação da dosagem de IgG4 específica para formiga/dosagem de IgE sérica específica antes e após 12 meses de iniciada a fase de manutenção do tratamento

e. Avaliar reações após ferroadas acidentais (em campo) durante o tratamento, se houver

f. Avaliar dosagem de IgE sérica específica basal e após 1 ano de iniciada a fase de manutenção do tratamento

g. avaliar e classificar as reações adversas durante a imunoterapia em local ou sistêmica em seus diferentes graus. 


\section{MÉTODOS}

\subsection{Aprovação ética}

Este estudo foi aprovado pela Comissão de Ética para Análise de Projetos de Pesquisa (CAPPesq) do HCFMUSP. O documento foi assinado em 20 de janeiro de 2016 (Registro online o: 14174). Os indivíduos incluídos nesse estudo assinaram o Termo de Consentimento Livre e Esclarecido (TCLE).

\subsection{Seleção dos pacientes:}

Pacientes atendidos no Ambulatório de Anafilaxia do Serviço de Imunologia Clínica e Alergia do Hospital das Clínicas da Faculdade de Medicina da Universidade de São Paulo, que apresentaram história de reação anafilática grave (gravidade III e IV de Mueller ${ }^{44}$ ) após ferroada de formiga da espécie Solenopsis sp, e segundo os seguintes critérios de inclusão:

- Idade de 5 a 65 anos

- Diagnóstico de hipersensibilidade tipo I confirmado por determinacão positiva de lgE sérica específica para Solenopsis sp (ImmunoCap® i70) e teste cutâneo de leitura imediata com titulação (prick test e intradérmico).

- Termo de consentimento livre e esclarecido assinado pelo paciente.

Os seguintes critérios de exclusão se aplicam:

- Uso de tratamento imunomodulador nos últimos cinco anos

- Tratamento prévio com imunoterapia alérgeno específica

- Asma persistente moderada ou grave e VEF1 < $80 \%$

- Gravidez

- Analfabetismo 
- Doença psiquiátrica

- Uso contínuo de $\beta$-bloqueadores

- Doenças cardiovasculares, insuficiência de órgãos e doenças que aumentem o risco dos efeitos colaterais da adrenalina.

- Outras doenças imunológicas, auto-imunes ou malignidade.

\subsection{Exames solicitados:}

\subsubsection{Pesquisa de IgE e IgG4 específica in vitro (ImmunoCap®, Thermofisher, Brasil):}

\section{Princípio do Método: FEIA - FLUOROENZIMAIMUNOENSAIO}

O alérgeno do qual se suspeita de alergia encontra-se acoplado por ligação covalente à fase sólida ImmunoCAP (polímero). Ele reage com anticorpos IgE específicos contidos na amostra de soro do paciente. Após os anticorpos não-específicos terem sido eliminados através de lavagem, é adicionado Conjugado, anticorpos anti-IgE ligados a uma enzima ( $\beta$ galactosidade). Após a incubação, os anticorpos não ligados são eliminados através de lavagem.

O substrato da enzima, contido na solução reveladora (Development), é adicionado ao meio reacional e então aguarda-se um período de incubação. Em seguida a reação é interrompida pela adição de solução Stop e a fluorescência do eluato é medida.

Quanto mais elevado for o valor de fluorescência, mais elevada é a quantidade de auto-anticorpos específicos daquela amostra. Para se quantificar essa amostra, os resultados de fluorescência (resp) medidos em unidades de resposta (RU) são comparados com a curva de calibração armazenada no equipamento.

Desse modo, as dosagens de IgE e lgG4 específicas para o veneno de Solenopsis foram realizadas através da técnica de ImmunoCAP. As 
dosagens foram realizadas em amostras do soro dos pacientes coletadas antes do início da imunoterapia, e após 12 meses da fase de manutenção da imunoterapia veneno específica.

\subsubsection{Teste cutâneo}

O teste cutâneo de leitura imediata foi realizado na superfície volar do antebraço, $3 \mathrm{~cm}$ abaixo da fossa cubital e $5 \mathrm{~cm}$ acima do pulso e $3 \mathrm{~cm}$ entre cada concentração. Para avaliar reações inespecíficas causadas pelo trauma induzido pelo teste (exemplo: dermografismo) foi realizado controle negativo com a solução diluente do alérgeno, e para documentar a reatividade cutânea normal foi realizado controle positivo com solução de histamina $10 \mathrm{mg} / \mathrm{ml}^{174}$.

O princípio básico do teste cutâneo de leitura imediata é a introdução de pequena quantidade do extrato do alérgeno dentro da epiderme. Após limpeza da pele com solução alcoólica a 70\%, pinga-se 1 gota do controle negativo, 1 gota do controle positivo e 1 gota do extrato de corpo total de formiga nas diversas concentrações citadas abaixo. Com uma lanceta deve-se gentilmente, mas firmemente realizar a puntura através do centro da gota, a lanceta deve ser pressionada, e não inserida, a 90 graus pela pele.

Após a realização da puntura dos controles e do veneno, retirou-se 0 excesso das soluções com papel absorvente sem espalhá-los. A leitura do resultado foi realizada após 15 a 20 minutos, medindo-se o diâmetro médio da pápula com uma régua.

O teste cutâneo de leitura imediata foi considerado positivo quando o diâmetro médio da pápula for maior que $3 \mathrm{~mm}$ (área $>7 \mathrm{~mm}^{2}$ ) que o controle negativo $^{175}$.

Nos casos positivo, finalizou-se o teste e não houve progressão para outras concentrações. Nos casos negativos na primeira concentração, fez-se o mesmo procedimento com a concentração seguinte e assim sucessivamente 
até a concentração final. Nos resultados negativos para a última concentração, realizou-se o teste intradérmico nas mesmas diluições crescentes.

As seguintes concentrações foram utilizadas para o teste cutâneo:

- Extrato de corpo total: 1/1.000.000; 1/100.000; 1/10.000; 1/1000 (peso/volume)

No teste intradérmico utilizou-se novamente a face média ventral (volar) do outro antebraço. Injeta-se 0,03 a 0,05 mL em concentrações crescentes do veneno por via intradérmica com uma seringa de $1 \mathrm{~mL}$, com agulha $10 \times 4,5$ ou $10 \times 5$ mantendo-se um intervalo mínimo de $5 \mathrm{~cm}$ entre cada concentração. Em sendo a via de aplicação correta, forma-se uma pápula, que foi evidenciada com marcação de caneta esferográfica, na qual os poros da pele ficam em maior evidência, com aspecto de "casca de laranja"175.

A leitura foi realizada após 20 minutos e foi considerada positiva quando o edema e eritema ultrapassarem a marcação da pápula original em $3 \mathrm{~mm}$ e com eritema ao redor da pápula (Figura 7$)^{176}$.

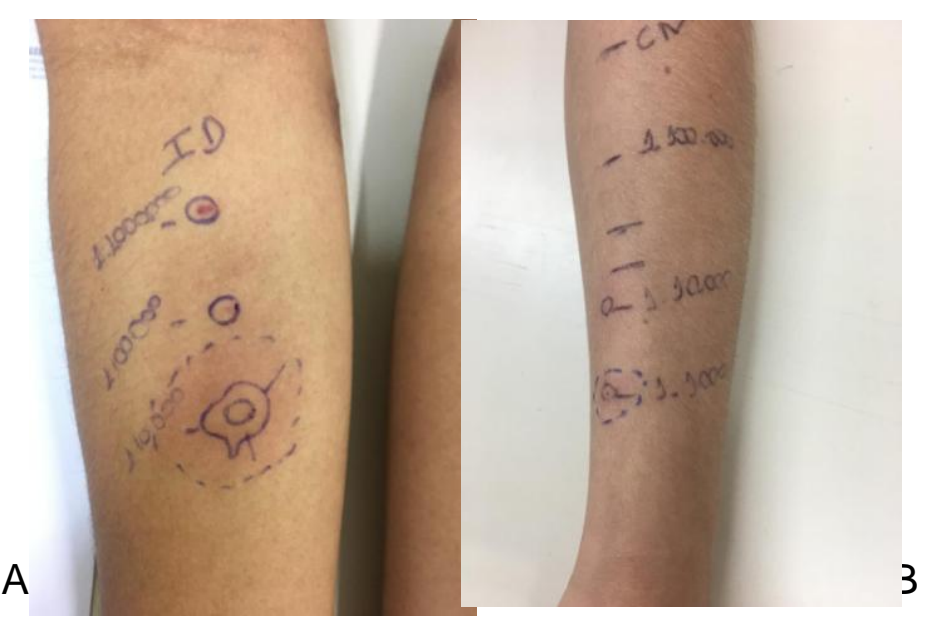

Figura 7: testes cutâneos positivos dos pacientes do estudo (A: positividade no teste intradérmico; B: positividade no prick teste)

\subsubsection{Exames laboratorais gerais:}

O hemograma e protoparasitológico de fezes serão realizadas apenas antes do início da imunoterapia.

As dosagens de $\lg E$ total, $\lg A$, $\lg G$ e $\lg M$ séricas totais serão realizadas apenas antes do início da imunoterapia. 


\subsubsection{Dosagem de Triptase total:}

Foi realizada no período basal também pela técnica ImmunoCAP Triptase (Thermofisher, Brasil), que se mede o nível de triptase liberado pelos mastócitos no soro.

Amostra de sangue foi colhida por venopunção, permitindo-se a sua coagulação, e o soro foi separado por centrifugação. As amostras foram guardadas à temperatura ambiente durante 2 dias, para posterior utilizacão. Foram estocadas a $2-8^{\circ} \mathrm{C}$ nos casos em que o ensaio foi realizado no prazo de 5 dias após a colheita e no caso de períodos mais longos, as amostras foram guardadas a $-20{ }^{\circ} \mathrm{C}$ ou $-70{ }^{\circ} \mathrm{C}$.

\section{Preparação das amostras}

Plasma: Coleta das amostras em tubo contendo anticoagulante EDTA ou citrato de sódio. Centrifugação das amostras a $1000 \mathrm{~g}$ a $4 \stackrel{\circ}{ } \mathrm{C}$ por 15 minutos, separar o soro e centrifugar novamente as amostras a $1000 \mathrm{~g}$ a $4^{\circ} \mathrm{C}$ por 10 minutos. Imediatamente congeladas as amostras a $-70^{\circ} \mathrm{C}$. Evita-se vários descongelamentos.

Soro: Coleta das amostras em tubo seco com gel, deixando a amostra coagular a temperatura ambiente por 30 a 45 minutos. Centrifugação das amostras a $1000 \mathrm{~g}$ a $4^{\circ} \mathrm{C}$ por 15 minutos, separação do plasma, e centrifugação novamente das amostras a $1000 \mathrm{~g}$ a $4^{\circ} \mathrm{C}$ por 10 minutos. Imediatamente congelar as amostras a $-70^{\circ} \mathrm{C}$. Deve-se evitar vários descongelamentos.

Pode-se manter todas as amostras congeladas até o uso.

\subsection{Obtenção do veneno}

Para o extrato de corpo total foi utilizado o extrato de formigas da empresa Hollister-Stier (EUA) que consiste na mistura das espécies Solenopsis invicta e S. richteri. 


\subsection{Imunoterapia veneno-específica}

Os pacientes foram submetidos à imunoterapia semi-rápida (concentrações aumentam a cada semana), com extrato aquoso de corpo total.

No dia da administração da dose, o paciente permanecia em observação por 30 minutos após a aplicação para o tratamento de eventuais reações imediatas. Antes de cada aplicação, o paciente foi avaliado de acordo com os seguintes passos:

- Queixas durante a última semana

- Queixas durante as últimas $24 \mathrm{~h}$

- Medicação utilizada

- Aferição e anotação da Pressão Arterial (PA) e Freqüência Cardíaca (FC) antes da aplicação

- Verificação Pico de Fluxo Expiratório - PFE antes e 30 minutos após a aplicação

- Aparecimento de alguma co-morbidade ou contraindicação

- Descrição reações e conduta na ficha de avaliação

\subsubsection{Técnica de aplicação}

1. Membro superior: na área do tríceps, porção posterior, terço médio, limpeza com álcool;

2. Injeção lenta no subcutâneo, aspirando previamente à injeção, se houver saída de sangue, desprezar material e repetir a aplicação em outro local por 15 a 20 segundos. Não massagear;

3. Observação do paciente por 30 minutos pelo risco de reação (ver abaixo). 


\subsubsection{Esquema posológico}

A concentração inicial foi baseada no resultado do teste cutâneo. Caso o teste tenha sido positivo no prick test, retornava-se 3 concentrações para o início da imunoterapia. Caso fosse positivo no teste intradérmico, retornava-se 2 concentrações.

Estabelecida a dose inicial, o aumento das concentrações ocorria semanalmente (fase de indução), até o estabelecimento de uma dose de manutenção $(0,5 \mathrm{~mL}$ de $1 / 100$ para o veneno de formigas), com 4 aplicações a intervalos de 15 dias, 4 aplicações a intervalos de 21 dias e de 28/28 dias até 0 término do tratamento.

A tabela 1 seguinte exemplifica o esquema de imunoterapia na fase de indução utilizado com dose aleatória inicial:

Tabela 1: esquema do protocolo utilizado exemplificando o aumento das concentrações semanalmente.

\begin{tabular}{|c|c|l|}
\hline Semana & Concentração & \multicolumn{1}{|c|}{ Volume } \\
\hline 1 & $1 / 100.000$ & $1 \mathrm{~mL}(0,1 \mathrm{~mL} ; 0,2 \mathrm{~mL} ; 0,3 \mathrm{~mL} ; 0,4 \mathrm{~mL})^{\star}$ \\
\hline 2 & $1 / 10.000$ & $1 \mathrm{~mL}(0,1 \mathrm{~mL} ; 0,2 \mathrm{~mL} ; 0,3 \mathrm{~mL} ; 0,4 \mathrm{~mL})^{\star}$ \\
\hline 3 & $1 / 1000$ & $1 \mathrm{~mL}(0,1 \mathrm{~mL} ; 0,2 \mathrm{~mL} ; 0,3 \mathrm{~mL} ; 0,4 \mathrm{~mL})^{*}$ \\
\hline 4 & $1 / 100$ & $0,5 \mathrm{~mL}(0,1 \mathrm{~mL} ; 0,2 \mathrm{~mL} ; 0,2 \mathrm{~mL})^{\star}$ \\
\hline 5 & $1 / 100$ & $0,5 \mathrm{~mL}(0,2 \mathrm{~mL} ; 0,3 \mathrm{~mL})^{\star}$ \\
\hline 6 & $1 / 100$ & $0,5 \mathrm{~mL}$ \\
\hline 7 & $1 / 100$ & $0,5 \mathrm{~mL}$ \\
\hline
\end{tabular}

*intervalo de 30 minutos a cada aplicação

Após alcançar a dose de $0,5 \mathrm{~mL}$ de $1 / 100$ peso/volume, as aplicações ocorreram a cada 7/7 dias por 4 semanas, depois a cada 15/15 dias 
por mais 4 vezes e depois a cada $21 / 21$ dias por mais 4 vezes e, então, a cada 28/28 dias até o término do tratamento, por 3 anos.

A dose seria ser suspensa caso o paciente apresentasse sintomas ou PFE $<70 \%$ do melhor valor pessoal.

\subsubsection{Protocolo de reinício e interrupção da imunoterapia}

* Caso ocorresse interrupção na fase de indução:

- Até 7 dias - manter esquema;

- De 8 a 13 dias - repetir dose anterior;

- De 14 a 21 dias - reduzir a dose anterior em $25 \%$

- De 21 a 28 dias - reduzir a dose anterior em 50\%

* Manutenção mensal em atraso de:

- Até 10 dias - repetir última dose;

- 11 a 20 dias - reduzir a dose em 25\%;

- 21 a 28 dias - reduzir a dose em 50\%;

\subsubsection{Local onde se realizaram os procedimentos}

Sala de aplicação de vacinas localizada dentro do ambulatório de Alergia, no 5a andar, bloco 4B, do Hospital das Clínicas da USP.

\subsubsection{Material necessário para testes cutâneos e imunoterapias:}

-Seringas, agulhas, puntores descartáveis, álcool e algodão.

-Medicamentos de emergência: adrenalina, antihistamínicos, corticoide e broncodilatadores.

-Material para entubação endotraqueal e para ventilação. 


\subsubsection{Técnica para aplicação subcutânea:}

Após assepsia da pele, injetar por via subcutânea o extrato na devida concentração no membro superior após aspiração.

\subsubsection{Reações adversas:}

\subsubsection{Reações locais:}

O extrato de veneno de formiga, por ser de corpo total causa muita reação local por conter o próprio exoesqueleto do inseto. Desse modo, foram consideradas reações locais que necessitassem de alguma intervenção (Figura 8) quando o tamanho do nódulo formado após a aplicação fosse maior ou igual a $50 \mathrm{~mm}^{177}$ ou até $60 \mathrm{~mm}^{66}$.

\begin{tabular}{|c|c|}
\hline Sintomas & Modificação da dose \\
\hline Pápula/eritema $<3 \mathrm{~cm}$ & Nenhuma modicação \\
\hline Pápula/eritema $<6 \mathrm{~cm}$ & Nenhuma modicação \\
\hline Urticária, prurido, angioedema, flushing & Repetir a dose \\
\hline $\begin{array}{l}\text { Congestão nasal, espirros, rinite, prurido oral } \\
\text { ou ocular ou no corpo }\end{array}$ & Retornar para dose anterior \\
\hline $\begin{array}{l}\text { Sibilos, dipsneia, aperto no peito, dor } \\
\text { abdominal, náuseas e vômitos }\end{array}$ & $\begin{array}{l}\text { Retornar para } 2 \text { doses } \\
\text { anteriores }\end{array}$ \\
\hline $\begin{array}{l}\text { Edema laríngeo, hipotensão, síncope, } \\
\text { tontura, choque, arritmia }\end{array}$ & $\begin{array}{l}\text { Encerrar dose do dia } e \\
\text { reavaliar fatores como } \\
\text { extrato, cofatores, técnica. }\end{array}$ \\
\hline
\end{tabular}

Figura 8: Gravidade de reação e modificação da dose (adaptado de Tanskerley et al. ${ }^{66}$ ) 


\subsubsection{Reações sistêmicas}

A World Allergy Organization (WAO) desenvolveu um sistema de classificação das reações sistêmicas à imunoterapia subcutânea visando uma melhor caracterização e padronização para fins de vigilância epidemiológica e estudos científicos, descrita na figura $9^{178,179}$ :

\begin{tabular}{|c|c|c|c|c|}
\hline Grau 1 & Grau 2 & Grau 3 & Grau 4 & Grau 5 \\
\hline $\begin{array}{l}\text { Sintomas e } \\
\text { sinais em um } \\
\text { órgão } \\
\text { sistema: } \\
\text { cutâneo } \\
\text { ou } \\
\text { trato } \\
\text { respiratório } \\
\text { superior } \\
\text { (rinite, prurido } \\
\text { em orofaringe } \\
\text { ou tosse) } \\
\text { conjuntivas } \\
\text { ou } \\
\text { outros } \\
\text { náuseas, } \\
\text { sabor } \\
\text { metálico ou } \\
\text { cefaléia }\end{array}$ & 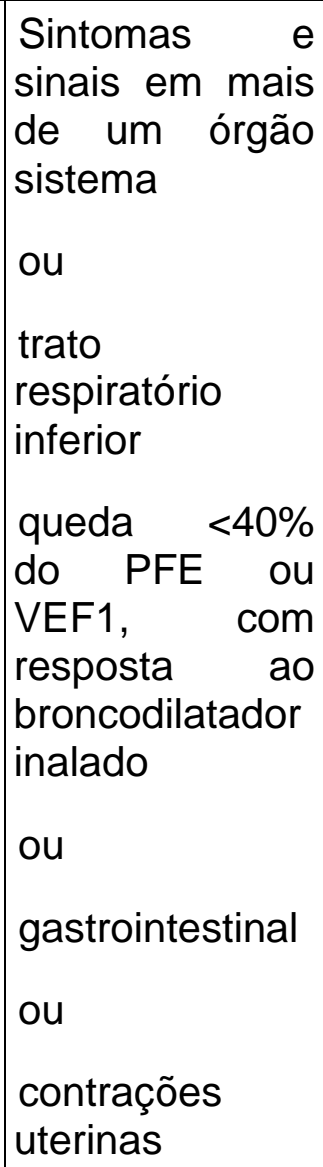 & $\begin{array}{l}\text { Trato } \\
\text { respiratório } \\
\text { inferior } \\
\text { queda }>40 \% \text { do } \\
\text { PFE ou VEF1 e } \\
\text { ausência de } \\
\text { resposta ao } \\
\text { broncodilatador } \\
\text { inalado } \\
\text { ou } \\
\text { trato } \\
\text { respiratório } \\
\text { superior } \\
\text { edema de } \\
\text { laringe, úvula } \\
\text { ou língua, com } \\
\text { ou sem estridor }\end{array}$ & $\begin{array}{l}\text { Insuficiência } \\
\text { respiratória } \\
\text { ou } \\
\text { cardiovascular }\end{array}$ & Óbito \\
\hline
\end{tabular}

Figura 9: classificação das reações sistêmicas a imunoterapia subcutânea 


\subsubsection{Conduta nas reações adversas}

Após a aplicação das imunoterapias, o paciente aguardou 30 minutos e foi reavaliado; caso apresentasse:

- Reação local ${ }^{180,181,182}$ : edema, eritema, prurido ou nódulos no local da aplicação

Conduta:

$\checkmark$ se necessário, prescrição de anti-histamínicos via oral para diminuir o prurido;

-Reação sistêmica ${ }^{178}$ :

1) Reações não específicas:

Conduta:

$\checkmark$ Sintomáticos

$\checkmark$ Considerar reajuste da dose

2) Reações sistêmicas brandas:

Conduta:

$\checkmark$ Antihistamínicos e $\beta$-2 agonistas

$\checkmark$ Considerar reajuste da dose

3) Reações sistêmicas sem risco de vida:

Conduta:

$\checkmark$ Venóclise

$\checkmark$ Corticóides sistêmicos, antihistamínicos, $\beta$-2 agonistas

$\checkmark$ Considerar reajuste da dose

4) Choque anafilático:

Conduta:

$\checkmark$ Venóclise 
$\checkmark$ Medidas para tratamento de choque:

- Adrenalina 1:1000 IM (vasto lateral da coxa)

- Crianças: $0,01 \mathrm{~mL} / \mathrm{kg}$

- Adulto: 0,3-0,5 mL

- Corticóides, antihistamínicos

- Agentes vasopressores

○ Oxigênio

- Hospitalização pode ser necessário

$\checkmark$ Considerar reajuste da dose ou interrupção da IT

PFE - pico de fluxo expiratório 


\section{RESULTADOS}

\subsection{Análise estatística}

Os dados categóricos foram resumidos usando porcentagens e analisados usando testes Pearson's qui-quadrado com Yates'continuity correction, teste $\mathrm{t}$ de Student e ANOVA com ajuste de Tukey ou teste de Wilcoxon, o que fosse mais apropriado. Significância para os resultados foi estabelecido quando os valores de p eram menores que 0,05 .

\subsection{População estudada}

Foram incluídos 33 pacientes que apresentarem história de reação anafilática grave (gravidade III e IV de Mueller) após ferroada de formiga da espécie Solenopsis, e que preencheram os critérios de inclusão. A grande maioria (93,93\%) morava na ocasião do estudo em zona urbana e apenas 2 pacientes $(6,07 \%)$ moravam em zona rural. Os exames gerais que foram colhidos: hemograma e protoparasitológico de fezes encontravam-se dentro dos padrões de normalidade e as dosagens de imunoglobulinas desses pacientes ( $\lg A, \lg G, \lg M)$ resultaram também todas dentro da normalidade (Tabela 2). 


\begin{tabular}{|c|c|c|c|}
\hline Paciente & IgA (unidade) & IgG (Unidade) & IgM (unidade) \\
\hline ASM & 146,9 & 972 & 252,4 \\
\hline ASS & 222,7 & 741 & 194,7 \\
\hline ALLN & 86 & 676 & 72 \\
\hline AMV & 101,7 & 779 & 76,4 \\
\hline BLRC & 82 & 1140 & 74 \\
\hline BKSR & 92,6 & 774 & 66,7 \\
\hline CGSM & 152 & 1431 & 83 \\
\hline CSSC & 169,4 & 965 & 162,7 \\
\hline DFS & 377,6 & 1016 & 118,8 \\
\hline DAG & 245,7 & 1111 & 165,7 \\
\hline ELSM & 211,6 & 1185 & 135,6 \\
\hline EJMS & 192 & 1249 & 111 \\
\hline ECAV & 157,9 & 959 & 71,4 \\
\hline GSN & 196,2 & 903 & 135,7 \\
\hline GRRS & 203 & 740 & 108,4 \\
\hline HPA & 606,7 & 1337 & 118,8 \\
\hline HGS & 187 & 1163 & 128 \\
\hline HCG & 187,5 & 1079 & 72 \\
\hline LRO & 86 & 1120 & 111 \\
\hline LFPS & 84,6 & 1227 & 88,3 \\
\hline LOD & 227,4 & 1437 & 86,5 \\
\hline MASB & 209,5 & 1050 & 122 \\
\hline MEDG & 87,4 & 992 & 105,8 \\
\hline MFL & 219 & 1023 & 410,9 \\
\hline NGRSD & 332,2 & 1034 & 101,4 \\
\hline PHMS & 182,5 & 1124 & 89,5 \\
\hline PAF & 177,6 & 1030 & 76,6 \\
\hline PPGF & 84,5 & 982 & 93,5 \\
\hline PAMBG & 167 & 1090 & 135 \\
\hline QFC & 139,6 & 1032 & 85,9 \\
\hline SSS & 331,1 & 1645 & 176,5 \\
\hline TRS & 164,2 & 1253 & 28,5 \\
\hline VC & 379,1 & 1183 & 248 \\
\hline
\end{tabular}

Tabela 2: dosagens de imunoglobulinas de cada paciente 
Ao longo do tratamento, quando já estavam na fase de manutenção, 3 pacientes abandonaram o tratamento: 2 deles relataram, que haviam sido ferroados 2 vezes e não apresentaram reações, somado à dificuldade de transporte. Já o terceiro paciente desistiu por medo de perder emprego.

\subsubsection{Idade:}

Os pacientes recrutados nesse estudo apresentavam idades entre 7 e 52 anos, distribuídos conforme a seguinte faixa etária (figura 10):

-Entre 5 a 10 anos: 6 pacientes (18,3\%)

-Entre 11 e 20 anos: 19 pacientes (57,6\%)

-Entre 21 e 30 anos: 4 pacientes (12,1\%)

-Entre 31 e 40 anos: 2 pacientes (6,0\%)

-Maiores que 41 anos: 2 pacientes (6,0\%)

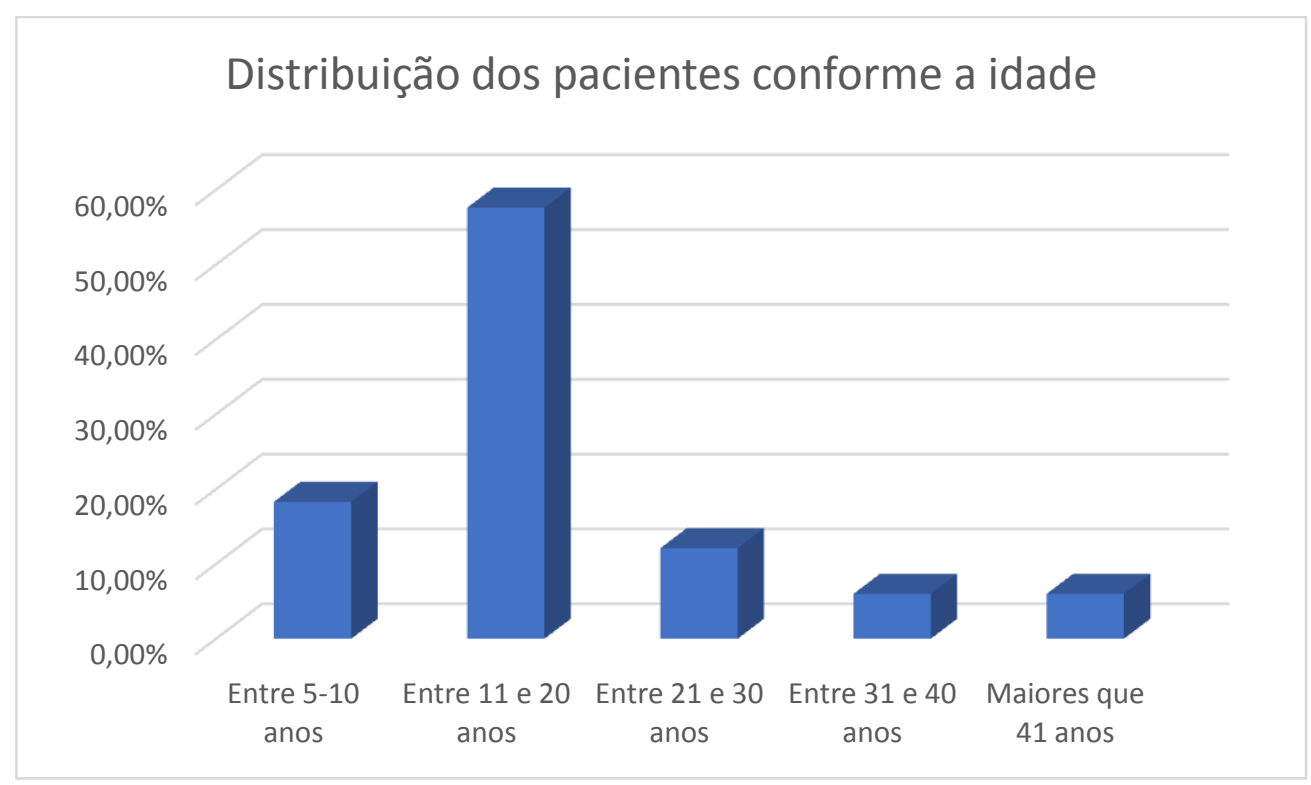

Figura 10: distribuição dos pacientes conforme a idade

Como pode ser observado, as reações após ferroada de formigas foram mais frequentes em menores de 20 anos, acometendo 75,9\% dos 
pacientes nesse estudo e dentro dessa faixa etária, os menores de 15 anos somam 17 pacientes $(51,51 \%)$ do total de pacientes.

\subsubsection{Gênero:}

Houve leve predomínio do gênero masculino: 51,5\% em relação ao feminino: 48,5\%, sendo que não houve influência do gênero na gravidade da reação (Pearson's Chi-squared test with Yates'continuity correction; $p=0,9151$ ).

\subsubsection{Gravidade dos sintomas}

Quanto a gravidade dos sintomas, considerando a indicação de imunoterapia, os quadros mais graves são os mais indicados e pelo ambulatório de Anafilaxia do HC-FMUSP ser referência no tratamento desses pacientes, apenas são encaminhados pacientes com reações grau III e IV que foram distribuídos da seguinte forma: 72,7\% dos pacientes apresentaram reação grau III (Muller) e 27,3\% deles apresentaram reação grau IV, sendo que nessas reações mais graves não houve predomínio em alguma faixa etária específica (tabela 3).

\begin{tabular}{|l|c|c|c|}
\hline Paciente & Idade (anos) & Gênero & $\begin{array}{c}\text { Gravidade de reação } \\
\text { (Mueller) }\end{array}$ \\
\hline ASM & 11 & feminino & III \\
\hline ASS & 11 & feminino & III \\
\hline ALLN & 7 & masculino & IV \\
\hline AMV & 13 & masculino & III \\
\hline BLRC & 23 & feminino & IV \\
\hline BKSR & 13 & feminino & IV \\
\hline CGSM & 12 & masculino & III \\
\hline CSSC & 36 & feminino & IV \\
\hline DFS & 28 & masculino & IV \\
\hline DAG & 10 & masculino & \\
\hline
\end{tabular}




\begin{tabular}{|c|c|c|c|}
\hline ELSM & 10 & feminino & III \\
\hline EJMS & 43 & feminino & IV \\
\hline ECAV & 7 & masculino & III \\
\hline GSN & 18 & masculino & III \\
\hline GRRS & 11 & feminino & III \\
\hline HPA & 18 & feminino & IV \\
\hline HGS & 9 & masculino & III \\
\hline HCG & 15 & masculino & III \\
\hline LRO & 15 & feminino & III \\
\hline LFPS & 12 & masculino & III \\
\hline LOD & 22 & feminino & III \\
\hline MASB & 19 & masculino & III \\
\hline MEDG & 13 & feminino & III \\
\hline MFL & 19 & masculino & III \\
\hline NGRSD & 13 & masculino & III \\
\hline PHMS & 9 & masculino & IV \\
\hline PAF & 12 & masculino & III \\
\hline PPGF & 15 & masculino & III \\
\hline PAMBG & 12 & masculino & III \\
\hline QFC & 16 & feminino & III \\
\hline SSS & 38 & feminino & IV \\
\hline TRS & 30 & feminino & III \\
\hline VC & 52 & masculino & III \\
\hline
\end{tabular}

Tabela 3: dados epidemiológicos e gravidade de reação dos pacientes incluídos

\subsubsection{Presença de atopia}

Conforme a tabela 4 abaixo, 17 pacientes $(51,51 \%)$ relataram diagnóstico de rinite alérgica e/ou asma alérgica. Quando se avaliou se asma era um fator de risco para gravidade de reação, não houve relação dessa doença nos pacientes que tiveram reação grau IV. ( $p$-value $=0.9233788$ ). 


\begin{tabular}{|c|c|c|}
\hline Paciente & Gravidade de reação (Mueller) & Atopia \\
\hline ASM & III & rinite \\
\hline ASS & III & rinite \\
\hline ALLN & IV & rinite e asma \\
\hline AMV & III & rinite e asma \\
\hline BLRC & IV & rinite \\
\hline BKSR & IV & não \\
\hline CGSM & III & não \\
\hline CSSC & III & não \\
\hline DFS & IV & não \\
\hline DAG & IV & rinite \\
\hline ELSM & III & rinite \\
\hline EJMS & IV & rinite \\
\hline ECAV & III & rinite \\
\hline GSN & III & rinite \\
\hline GRRS & III & rinite \\
\hline HPA & IV & rinite \\
\hline HGS & III & Não \\
\hline HCG & III & Não \\
\hline LRO & III & rinite e asma \\
\hline LFPS & III & Não \\
\hline LOD & III & Não \\
\hline MASB & III & asma \\
\hline MEDG & III & Não \\
\hline MFL & III & rinite \\
\hline NGRSD & III & rinite e asma \\
\hline PHMS & IV & rinite e asma \\
\hline PAF & III & rinite e asma \\
\hline PPGF & III & rinite \\
\hline PAMBG & III & não \\
\hline QFC & III & não \\
\hline
\end{tabular}




\begin{tabular}{|l|l|l|} 
SSS & IV & rinite \\
\hline TRS & III & rinite \\
\hline VC & III & rinite \\
\hline
\end{tabular}

Tabela 4: presença de atopia segundo a gravidade de reação em cada paciente

Considerando ainda apenas as reações graves grau IV (tabela 3), quando avaliamos as reações anteriores a essas, com o objetivo de avaliar a história natural, verificou-se que não houve relação com nenhuma reação específica (figura 11): 11,11\% apresentaram reação anterior grau II; $22,22 \%$ apresentaram reação anterior grau IV; 55,56\% apenas reação local e 11,11\% tinham apresentado reação local extensa. Nesses pacientes não houve uma relação entre apresentar determinada gravidade de reação em ferroadas anteriores e depois evoluir para uma reação mais grave em ferroadas posteriores $(p=1,207)$, e a grande maioria relatou reação local.

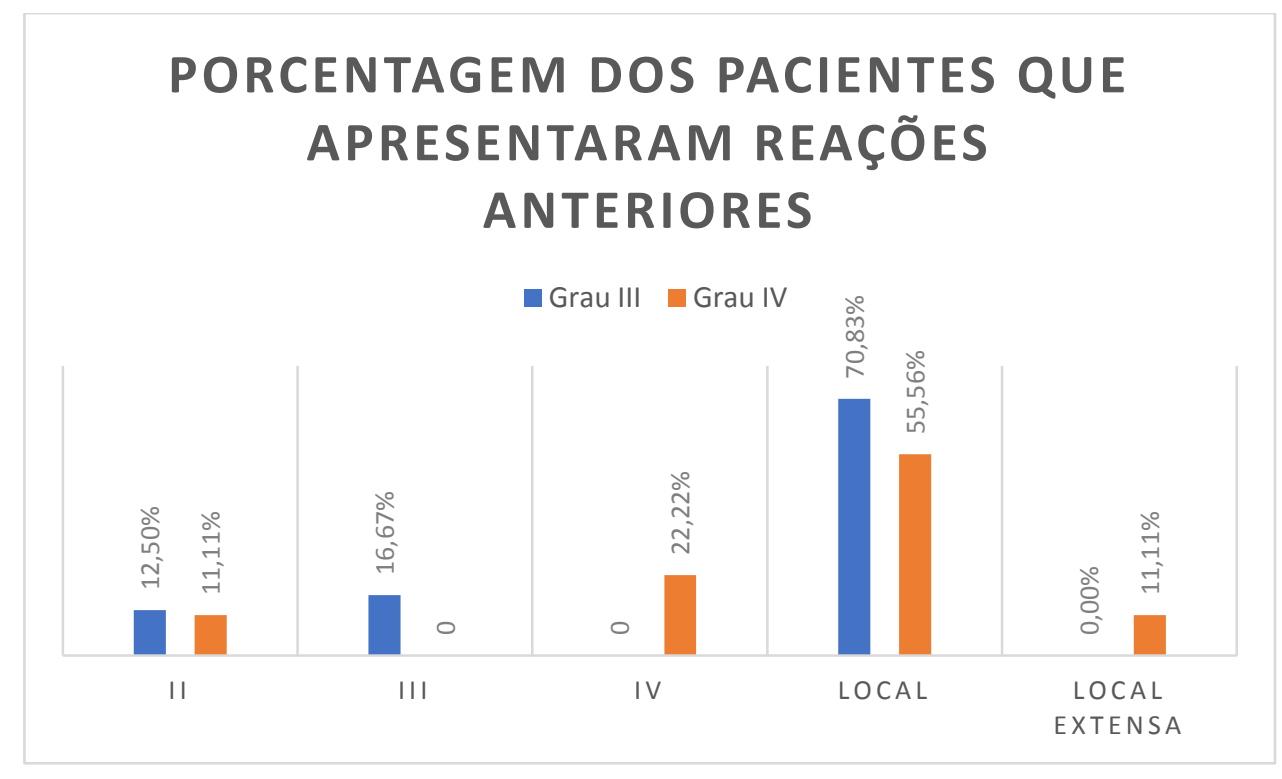

Figura 11: porcentagem dos pacientes distribuídos de acordo com a gravidade da reação anterior

\subsection{Dosagem de IgE sérica tota}

Considerando o valor de referência de $156 \mathrm{kU} / \mathrm{L}$, apenas 7 pacientes apresentaram dosagem de lgE total abaixo desse valor (Figura 12 e Tabela 5) : 


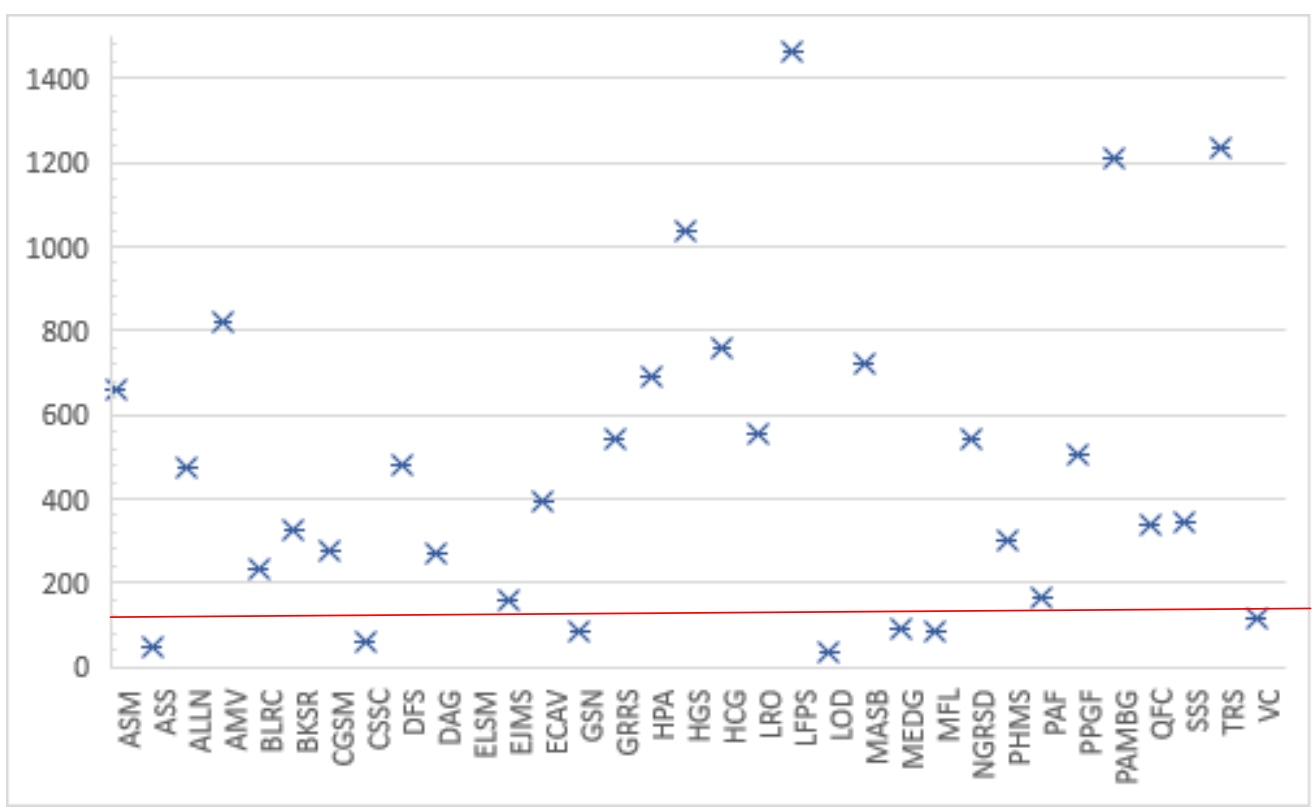

Figura 12: dosagens da IgE total de cada paciente (linha vermelha: valor de referência)

\begin{tabular}{|c|c|}
\hline Paciente & $\lg E(k U / L)$ \\
\hline ASM & 661,9 \\
\hline ASS & 48,8 \\
\hline ALLN & 476 \\
\hline AMV & 819 \\
\hline BLRC & 230 \\
\hline BKSR & 323,1 \\
\hline CGSM & 278 \\
\hline CSSC & 57 \\
\hline DFS & 478,7 \\
\hline DAG & 269,9 \\
\hline ELSM & 1605 \\
\hline EJMS & 158,7 \\
\hline ECAV & 396,8 \\
\hline GSN & 86,4 \\
\hline GRRS & 540,2 \\
\hline
\end{tabular}




\begin{tabular}{|c|c|}
\hline HPA & 690,9 \\
\hline HGS & 1040 \\
\hline HCG & 758 \\
\hline LRO & 552 \\
\hline LFPS & 1462 \\
\hline LOD & 35,3 \\
\hline MASB & 721 \\
\hline MEDG & 91,7 \\
\hline MFL & 87,7 \\
\hline NGRSD & 540 \\
\hline PHMS & 299 \\
\hline PAF & 163 \\
\hline PPGF & 506,4 \\
\hline PAMBG & 1208 \\
\hline QFC & 340,2 \\
\hline SSS & 345,2 \\
\hline TRS & 1236,6 \\
\hline VC & 113,1 \\
\hline
\end{tabular}

Tabela 5: valores de IgE total de cada paciente

\subsection{Dosagens de IgE séricas específicas ao veneno de formiga (Immunocap i70®)}

Considerando a relação da gravidade da reação com dosagem de IgE sérica específica contra o veneno de formiga (i70), não houve diferença estatística entre os grupos ( $p=0,776)$ : pacientes com reação grau III (Figura 13) apresentaram média de valor de 26,3 kU/L, com desvio padrão: 32,4 e pacientes com reação grau IV (Figura 14) apresentaram média de valores de 45,9 kU/L e desvio padrão: 49,2. 


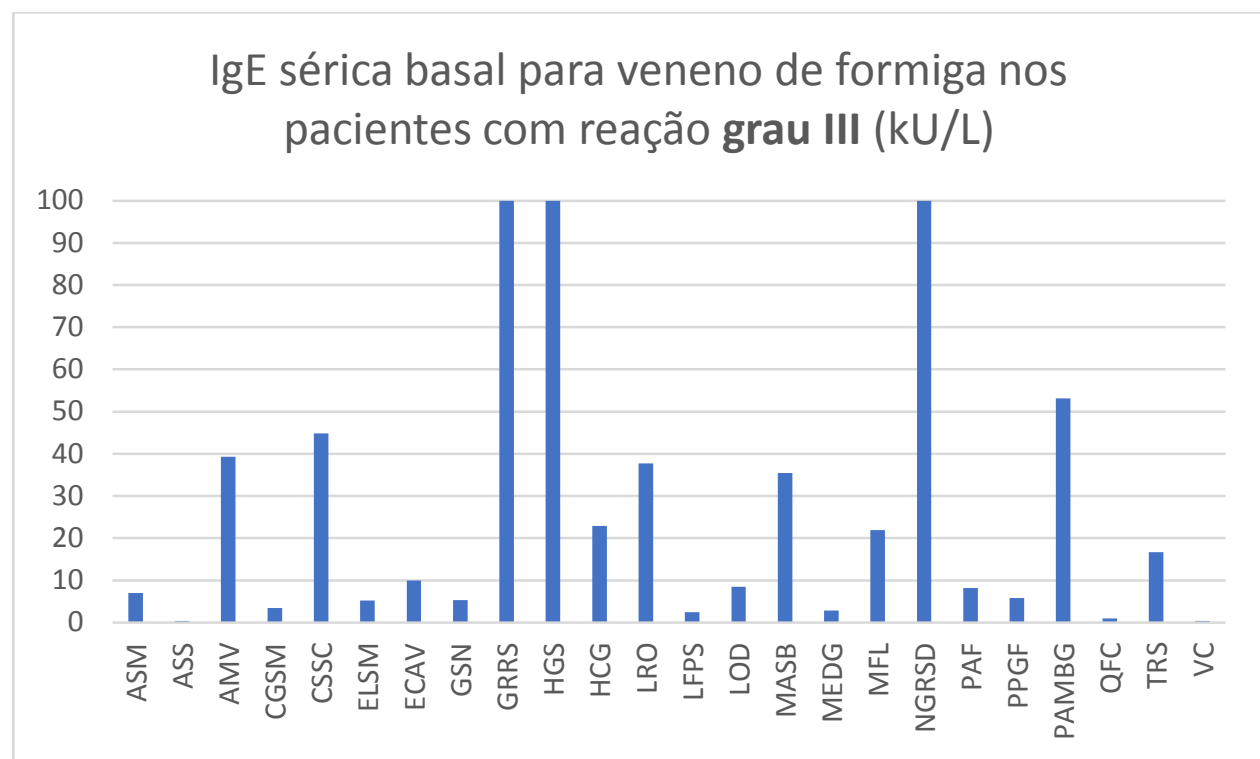

Figura 13: valores de IgE sérica basal para veneno de formiga (i70) nos pacientes com reação grau III

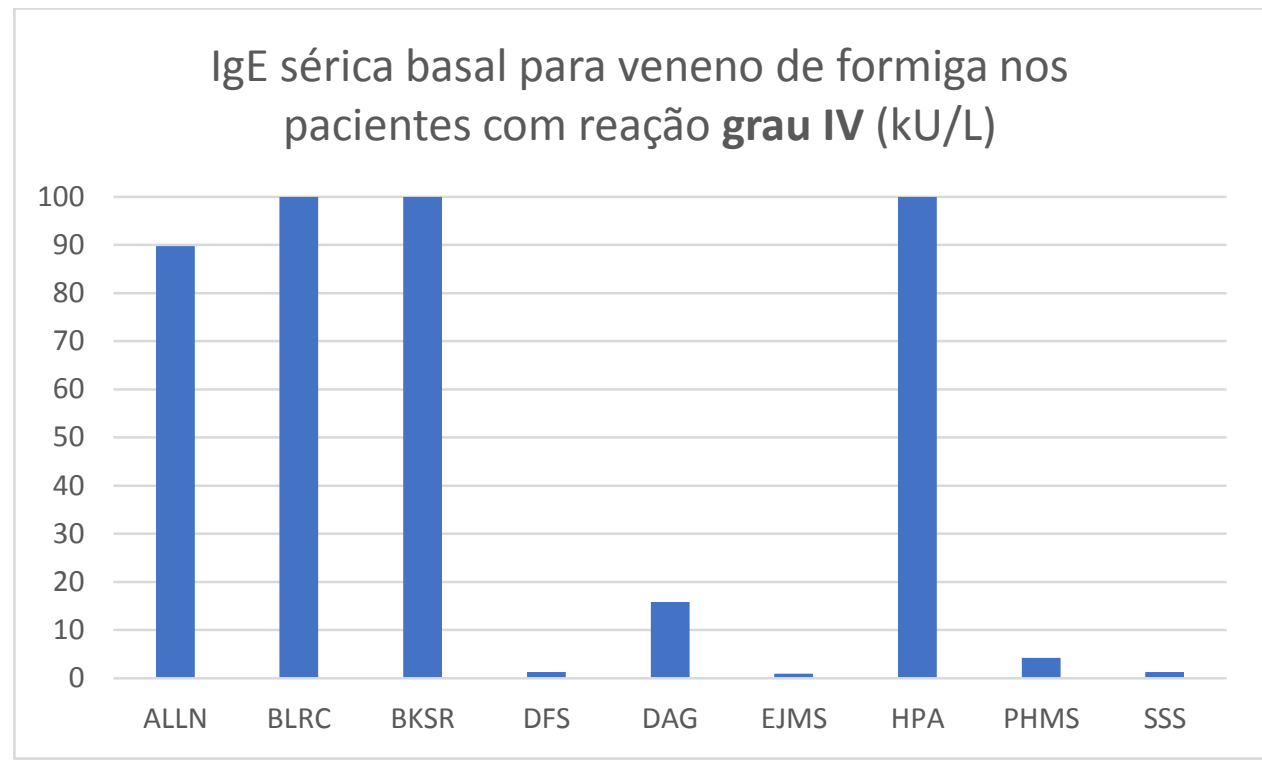

Figura 14: valores de IgE sérica basal para veneno de formiga (i70) nos pacientes com reação grau IV

Ao avaliar-se a relação da dosagem da lgE sérica específica (Immunocap® ${ }^{\circledR}$ i70) de cada paciente antes e após 1 ano da fase de manutenção da imunoterapia, houve uma diferença estatística significante $(p=0.0041)$, sendo que os valores diminuíram nesse intervalo de tempo em 
73,3\% dos pacientes (média período basal: 31,67 kU/L; média após 1 ano da fase de manutenção: $9,86 \mathrm{kU} / \mathrm{L})$. Tabela 6

\begin{tabular}{|c|c|c|c|}
\hline Paciente & \begin{tabular}{c|} 
Gravidade \\
de reação \\
(Mueller)
\end{tabular} & $\begin{array}{l}\text { IgE sérica para } \\
\text { veneno de formiga } \\
\text { basal (kU/L) }\end{array}$ & $\begin{array}{l}\text { IgE sérica para veneno de } \\
\text { formiga após } 1 \text { ano da fase } \\
\text { de manutenção (kU/L) }\end{array}$ \\
\hline ASM & III & 7,03 (classe3) & 86 (classe 5) \\
\hline ASS & III & $<0,35$ (classe 0 ) & 9,78 (classe 3) \\
\hline ALLN & IV & 89,7 (classe 6) & $<0,35$ (classe 0 ) \\
\hline AMV & III & 39,3 (classe 4) & 9,78 (classe 3 ) \\
\hline BLRC & IV & $>100$ (classe 6$)$ & 1,21 (classe 2) \\
\hline BKSR & IV & $>100$ (classe 6$)$ & $<0,35$ (classe 0 ) \\
\hline CGSM & III & 3,45 (classe 2 ) & 0,72 (classe 2) \\
\hline CSSC & III & 44,8 (classe 4) & $<0,35$ (classe 0 ) \\
\hline DFS & IV & 1,3 (classe 2) & abandonou tratamento \\
\hline DAG & IV & 15,8 (classe 3 ) & $<0,35$ (classe 0 ) \\
\hline ELSM & III & 5,22 (classe 3) & 16,2 (classe 3) \\
\hline EJMS & IV & 0,91 (classe 2) & $<0,35$ (classe 0 ) \\
\hline ECAV & III & 9,98 (classe 3) & 1,01 (classe 2) \\
\hline GSN & III & 5,35 (classe 3) & 1,64 (classe 2) \\
\hline GRRS & III & $>100$ (classe 6$)$ & 3,62 (classe 3) \\
\hline HPA & IV & $>100$ (classe 6$)$ & abandonou tratamento \\
\hline HGS & III & $>100$ (classe 6$)$ & 72,5 (classe 5 ) \\
\hline $\mathrm{HCG}$ & III & 22,9 (classe 4) & $<0,35$ (classe 0 ) \\
\hline LRO & III & 37,7 (classe 4) & 7,62 (classe 3) \\
\hline LFPS & III & 2,42 (classe 2) & 6,76 (classe 3) \\
\hline LOD & III & 8,5 (classe 3 ) & abandonou tratamento \\
\hline MASB & III & 35,4 (classe 4) & 3,15 (classe 2 ) \\
\hline MEDG & III & 2,86 (classe 2 ) & $<0,35$ (classe 0 ) \\
\hline MFL & III & 21,9 (classe 4) & 1,2 (classe 2 ) \\
\hline NGRSD & III & $>100($ classe 6$)$ & 13,4 (classe 3) \\
\hline
\end{tabular}




\begin{tabular}{|l|c|c|c|} 
PHMS & IV & 4,25 (classe 3) & 3,62 (classe 3) \\
\hline PAF & III & 8,22 (classe 3) & 6,11 (classe 3) \\
\hline PPGF & III & 5,79 (classe 3) & 19,4 (classe 4) \\
\hline PAMBG & III & 53,1 (classe 5) & 18,1 (classe 4) \\
\hline QFC & III & $0,96$ (classe 2$)$ & 3,83 (classe 3) \\
\hline SSS & IV & $1,3$ (classe 2$)$ & $1,57$ (classe 2$)$ \\
\hline TRS & III & 16,7 (classe 3) & 6,08 (classe 3) \\
\hline VC & III & $<0,35$ (classe 0$)$ & $1,3$ (classe 2$)$ \\
\hline
\end{tabular}

Tabela 6: valores de IgE sérica para veneno de formiga (i70) no período basal e após 1 ano da fase de manutanção em cada paciente

\subsection{Teste cutâneo}

Os pacientes apresentaram seguintes resultados de teste cutâneo (prick e intradérmico), sendo que a maioria apresentou resultados positivos no teste intradérmico $(81,8 \%)$ : Figura 15

-Prick test na concentração 1:1000: 6 pacientes (18,2\%)

-Teste intradérmico na concentração 1/1.000.000: 15 pacientes $(45,5 \%)$

-Teste intradérmico na concentração 1/100.000: 7 pacientes $(21,2 \%)$

-Teste intradérmico na concentração 1/10.000: 4 pacientes (12,1\%)

-Teste intradérmico na concentração 1/1000: 1 paciente (3,03\%)

Não há relação entre positividade em determinada concentração do teste cutâneo com gravidade da reação apresentada (teste de qui-quadrado; $\mathrm{p}=0,7354)$. 


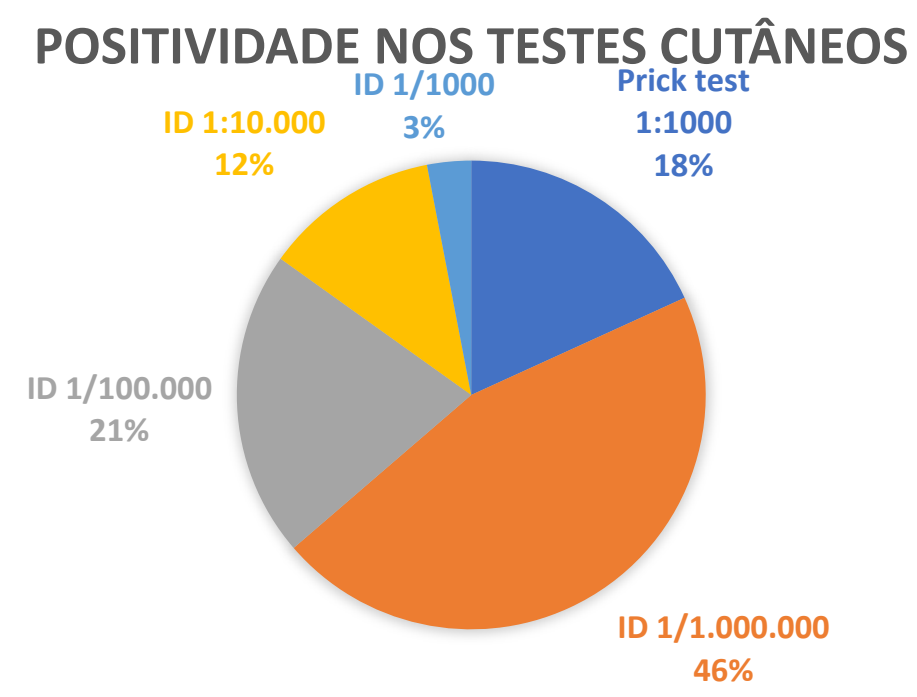

Figura 15: porcentagem de positividade dos testes cutâneos

\subsection{Dosagem de IgG4 específica}

Foram realizadas dosagens de IgG4 específica ao veneno de formiga no período basal e após 12 meses do início da fase de manutenção da imunoterapia. A figura abaixo (Figura 16) mostra um comparativo de cada paciente:

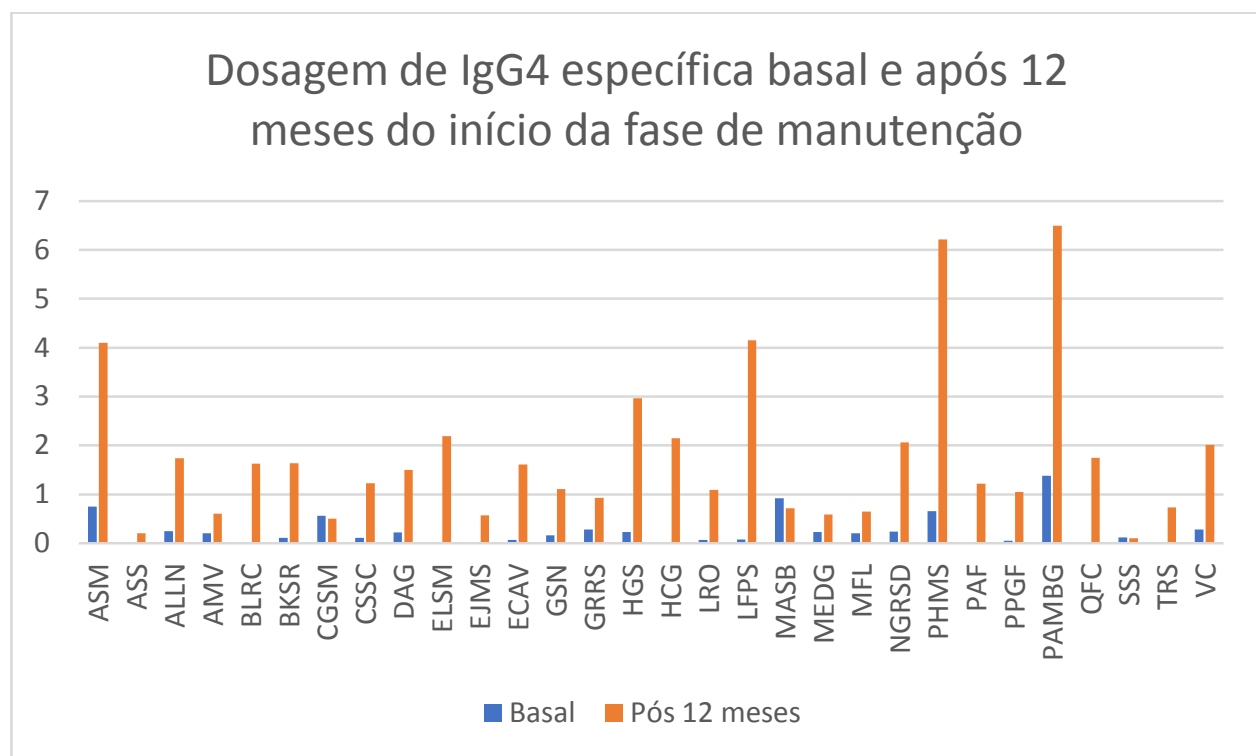

Figura 16: Dosagens de IgG4 específica basal e após 12 meses do início da fase de manutenção por paciente 


\subsection{Relação IgG4/lgE séricas específicas}

Ao se comparar a razão $\operatorname{lgG} 4 / \lg$ E séricas específicas ao veneno de formiga no período basal e após 1 ano do paciente estar na fase de manutenção do tratamento (Tabela 7 ), houve uma diferença (Figura 17) estatística significante (teste de Wilcoxon, $\mathrm{p}=0,0000318$ ).

\begin{tabular}{|l|r|r|}
\hline Paciente & Basal (Unidade) & Pós 12 meses (Unidade) \\
\hline ASM & 0,75 & 4,1 \\
\hline ASS & 0,01 & 0,21 \\
\hline ALLN & 0,25 & 1,74 \\
\hline AMV & 0,21 & 0,61 \\
\hline BLRC & 0 & 1,63 \\
\hline BKSR & 0,11 & 1,64 \\
\hline CGSM & 0,56 & 0,5 \\
\hline CSSC & 0,11 & 1,23 \\
\hline DFS & 0,02 & $*$ \\
\hline DAG & 0,22 & 1,5 \\
\hline ELSM & 0,01 & 2,19 \\
\hline EJMS & 0,01 & 0,57 \\
\hline ECAV & 0,07 & 1,61 \\
\hline GSN & 0,16 & 1,11 \\
\hline GRRS & 0,28 & 0,93 \\
\hline HPA & $* *$ & $*$ \\
\hline HGS & 0,23 & 2,97 \\
\hline HCG & 0,003 & 2,15 \\
\hline LRO & 0,07 & 1,09 \\
\hline LFPS & 0,08 & 4,15 \\
\hline LOD & 0,23 & 0,72 \\
\hline MASB & 0,92 & 0 tinua \\
& & $*$ \\
\hline & & \\
\hline
\end{tabular}




\begin{tabular}{|l|r|r|} 
MEDG & 0,23 & 0,59 \\
\hline MFL & 0,21 & 0,65 \\
\hline NGRSD & 0,24 & 2,06 \\
\hline PHMS & 0,66 & 6,21 \\
\hline PAF & 0,01 & 1,22 \\
\hline PPGF & 0,05 & 1,05 \\
\hline PAMBG & 1,38 & 6,49 \\
\hline QFC & 0,01 & 1,75 \\
\hline SSS & 0,12 & 0,1 \\
\hline TRS & 0,03 & 0,73 \\
\hline VC & 0,28 & 2,01 \\
\hline
\end{tabular}

*abandono de tratamento **erro na leitura

Tabela 7: dosagens de IgG4 específicas ao veneno de formiga no período basal e após 1 ano do início da fase de manutenção

IgG4/IgE Mann-Whitney test, $p=0,0000318$

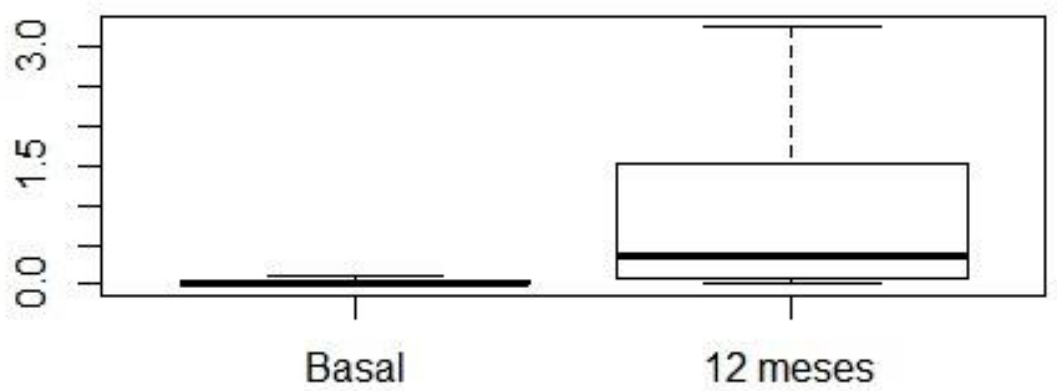

Figura 17: comparativo da razão das dosagens de lgG4/lgE específicas basais e após 12 meses da fase de manutenção da imunoterapia 


\subsection{Dosagem de triptase}

Os pacientes com reação anafilática grau III apresentaram dosagem média de triptase basal de $3,63 \mathrm{ng} / \mathrm{mL}$, com desvio padrão de $3,06 \mathrm{ng} / \mathrm{mL}$. Os pacientes com reação anafilática grau IV apresentaram média de $4,76 \mathrm{ng} / \mathrm{mL}$, com desvio padrão de 6,98 ng/mL. (Tabela 8) Não houve relação da dosagem de triptase sérica com reação grau IV (Wilcoxon rank com correção de continuidade; $p=0,4333$ ).

\begin{tabular}{|l|c|}
\hline Paciente & Triptase (Unidade) \\
\hline ASM & $\mathbf{2 , 7 9}$ \\
\hline ASS & $\mathbf{2 , 6 1}$ \\
\hline ALLN & $\mathbf{2 , 9 3}$ \\
\hline AMV & $\mathbf{2 , 6 1}$ \\
\hline BLRC & $\mathbf{2 , 2 7}$ \\
\hline BKSR & $\mathbf{1 , 3 5}$ \\
\hline CGSM & $\mathbf{1 , 2 7}$ \\
\hline CSSC & $\mathbf{2 , 8 7}$ \\
\hline DFS & $\mathbf{2 , 7 6}$ \\
\hline DAG & $\mathbf{2 , 6 5}$ \\
\hline ELSM & $\mathbf{2 , 6 9}$ \\
\hline EJMS & $\mathbf{2 , 4}$ \\
\hline ECAV & $\mathbf{1 , 7 8}$ \\
\hline GSN & $\mathbf{2 , 7 3}$ \\
\hline GRRS & $\mathbf{1 , 9}$ \\
\hline HPA & $\star$ \\
\hline HGS & $\mathbf{2 , 9 8}$ \\
\hline HCG & $\mathbf{1 , 6 7}$ \\
\hline LRO & $\mathbf{2 , 0 4}$ \\
\hline LFPS & $\mathbf{8 , 5 2}$ \\
\hline LOD & $\mathbf{3 , 2 7}$ \\
& \\
\hline & \\
\hline
\end{tabular}




\begin{tabular}{|l|c|} 
MASB & $\mathbf{2 , 1 3}$ \\
\hline MEDG & $\mathbf{2 , 3 9}$ \\
\hline MFL & $\mathbf{4 , 0 9}$ \\
\hline NGRSD & $\mathbf{4 , 1 6}$ \\
\hline PHMS & $\mathbf{1 , 7 5}$ \\
\hline PAF & $\mathbf{2 , 2 7}$ \\
\hline PPGF & $\mathbf{2 , 9 6}$ \\
\hline PAMBG & $\mathbf{2 , 9 9}$ \\
\hline QFC & $\mathbf{8 , 0 2}$ \\
\hline SSS & $\mathbf{2 2}$ \\
\hline TRS & $\mathbf{2 , 9 8}$ \\
\hline VC & $\mathbf{1 5 , 5}$ \\
\hline
\end{tabular}

* erro na leitura (paciente abandonou tratamento, não coletou novamente)

Tabela 8: dosagens de triptase de cada paciente

Como visto na tabela 8, 2 pacientes apresentaram dosagens acima de $11,4 \mathrm{ng} / \mathrm{mL}$. O paciente que apresentou dosagem de $15,5 \mathrm{ng} / \mathrm{mL}$ tinha história de reação anafilática com outro inseto (vespa) e a outra paciente com dosagem de $22 \mathrm{ng} / \mathrm{mL}$ não apresentava anafilaxia com nenhum outro agente a não ser com formiga. Em ambos não havia sinais de mastocitose cutânea e foram encaminhados a hematologia para investigação de mastocitose sistêmica, sendo descartado esse diagnóstico em ambos pacientes, mas manterão seguimento para acompanhamento de quaisquer sintomas novos relatados.

\subsection{Reações adversas durante a imunoterapia}

Como já citado na parte de reações adversas a imunoterapia, a reação local foi contabilizada quando o nódulo foi maior ou igual a $50 \mathrm{~mm}$. 


\subsubsection{Reações na fase de indução:}

Durante a fase de indução 2 pacientes (6,06\%) apresentaram reações sistêmicas grau 1 (apenas 1 órgão: cutâneo - urticária leve intensidade) e 4 pacientes $(36,36 \%)$ apresentaram reações locais após injeção subcutânea; e em $57,58 \%$ houve ou reação local menor que $50 \mathrm{~mm}$ ou nenhuma reação. Figura 18

Como o mesmo paciente teve várias vezes reações locais, ao considerar risco de reação em cada injeção aplicada, tivemos 12 reações $(1,03 \%)$ em 1167 aplicações realizadas durante a fase de indução, sendo que em 58,33\% das reações ocorreram na concentração de 1:100. O risco de reação sistêmica por injeção foi de $0,017 \%$ nessa fase.

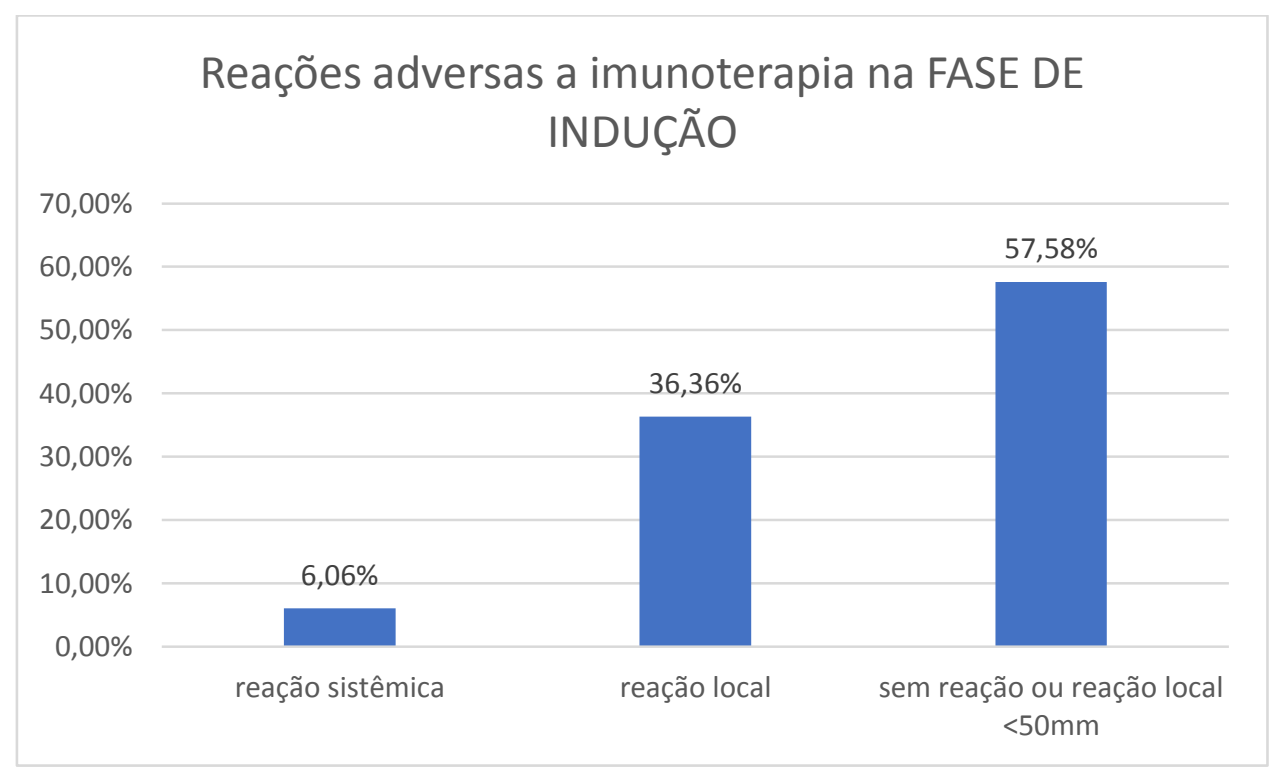

Figura 18: porcentagem das reações adversas ocorridas durante a fase de indução da imunoterapia

\subsubsection{Reações na fase de manutenção:}

Durante a fase de manutenção, 5 pacientes (15,15\%) apresentaram reações locais no sítio de aplicação, e $84,85 \%$ não apresentaram reação ou apresentaram reação menor que $50 \mathrm{~mm}$. Nenhum paciente teve reação sistêmica na fase de manutenção do tratamento. Figura 19 
Ao considerar risco de reação em cada injeção aplicada, tivemos 5 reações $(1,4 \%)$ em 360 aplicações realizadas durante a fase de manutenção, sendo somente reações locais. Figura 20

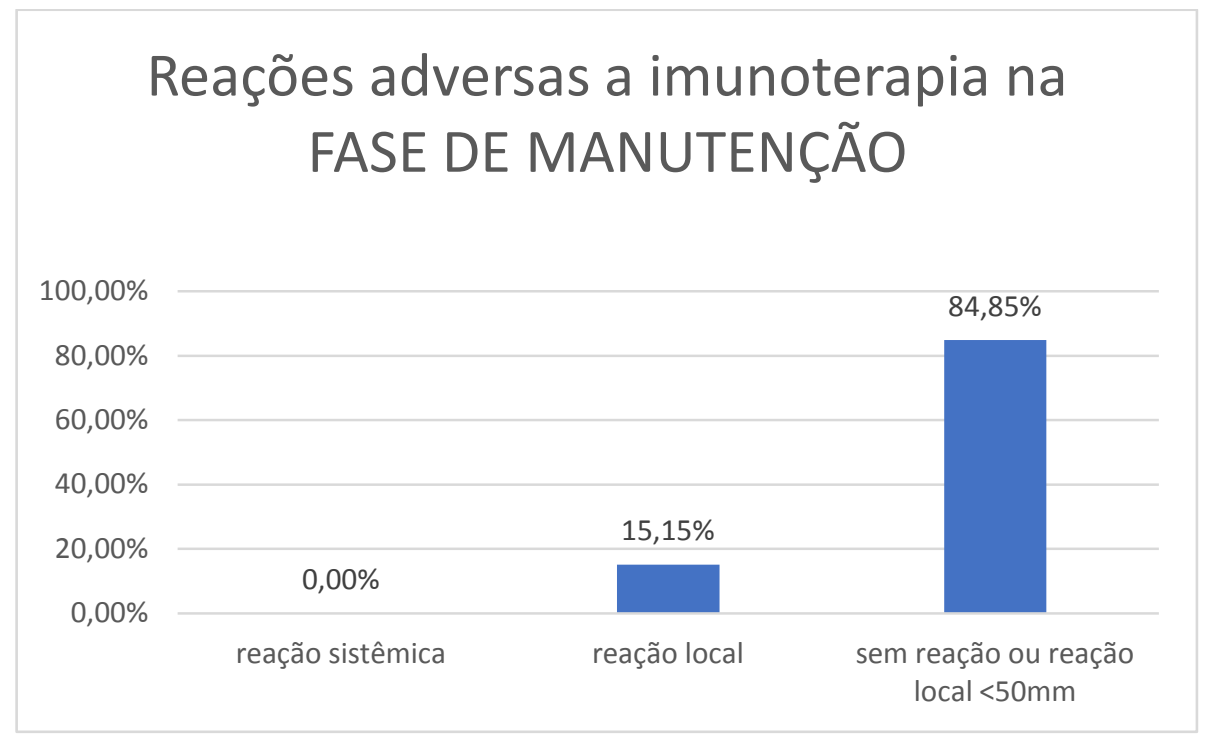

Figura 19: porcentagem das reações adversas ocorridas durante a fase de manutenção da imunoterapia

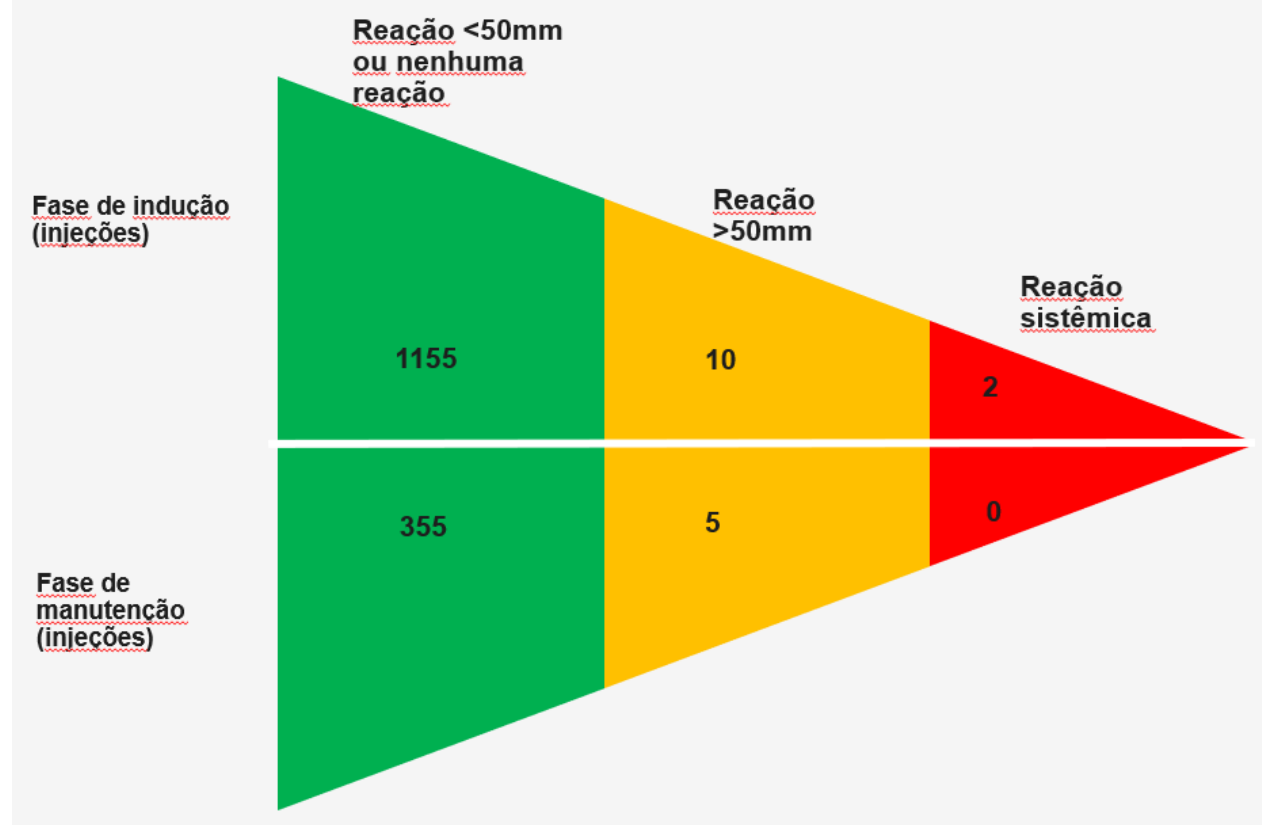

Figura 20: número de reações adversas (por injeção) durante a imunoterapia de acordo com a fase e tipo de reação 
Não houve necessidade de uso de adrenalina intramuscular em nenhum momento durante $o$ tratamento e as reações sistêmicas que ocorreram na fase de indução foram tratadas apenas com antihistamínicos por via oral e com melhora total após $2 \mathrm{~h}$ de ficar em período de observação.

\subsection{Ferroadas acidentais durante o tratamento}

Durante todo o tratamento, 20 pacientes $(60,6 \%)$ foram ferroados acidentalmente por formigas, com confirmação do inseto.

Durante a fase de indução: 5 pacientes foram ferroados durante essa fase, apresentando em 4 deles somente reação local e 1 deles apresentou reação sistêmica de grau I: urticária de leve intensidade que melhorou somente com uso de antihistamínico, não havendo necessidade de procurar pronto atendimento e nem de utilizar adrenalina auto injetável. Tabela 9

No total, tivemos 9 ferroadas acidentais pois 2 pacientes foram ferroados 2 vezes durante o período de indução, 1 paciente foi ferroado por 3 vezes e o restante levou 1 ferroada apenas. Tabela 9

\begin{tabular}{|l|l|l|}
\hline Paciente & $\begin{array}{l}\text { Ferroada durante } \\
\text { fase indução }\end{array}$ & $\begin{array}{l}\text { Sintomas após ferroada } \\
\text { acidental durante fase indução }\end{array}$ \\
\hline ASS & 1 & Reação local \\
\hline BLRC & 2 & Reações locais \\
\hline CGSM & 2 & Reações locais \\
\hline HCG & 1 & reação local \\
\hline VC & 3 & $\begin{array}{l}\text { 2 Reações locais } \\
\text { 1 Reação Sistêmica: urticária leve }\end{array}$ \\
\hline
\end{tabular}

Tabela 9: número de ferroadas e sintomas após ferroada acidental durante a fase de indução em cada paciente

Durante 1 ano de observação na fase de manutenção: 19 pacientes $(57,6 \%)$ foram ferroados acidentalmente, sendo que 17 pacientes $(89,5 \%)$ 
apresentaram reação local e 2 pacientes (10,5\%) apresentaram reações sistêmicas grau I: urticária, sem necessidade de procurar pronto atendimento ou utilizar adrenalina auto injetável, com ingesta apenas de antihistamínicos e resolução do quadro. Tabela 10

\begin{tabular}{|l|r|l|}
\hline Paciente & $\begin{array}{c}\text { Ferroada durante } \\
\text { fase manutenção }\end{array}$ & $\begin{array}{c}\text { Sintomas após ferroada } \\
\text { acidental durante fase } \\
\text { manutenção }\end{array}$ \\
\hline ASM & 1 & pustula no local \\
\hline ASS & 2 & reação local \\
\hline ALLN & 2 & reação local \\
\hline AMV & 1 & reação local \\
\hline BKSR & 4 & reação local \\
\hline CGSM & 6 & reação local \\
\hline ELSM & 2 & reação local \\
\hline EJMS & 1 & urticária leve, melhorou com \\
\hline GSN & 1 & reação local \\
\hline HCG & 1 & reação local \\
\hline LRO & 1 & reação local \\
\hline LFPS & 1 & reação local \\
\hline MEDG & 1 & reação local \\
\hline MFL & 3 & reação local \\
\hline PHMS & 2 & reação local \\
\hline PAMBG & 2 & reação local \\
\hline QFC & 1 & reação local \\
\hline TRS & 2 & reação local \\
\hline VC & 1 & urticária leve, melhorou com \\
\hline
\end{tabular}

Tabela 10: número de ferroadas e sintomas após ferroada acidental durante a fase de manutenção em cada paciente 
Como alguns pacientes foram ferroados mais de uma vez, no total tivemos 35 ferroadas acidentais durante o primeiro ano da fase de manutenção da imunoterapia, como mostra a figura 21.

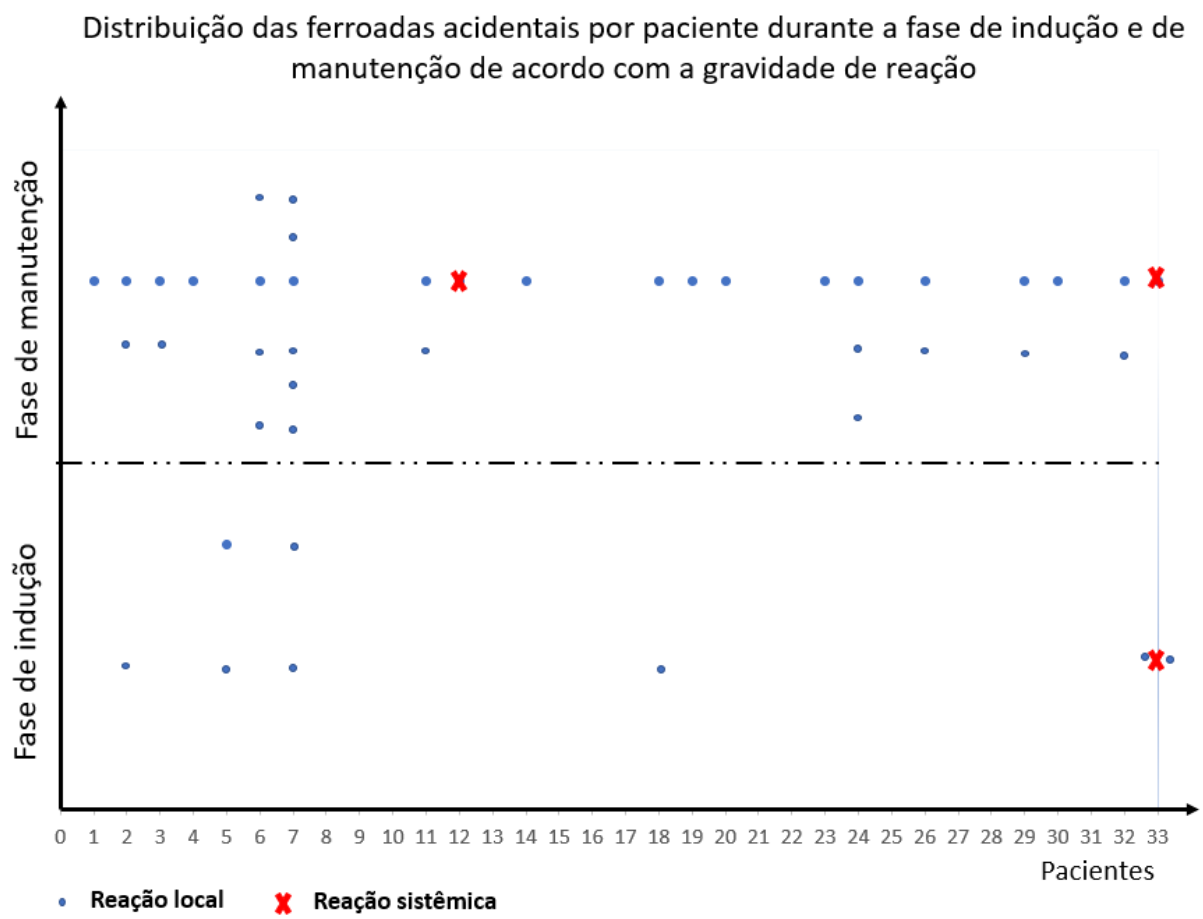

Figura 21: Distribuição das ferroadas acidentais por paciente durante a fase de indução e de manutenção de acordo com a gravidade de reação

Chama atenção paciente CGSM (paciente 7 da figura 21), que por morar em zona rural já foi ferroado 8 vezes, sendo 2 vezes na fase de indução e 6 vezes na fase de manutenção, com reação local em todas ferroadas, relatadas pela mãe do paciente.

Os pacientes que tinham apresentado reação grau IV, 4 deles foram ferroados acidentalmente, sendo que o paciente ALLN foi ferroado 2 vezes; paciente BKSR 4 vezes; paciente PHMS 2 vezes e não apresentaram reação sistêmica. A paciente EJMS levou 1 ferroada em campo e teve uma reação sistêmica leve, com urticária e com melhora após uso de Alektos. 


\section{DISCUSSÃO}

Esse estudo foi desenhado objetivando avaliar dados clínicos e laboratoriais dos pacientes submetidos à imunoterapia com corpo total de Solenopsis sp como um tratamento de anafilaxia ao veneno de formiga.

As ferroadas por formiga são mais frequentes na idade pediátrica: $32 \%$ a $54 \%$ da população pesquisada ${ }^{183}$. Assim como na literatura, as reações sistêmicas após ferroadas de formiga no nosso estudo também demonstrou que foi mais prevalente nos menores de 15 anos de idade: 17 pacientes (51,51\%), e se ampliarmos para até 20 anos de idade, $75,9 \%$ deles encontravam-se nessa faixa de idade. Considerando apenas as reações grau IV, nessas reações mais graves não houve predomínio em alguma faixa etária específica.

Quanto ao gênero, não há na literatura associação com gravidade de reação nos pacientes ferroados por outros himenópteros: abelhas e vespas $^{184}$. Não há dados com veneno de formiga. Nesse estudo também não houve influência do gênero na gravidade da reação, com leve predomínio do gênero masculino: $51,5 \%$ em relação ao feminino: $48,5 \%$.

Quanto a atopia, sabe-se que é um fator de risco para anafilaxia desencadeada por alimentos, exercício e látex ${ }^{185}$. Ainda não foi estabelecido que a doença atópica aumenta o risco de anafilaxia associada a ferroada de himenópteros ${ }^{186}$ e neste estudo também não verificamos associação com atopia.

Como indicado em um consenso internacional sobre o documento de anafilaxia (ICON ${ }^{187}$, doença cardiovascular e asma são fatores de risco bem reconhecidos para anafilaxia grave em geral. Nesse estudo, ao avaliar se asma era um fator de risco para gravidade de reação, não houve relação dessa doença nos pacientes que tiveram reação grau IV.

Considerando as reações que antecederam a reação sistêmica grave, na literatura, $18 \%$ das reações sistêmicas leves em ferroadas anteriores evoluíram para reações sistêmicas graves. Nesse mesmo estudo, um terço dos pacientes $(24 \%)$ desenvolveram a mesma gravidade das reações anteriores ${ }^{188}$. 
Quanto as reações locais extensas prévias, no estudo de Golden et al $^{189}$, 7\% de crianças que tiveram ferroadas posteriormente progrediram para reação sistêmica. Graft e colaboradores ${ }^{117}$ relataram $2 \%$ de reação sistêmica por ferroada quando apresentaram reações locais extensas anteriormente.

Nos nossos pacientes, em relação a literatura, a porcentagem foi maior em todas as reações prévias: $11,11 \%$ apresentaram reação anterior grau II; 22,22\% apresentaram reação anterior grau IV; 55,56\% apenas reação local e $11,11 \%$ tinham apresentado reação local extensa. Nesses pacientes não houve uma relação entre apresentar determinada gravidade de reação em ferroadas anteriores e depois evoluir para uma reação mais grave em ferroadas posteriores $(p=1,207)$, e a grande maioria relatou apenas reação local na ferroada anterior que antecedeu a anafilaxia.

O histórico de reação local extensa acarreta um risco menor de reação sistêmica do que em todos os outros pacientes sensibilizados. E um dado que chama a atenção no nosso estudo é que em 4 de 18 pacientes, a primeira reação sistêmica foi grave e pacientes não foram encaminhados a especialista para investigação. Somente na repetição da reação 2 pacientes foram orientados a procurar especialista pata investigação diagnóstica e os outros 2 pacientes não foram referenciados para ambulatórios especializados, procuram especialista por vontade própria.

Comparando o resultado das dosagens de $\lg \mathrm{E}$ sérica específica contra o veneno de formiga e os resultados dos testes cutâneos nos pacientes que apresentaram reações graves, grau IV, os nossos achados corroboram com a literatura ${ }^{191,192,193}$ que não há relação entre o grau de sensibilização e gravidade da reação.

\section{Alterações nas concentrações das imunoglobulinas IgE e IgG4} específicas

Os níveis de $\lg E$ específicas ao veneno de formiga diminuíram no período observado em $73,3 \%$ dos pacientes, enquanto os níveis de lgG4 aumentaram nesse período. Desse modo, a razão lgE/lgG4 no período basal e após 12 meses da fase de manutenção mostrou diferenças muito significativas. 
Após um aumento inicial nos primeiros meses de tratamento, os níveis de $\lg \mathrm{E}$ ao respectivo veneno tendem a diminuir durante a imunoterapia $^{194,195}$ e geralmente permanecem baixos mesmo após a descontinuação do tratamento ${ }^{196}$.

Por outro lado, os níveis de lgG4 séricos específicos aumentam durante a imunoterapia com veneno ${ }^{197,198,199}$. Sabe-se que altos níveis de IgG4 séricos estão positivamente correlacionados com o número de ferroadas, pelo menos nos apicultores $200,201,202$.

Dessa forma, o anticorpo IgG4 específico é considerado um indicador de tolerância em indivíduos alérgicos pois tem sido sugerido na literatura que esses anticorpos podem bloquear a interação entre o alérgeno e os anticorpos $\lg \mathrm{E}$ específicos, impedindo assim as reações $\lg \mathrm{E}$ imune mediadas. Esses efeitos devem ser refletidos na proporção $\operatorname{lgE} / \lg G 4$ específicos $^{203,204}$.

A explicação para isso é devido as populações celulares reguladoras que formam um meio supressor, acabando com uma lenta diminuição na produção de alérgenos específicos $\lg E$ e troca precoce de células $B$ para produzir IgG4 e consequentemente, aumento de anticorpos IgG4, que é um agente não inflamatório nos distúrbios alérgicos ${ }^{111,205}$.

\section{Dosagem de Triptase}

Na literatura, cerca de $80 \%$ dos pacientes com anafilaxia (grau 4 de Mueller) a venenos de himenópteros (abelhas e vespas) apresentam diagnóstico de mastocitose, sendo que nessas reações graves, pode acontecer que $20 \%$ dos pacientes não apresentarem sinais de mastocitose ${ }^{51}$. Bonadonna e $\operatorname{cols}^{165}$ relataram uma correlação entre reação sistêmica à ferroada de Hymenoptera e triptase de mastócitos. Dos 379 pacientes com história de reações sistêmicas após ferroada desses insetos, 11,6\% apresentaram níveis séricos de triptase de mastócitos que excederam 11,4 ng/mL. Desse grupo, a taxa de anafilaxia (grau IV de Muller) foi de 70,5\%. Blum e cols. ${ }^{205}$ confirmaram esses achados em um estudo restrospectivo de 5 anos, com 868 pacientes que apresentaram reações graves após ferroada desses insetos (758 pacientes 
tinham ambos: IgE total e nível de triptase basal acima dos valores de referência). Triptase basal elevada $(>11,4 \mathrm{ng} / \mathrm{mL})$ foi associada com reações sistêmicas graves $(p<0,03)$. Por essa forte associação, os guidelines sobre alergia a venenos de himenópteros sempre recomendam a dosagem da triptase nesses pacientes.

Em nosso estudo 2 pacientes (6,25\%) apresentaram dosagem de triptase maior que $11,4 \mathrm{ug} / \mathrm{ml}$, porém, pela investigação da hematologia, foi descartado diagnóstico de Mastocitose Sistêmica. Como já citado, na literatura há muita correlação com anafilaxia grave e ferroadas de himenópteros, mas sendo relatados por abelhas e vespas. Não há dados com veneno de formiga até o momento.

\section{Reações adversas durante a imunoterapia}

Eventos adversos são mais frequentemente observados quando são utilizados extratos não purificados e as formulações aquosas tendem a causar mais reações locais em comparação com os diluentes de depósito $(\text { depot })^{206,207,208}$.

Os principais fatores de risco que provocam o aparecimento de reações graves na literatura ${ }^{178}$ foram muito bem revisados em cada visita do paciente e controlados nesse estudo: erro de dosagem, administração da injeção sem supervisão de profissional capacitado, presença de asma não controlada, grau elevado de sensibilidade, uso concomitante de $\beta$ bloqueadores, reações sistêmicas anteriores à imunoterapia e uso de lotes com novos produtos.

Quando apresentavam reação local maior que $50 \mathrm{~mm}$, eram orientados a fazer uso de fexofenadina $180 \mathrm{mg}$ ou Bilastina $20 \mathrm{mg}$ para adultos e para crianças a dose era ajustada de acordo com peso apresentado para fexofenadina. Somente uma paciente adulta fez uso do antihistamínico (Bilastina $20 \mathrm{mg}$ ) porque apresentava reação local que a incomodava, os outros pacientes não fizeram uso da medicação por escolha própria. 
Em um estudo multicêntrico avaliando dados de 840 pacientes, os efeitos colaterais à imunoterapia (reações sistêmicas) com veneno foram observados em um total de $20 \%$ dos pacientes ${ }^{138}$. A maioria dessas reações foram leves e apenas um terço exigiu tratamento médico. Uma frequência similar de efeitos adversos sistêmicos foram observados em um estudo publicado analisando dados de 178 pacientes $^{209}$.

A fase de indução da imunoterapia com veneno é a que apresenta mais efeitos adversos do que a fase de manutenção. Em um estudo prospectivo $^{138}$ avaliando tolerância, de 26601 injeções em 840 pacientes, as reações sistêmicas foram observadas em $1,9 \%$ das injeções durante a fase de indução e apenas em $0,5 \%$ durante a fase de manutenção $(p<0,05)$.

No nosso estudo, a taxa de reação sistêmica durante a imunoterapia foi menor que da literatura: 6,06\% durante a fase de indução e foi menor também quando se compara por injeção: $0,017 \%$. Na fase de manutenção não houve surgimento de reações sistêmicas. A semelhança se manteve na gravidade leve dessas reações. E lembrando que os dados da literatura foram observados na imunoterapia com abelha e vespa, não há dados com imunoterapia com veneno de Solenopsis.

Assim, a gravidade dos efeitos colaterais devidos a imunoterapia não se correlaciona necessariamente com a gravidade dos sintomas da doença alérgica tratada. Podem ocorrer reações sistêmicas induzidas pela imunoterapia com veneno, mas a grande maioria dos pacientes tolera a imunoterapia sem efeitos colaterais relevantes.

\section{Ferroadas acidentais durante o tratamento}

A avaliação da reação após uma ferroada durante o tratamento ou após término deste (seja por teste de provocação com inseto responsável e por ferroada em campo ou acidental) é um método disponível para identificar pacientes respondendo à imunoterapia com veneno ${ }^{170}$. 
Quando a provocação com próprio inseto (teste de provocação) foi realizada em uma série de pacientes submetidos a imunoterapia com veneno de abelha e vespa, cerca de 75 a $85 \%^{59,195,210}$ ou até mais de $95 \%{ }^{211,212}$ estavam protegidos.

No Brasil, por questões éticas, não podemos realizar o teste de provocação com o inseto responsável, desse modo temos que aguardar que ferroadas acidentais ocorram. Quando ocorrera, procuramos confirmar por história para a certeza do inseto que ferroou. Em nosso meio a formiga é muito prevalente e é de fácil identificação pelo paciente e/ou responsável, geralmente não ocorrem dúvidas.

Nesse estudo, 20 pacientes foram ferroados, com 35 ferroadas no total, pois alguns deles foram ferroados mais de uma vez.

Durante a fase de indução há uma chance aumentada de ocorrerem reações sistêmicas por exposição natural. A paciente que apresentou reação sistêmica na fase de indução em nosso estudo, apresentou apenas uma reação leve (somente urticária, sem necessidade de procurar pronto atendimento ou uso de adrenalina auto injetável). Desse modo, temos 1 reação sistêmica em 19 pacientes ferroados de forma natural, no total: 5,2\%, não tendo sido considerado falha de tratamento por encontrar-se na fase de indução. Durante a fase de manutenção, 2 pacientes foram ferroados acidentalmente e tiveram reações sistêmicas (10,5\%), mas também descritas como reações leves: somente urticária, sem necessidade de procurar pronto atendimento ou uso de adrenalina auto injetável.

Essas quantidade de reações tanto da fase de indução $(5,2 \%)$ quanto da fase de manutenção $(10,5 \%)$ são menores que as porcentagens encontradas na literatura, que considera aproximadamente um risco de $25 \%$ de uma nova reação sistêmica generalizada se for ferroado novamente nos pacientes que receberam imunoterapia com veneno de himenópteros por 1 ou $2 \operatorname{anos}^{137}$. 


\section{CONCLUSÃO}

Poucos estudos avaliaram pacientes submetidos a imunoterapia com veneno de Solenopsis e este nosso estudo é inédito na avaliação de dados clínicos e laboratoriais no tratamento com veneno dessas formigas.

O desevolvimento de tolerância periférica é o principal mecanismo de ação da imunoterapia. Neste estudo verificamos diferença significativa, antes e após 1 ano da fase de manutenção, entre as razões das dosagens de $\lg \mathrm{E} / \lg \mathrm{G} 4$ específicas, reforçando a hipótese de que o anticorpo lgG4 tenha modo de ação de bloquear a lgE específica.

É importante notar que a lgG4 específica de alérgenos pode interferir não apenas na elucidação das respostas alérgicas desencadeadas por lgE em efetores mas também a apresentação de antígeno mediado por lgE às células $T$, que pode ser importante para diminuir as respostas das células TH2 específicas do alérgeno, por isso a importância de se considerar não apenas os valores individuais de cada anticorpo, mas a razão entre eles no período basal e durante a imunoterapia. Nesse sentido, seria interessante obter mais estudos sobre comportamento das células $T$ específicas durante a imunoterapia com veneno de formiga, pois não foi foco desse estudo em questão.

A dose de manutenção de $0,5 \mathrm{~mL}$ na concentração 1:100 peso/volume (extrato Holister Stier, USA) de uma mistura de extrato de corpo total de Solenopsis invicta e richteri foi eficaz. Os poucos casos de pacientes ferroados por exposição acidental que apresentaram reações sistêmicas durante o tratamento (1 ano da dose de manutenção), foram de intensidade leve (urticária), com melhora após uso de anti-histamínico por via oral.

As reações adversas a imunoterapia foram raras.

As lições aprendidas neste estudo nos ajudaram a melhorar 0 conhecimento tanto da eficácia quanto da manutenção da tolerância ao veneno de formiga induzida pela imunoterapia específica. 
Para o futuro, todos os pacientes que completaram o tratamento por 3 anos a partir da dose de manutenção serão acompanhados por nossa equipe durante um longo período após descontinuação do tratamento. 


\section{REFERÊNCIAS BIBLIOGRÁFICAS}

1- $\quad$ Portier P, Richet CR. De l'action anaphylactique de certains venins. CR Soc Biol (Paris) 1902;54:170-2.

2- Lieberman P, Nicklas RA, Randolph C, Oppenheimer J, Bernstein D, Bernstein J, et al. Anaphylaxis-a practice parameter update 2015. Ann Allergy Asthma Immunol 2015;115:341-84.

3- Lieberman PL. Anaphylaxis and anaphylactoid reactions. In: Adkinson NF, Yunginger JW, Busse WW, Bochner BS, Holgate ST, Simons FER, editors. 4- Middleton's Allergy Principles and Practice. 6th ed. St Louis, Mo: Mosby; 2003. p.1497-522.

5- Castells M. Diagnosis and management of anaphylaxis in precision medicine. J Allergy Clin Immunol 2017;140:321-33.

6- Wood RA, Camargo CA, Jr., Lieberman P, Sampson HA, Schwartz LB, Zitt $M$, et al. Anaphylaxis in America: the prevalence and characteristics of anaphylaxis in the United States. J Allergy Clin Immunol. 2014;133(2):461-7.

7- Liew WK, Chiang WC, Goh AE, Lim HH, Chay OM, Chang S, et al. Paediatric anaphylaxis in a Singaporean children cohort: changing food allergy triggers over time. Asia Pac Allergy. 2013;3(1):29-34.

8- Grabenhenrich LB, Dolle S, Moneret-Vautrin A, Kohli A, Lange L, Spindler T, et al. Anaphylaxis in children and adolescents: The European Anaphylaxis Registry. J Allergy Clin Immunol. 2016;137(4):1128-1860 37.e1.

9- Gonzalez-Estrada A, Silvers SK, Klein A, Zell K, Wang XF, Lang DM. Epidemiology of anaphylaxis at a tertiary care center: A report of 730 cases. Ann Allergy Asthma Immunol. 2017;118(1):80-5.

10- Carrard A, Rizzuti D, Sokollik C. Update on food allergy. Allergy. 2015;70(12):1511-20.

11- Gupta RS, Springston EE, Warrier MR, Smith B, Kumar R, Pongracic J, et al. The prevalence, severity, and distribution of childhood food allergy in the United States. Pediatrics. 2011;128(1):e9-17.

12- Gupta RS, Warren CM, Smith BM, Jiang J, Blumenstock JA, Davis MM, et al. Prevalence and Severity of Food Allergies Among US Adults. JAMA Netw Open. 2019;2(1):e185630. 
13- World Allergy Organization. White Book on Allergy: Update 2013, Executive Summary: World Allergy Organ; 2013.

14- Worm M, Moneret-Vautrin A, Scherer K, Lang R, Fernandez-Rivas M, Cardona $\mathrm{V}$, et al. First European data from the network of severe allergic reaction (NORA). Allergy 2014; (69):1397-1404. doi:10.1111/all.12475.

15- Tankersley MS, Ledford DK. Stinging insect allergy: state of the art 2015. J Allergy Clin Immunol Pract. 2015 May-Jun;3(3):315-22; quiz 323. doi: 10.1016/j.jaip.2015.03.012.

16- Golden DBK. Insect allergy. In: Adkinson NF Jr, Bochner BS, Busse WW, Holgate ST, Lemanske RF, Simons FER, editors. Adkinson: Middleton's Allergy: Principles and Practice. 8th ed. Philadelphia: Mosby Elsevier; 2014. p.1260-72 (p. 1261, Table 78-1).

17- Castro FFM, Palma MS. Alergia e venenos de insetos - série Alergias. $1^{\text {a }}$ edição. Editora manole.

18- Palma MS. Venenos de Hymenoptera sociais: coleta, composição, bioquímica e farmacologia. Rev Bras Alergia Imunopatol 1992;15(4):126-8.

19- Cohen PR. 1992. Imported fire ant stings: clinical manifestations and treatment. Pediatric Dermatology 9: 44-48.

20- DeShazo RD. Butcher BT, Banks WA. Reactions to the stings of the imported fire ant. N Engl J Med 1990: 323:462-6.

21- Rhoades RB, Stafford CT, James FK Jr, Survey of fatal anaphylactic reactions to imported fire ant stings. J Allergy Clin Immunol 1989: 84: 159-62.

22- Stafford CT, Hutto LS, Rhoades RB, Thompson WO, Impson LK. Imported fire ant as a health hazard.South Med J 1989: 82: 1515-19.

23- Banks WA, Adams CT, Lofgren CS. Damage to North Carolina and Florida highways by red imported fire ants (Hymenoptera, Formicidae). Fla Entomol 1990: 73: 198-9.

24- Green HB. Biology and control of the imported fire ant in Mississippi. J Econ Entomol 1952: 45: 593-7

25- Lofgren CS, Vander Meer RK, et al. Fire ants and leaf-cutting ants. Biology and management. Boulder, CO: West-view, 1986.

26- Hedges SA. 1997. Handbook of Pest Control, 8th Ed. (Moreland D, editor) pp. 531-535. Mallis Handbook and Technical Training Company. 
27- Vinson SB, Sorenson, AA. 1986. Imported Fire Ants: Life History and Impact. The Texas Department of Agriculture. P. O. Box 12847, Austin, Texas 78711.

28- Hedges SA. 1997. Handbook of Pest Control, 8th Ed. (Moreland D, editor) pp. 531-535. Mallis Handbook and Technical Training Company.

29- HoffmanDR, Dove DE, Jacobson RS. Allergens in Hymenoptera venom. $X X$. Isolation of four allergens from imported fire ant (Solenopsis invicta) venom. J Allergy Clin Immunol 1988: 82: 818-27.

30- Hoffman, D. R. Fire ant venom allergy. Allergy 1995, 50 (7),535-544.

31- Hoffman DR. Allergens in Hymenoptera venom. XXIV. The amino acid sequences of imported fire ant venom allergens Sol i II, Sol i III and Sol i IV. J Allergy Clin Immunol1993: 91: 71-8.

32- Hoffman DR. Dove DE, Moffitt JE, Stafford CT. Allergens in Hymenoptera venom. XXI. Cross-reactivity and multiple reactivity between fire ant venom and bee and wasp venoms. J Allergy Clin Immunol 1988: 82: 82834.

33- Bakna SL, Strimas JH, Reed MA, Butcher BT. Imported fire ant allergy in young children: skin reactivity and serum $\lg E$ antibodies to venom and wholebody extract. J Allergy Clin Immunol 1988: 82: 419-24.

34- James FK, Pence HL, Driggers RL, Horton DE. Im-ported fire ant hypersensitivity: studies of human reactions tofire ant venom. J Allergy Clin Immunol 1976: 58: 110-20.

35- Paull BR, Coghlan TH, Vinson SB, Fire ant venom hypersensitivity, I, Comparison of fire ant venom and whole-body extract in the diagnosis of fire ant allergy, J Allergy Clin Immunol 1983: 71: 448-53.

36- Strom GB, Boswell RN, Jacobs RL, In vivo and in vitro comparison of fire ant venom and fire ant whole body extract, J Allergy Clin Immunol 1983: 72: 4653.

37- Butcher BT, DeShazo RD, Ortiz AA, Reed MA. RAST inhibition studies of the imported fire ant Solenopsis invicta with whole body extracts and venom preparations. J Allergy Clin Immunol 1988: 81: 1096-1100. 
38- Butcher BT, DeShazo RD, Ortiz AA, Reed MA. Superiority of Solenopsis invicta venom to whole body extract in RAST for diagnosis of imported fire ant allergy. Int Arch Allergy Appl Immunol 1988: 85: 458-61.14.

39- Butcher BT, Reed MA. Evaluation of commercial imported fire ant extracts by crossed immunoelectrophoresis and radioallergosorbent test. $J$ Allergy Clin Immunol 1988:82: 770-7

40- Hannan CJ Jr, Stafford CT, Rhoades RB, Wray BB, Baer H, Anderson MC. Seasonal variation in antigens of the imported fire ant Solenopsis invicta. $J$ Allergy Clin Immunol 1986: 78: 331-6.

41- Nordvall SL, Johansson SGO, Ledford DK, Lockey RF. Allergens of the imported fire ant, J Allergy Clin Immunol 1988: 82: 567-76.

42- Kucuksezer UC, Ozdemir C, Cevhertas L, Ogulur I, Akdis M, Akdis CA. Mechanisms of allergen-specific immunotherapy and allergen tolerance. Allergol Int. 2020 Oct;69(4):549-560. doi: 10.1016/j.alit.2020.08.002. Epub 2020 Sep 6. PMID: 32900655.

43- Van der Linden PW, Hack CE, Struyvenberg A, van der Zwan JK. Insectsting challenge in 324 subjects with a previous anaphylactic reaction: current criteria for insect-venom hypersensitivity do not predict the occurrence and the severity of anaphylaxis. J Allergy Clin Immunol. 1994 Aug;94(2 Pt 1):151-9.

44- Mueller HL. Diagnosis and treatment of insect sensitivity. J Asthma Res 1996;3:331-3.

45- deShazo RD, Williams DF, Moak ES. Fire ant attacks on residents in health care facilities: a report of two cases. Ann Intern Med. 1999;131:424-9.

46- Stafford CT. Hypersensitivity to fire ant venom. Ann Allergy Asthma Immunol. 1996;77:87-95.

47- Triplett RF. The imported fire ant: health hazard or nuisance? South Med J. 1976;69:258-9.

48- Disponível em: http://www.saude.sp.gov.br/resources/cve-centro-devigilancia-epidemiologica/areas-de-vigilancia/doencas-de-transmissao-porvetores-e-zoonoses/dados/peconhentos/peco_abelhas.pdf. Fonte: Divisão de Zoonoses - CVE - Sinanw e Sinan Net. Visto em 29/05/2020.

49- Golden DBK. Insect sting allergy and venom immunotherapy: A model and a mystery. J Allergy Clin Immunol 2005;115(3):439-47. 
50- Bilo BM, Rueff F, Mosbech H, Bonifazi F, Oude-Elberink JN. Diagnosis of Hymenoptera venom allergy. Allergy. 2005 Nov;60(11):1339-49.

51- Przybilla B, Ruëff F. Hymenoptera venom allergy. J Dtsch Dermatol Ges. 2010 Feb;8(2):114-27; quiz 128-30. doi: 10.1111/j.1610-0387.2009.07125.x. Epub 2009 Sep 14.

52- Charpin D, Birnbaum J, Lanteaume A, Vervolet D. Prevalence of allergy to Hymenoptera sting in different samples of the general population. J Allergy Clin Immunol 1992;90:331-334.

53- Bilò BM, Ruëff $F$, Mosbech $H$, Bonifazi $F$, Oude Elberink JNG, the EAACI Interest Group on Insect Venom Hypersensitivity. Diagnosis of hymenoptera venom allergy. Allergy 2005; (60):1339-1349. doi:10.1111/j.13989995.2005.00963.x.

54- González-de-Olano D, Alvarez-Twose I, Vega A, Orfao A, Escribano L. Venom immunotherapy in patients with mastocytosis and hymenoptera venom anaphylaxis. Immunotherapy 2011; (3):637-651. doi:10.2217/imt.11.44.

55- Bonifazi F, Jutel M, Bilo BM, et al, the EAACI Interest Group on Insect Venom Hypersensitivity. Prevention and treatment of hymenoptera venom allergy: guidelines for clinical practice. Allergy 2005; 60:1459-1470.

56- Campbell RL, Li JT, Nicklas RA, et al; Members of the Joint Task Force; Practice Parameter Workgroup: Emergency department diagnosis and treatment of anaphylaxis: A practice parameter. Ann Allergy Asthma Immunol 2014; 113:599-608.

57- Kemp SF, Lockey RF, Simons FE. Epinephrine: the drug of choice for anaphylaxis. A statement of the World Allergy Organization. Allergy. 2008, Vol. 63, 1061-70.

58- Alvaro-Lozano M, Akdis CA, Akdis M, Alviani C, Angier E, Arasi S, ArztGradwohl L, Barber D, Bazire R, Cavkaytar O, Comberiati P, Dramburg S, Durham SR, Eifan AO, Forchert L, Halken S, Kirtland M, Kucuksezer UC, Layhadi JA, Matricardi PM, Muraro A, Ozdemir C, Pajno GB, Pfaar O, Potapova E, Riggioni C, Roberts G, Rodríguez Del Río P, Shamji MH, Sturm GJ, Vazquez-Ortiz M. EAACI Allergen Immunotherapy User's Guide. Pediatr Allergy Immunol. 2020 May;31 Suppl 25:1-101. doi: 10.1111/pai.13189. PMID: 32436290 . 
59- Muller U, Helbling A, Berchtold E. Immunotherapy with honeybee venom and yellow jacket venom is different regarding efficacy and safety. J Allergy Clin Immunol 1992; 89:529-35.

60- Ruëff F, Vos B, Oude Elberink J, Bender A, Chatelain R, Dugas-Breit S, Horny HP, Küchenhoff H, Linhardt A, Mastnik S, Sotlar K, Stretz E, Vollrath R, Przybilla B, Flaig M. Predictors of clinical effectiveness of Hymenoptera venom immunotherapy. Clin Exp Allergy. 2014;44(5):736-46. doi: 10.1111/cea.12275. PMID: 24447114.

61- Triplett RF. Sensitivity to the imported fire ant: successful treatment with immunotherapy. South Med J 1973-66-477-80.

62- Stafford CT, Rhoades RB, Bunker-Soler AL, Thompson WO, Impson BS, Survey of whole-body extract immunotherapy for imported fire ant and other Hymenoptera sting allergy, J Allergy Clin Immunol 1989: 83: 1107-11,

63- Freeman TM, Hylander R, Ortiz A, Martin ME. Imported Fire Ant Immunotherapy: Effectiveness of whole-Body Extracts. J Allergy Clin Immunol. 1992 Aug;90(2):210-5. doi: 10.1016/0091-6749(92)90073-b.

64- Hofman DR. Fire ant venom allergy. Allergy 1995;50:535-44.

65- QUINN JM. TAJIRI KS, MOTTA P, FREEMAN TM. Long-term efficacy after discontinuation of imported fire ant (Solenopsis invicta) immunotherapy, J Allergy Clin Immunol 1994 (Suppl 1): 93: S223.

66- Tankersley MS, Walker RL, Butler WK, Hagan LL, Napoli DC, Freeman TM. Safety and efficacy of an imported fire ant rush immunotherapy protocol with and without prophylactic treatment. J Allergy Clin Immunol 2002; 109:55662.

67- Duplantier JE, Freeman TM, Bahna SL, Good RA, Sher MR. Successful rush immunotherapy for anaphylaxis to imported fire ants. J Allergy Clin Immunol. 1998;101(6 Pt 1):855-856. doi:10.1016/s0091-6749(98)70318-5.

68- Judd CA, Parker AL, Meier EA, Tankersley MS. Successful administration of a 1-day imported fire ant rush immunotherapy protocol. Ann Allergy Asthma Immunol. 2008;101(3):311-315. doi:10.1016/S10811206(10)60497-8. 
69- Adams KE, Johnson KS. Safety of Repeated Imported Fire Ant UltraRush Protocols. Mil Med. 2019;184(5-6):e483-e485. doi:10.1093/milmed/usy275

70- Beveridge GB, Tankersley MS. Successful completion of an imported fire ant cluster immunotherapy protocol. Ann Allergy Asthma Immunol. 2019;123(1):95-96. doi:10.1016/j.anai.2019.04.017

71- Dietrich JJ, Moore LM, Nguyen S, Hagan LL, Tankersley MS. Imported fire ant hypersensitivity: a 1-day rush immunotherapy schedule without premedication. Ann Allergy Asthma Immunol. 2009;103(6):535e536. https://doi.org/10.1016/S1081-1206(10)60271-2.

72- $\quad$ Arseneau AM, Nesselroad TD, Dietrich JJ, et al. A 1-day imported fire ant rush immunotherapy schedule with and without premedication. J Allergy Clin Immunol. 2013;111(6):562e566.

73- https://doi.org/10.1016/j.anai.2013.08.021.

74- Brown SG, Wiese MD, Blackman KE, Heddle RJ. Ant venom immunotherapy: a double-blind, placebo-controlled, crossover trial. Lancet. 2003;361(9362):1001-1006. doi:10.1016/S0140-6736(03)12827-9

75- Wauters $\mathrm{RH}$, Brooks DI, Schwartz DJ. Imported fire ant immunotherapy prescribing patterns in a large health care system during an 11-year period [published online ahead of print, 2020 Jun 13]. Ann Allergy Asthma Immunol. 2020;S1081-1206(20)30408-7. doi:10.1016/j.anai.2020.06.013

76- Dhami S, Zaman H, Varga EM, Sturm GJ, Muraro A, Akdis CA, et al. Allergen immunotherapy for insect venom allergy: a systematic review and meta-analysis. Allergy 2017; 72:342-65.

77- Mobs C, Ipsen H, Mayer L, Slotosch C, Petersen A, Würtzen PA, Hertl M, Pfützner W. Birch Pollen Immunotherapy Results in Long-Term Loss of Bet v 1specific TH2 Responses, Transient TR1 Activation, and Synthesis of IgEblocking Antibodies. J Allergy Clin Immunol. 2012 Nov;130(5):1108-1116.e6. doi: 10.1016/j.jaci.2012.07.056. Epub 2012 Sep 27.

78- Benjaponpitak S, Oro A, Maguire P, Marinkovich V, DeKruyff $\mathrm{RH}$, Umetsu DT. The kinetics of change in cytokine production by CD4 T cells during conventional allergen immunotherapy. J Allergy Clin Immunol 1999;103:468-75. 
79- Durham SR, Varney V, Gaga M, Frew AJ, Jacobson M, Kay AB. Immunotherapy and allergic inflammation. Clin Exp Allergy 1991;21(suppl 1):206-10.

80- Ebner C, Siemann U, Bohle B, Willheim M, Wiedermann U, Schenk S, et al. Immunological changes during specific immunotherapy of grass pollen allergy: reduced lymphoproliferative responses to allergen and shift from $\mathrm{TH} 2$ to TH1 in T-cell clones specific for Phl p 1, a major grass pollen allergen. Clin Exp Allergy 1997;27:1007-15.

81- Rolland JM, Gardner LM, O'Hehir RE. Functional regulatory T cells and allergen immunotherapy. Curr Opin Allergy Clin Immunol 2010;10:559-66.

82- Akdis CA, Akdis M. Mechanisms of allergen-specific immunotherapy. J Allergy Clin Immunol 2011;127:18-27.

83- Bohle B, Kinaciyan T, Gerstmayr M, Radakovics A, Jahn-Schmid B, Ebner C. Sublingual immunotherapy induces IL-10-producing T regulatory cells, allergenspecific T-cell tolerance, and immune deviation. J Allergy Clin Immunol 2007;120:707-13.

84- Jutel M, Akdis M, Budak F, Aebischer-Casaulta C, Wrzyszcz M, Blaser K, et al. IL-10 and TGF-beta cooperate in the regulatory $T$ cell response to mucosal allergens in normal immunity and specific immunotherapy. Eur $\mathrm{J}$ Immunol 2003;33:1205-14.

85- Yamanaka K, Yuta A, Kakeda M, Sasaki R, Kitagawa H, Gabazza EC, et al. Induction of IL-10-producing regulatory T cells with TCR diversity by epitopespecific immunotherapy in pollinosis. J Allergy Clin Immunol 2009;124:842-5, e7.

86- Anderson AE, Mackerness KJ, Aizen M, Carr VA, Nguyen D, Du Pre F, et al. seasonal changes in suppressive capacity of CD41 CD251 T cells from patients with hayfever are allergen-specific and may result in part from expansion of effector $\mathrm{T}$ cells among the CD251 population. Clin Exp Allergy 2009;39:1693-9.

87- Radulovic S, Jacobson MR, Durham SR, Nouri-Aria KT. Grass pollen immunotherapy induces Foxp3-expressing CD41 CD251 cells in the nasal mucosa. J Allergy Clin Immunol 2008;121:1467-72, e1. 
88- Shin JU, Kim SH, Noh JY, et al. Allergen specific immunotherapy induces regulatory $\mathrm{T}$ cells in an atopic dermatitis mouse model. Allergy. 2018;73(9):1801-1811.

89- Smaldini PL, Trejo F, Cohen JL, Piaggio E, Docena GH. Systemic IL2/anti-IL-2Ab complex combined with sublingual immunotherapy suppresses experimental food allergy in mice through induction of mucosal regulatory $T$ cells. Allergy. 2018;73(4):885-895.

90- Bachmann MF, Kundig TM. Allergen specific immunotherapy: is it vaccination against toxins after all? Allergy. 2017;72 (1):13-23.

91- Meiler F, Zumkehr J, Klunker S, Ruckert B, Akdis CA, Akdis M. In vivo switch to IL-10-secreting $\mathrm{T}$ regulatory cells in high dose allergen exposure. $\mathrm{J}$ Exp Med. 2008;205(12):2887-2898.

92- Kucuksezer UC, Ozdemir C, Akdis M, Akdis CA. Precision/Personalized Medicine in Allergic Diseases and Asthma. Arch Immunol Ther Exp. 2018;66(6):431-442.

93- Lou W, Wang C, Wang Y, Han D, Zhang L. Responses of CD4(+) CD25(+) Foxp3(+) and IL-10-secreting type I T regulatory cells to clusterspecific immunotherapy for allergic rhinitis in children. Pediatr Allergy Immunol. 2012;23(2):140-149.

94- Boonpiyathad T, Sokolowska M, Morita $H$, et al. Der $p$ 1-specific regulatory T-cell response during house dust mite allergen immunotherapy. Allergy. 2019;74:976-985.

95- Zaleska A, Eiwegger $T$, Soyer $O$, et al. Immune regulation by intralymphatic immunotherapy with modular allergen translocation MAT vaccine. Allergy. 2014;69(9):1162-1170.

96- Soyer OU, Akdis M, Ring J, et al. Mechanisms of peripheral tolerance to allergens. Allergy. 2013;68(2):161-170.

97- O'Hehir RE, Gardner LM, de Leon MP, Hales BJ, Biondo M, Douglass JA, et al. House dust mite sublingual immunotherapy: the role for transforming growth factor-beta and functional regulatory T cells. Am J Respir Crit Care Med 2009; 180:936-47.

98- Nieminen K, Laaksonen K, Savolainen J. Three-year follow-up study of allergen induced in vitro cytokine and signalling lymphocytic activation molecule 
mRNA responses in peripheral blood mononuclear cells of allergic rhinitis patients undergoing specific immunotherapy. Int Arch Allergy Immunol 2009;150:370-6.

99- Jones SM, Pons L, Roberts JL, Scurlock AM, Perry TT, Kulis M, et al. Clinical efficacy and immune regulation with peanut oral immunotherapy. J Allergy Clin Immunol 2009;124:292-300, e1-97.

100- Mobs C, Slotosch C, Loffler H, Jakob T, Hertl M, Pfutzner W. Birch pollen immunotherapy leads to differential induction of regulatory $T$ cells and delayed helper T cell immune deviation. J Immunol 2010;184:2194-203.

101- Van Overtvelt L, Wambre E, Maillere B, von Hofe E, Louise A, Balazuc AM, et al. Assessment of Bet v 1-specific CD41 T cell responses in allergic and nonallergic individuals using MHC class II peptide tetramers. J Immunol 2008;180:4514-22.

102- Wambre E, DeLong JH, James EA, LaFond RE, Robinson D, Kwok WW. Differentiation stage determines pathologic and protective allergen-specific CD41 T-cell outcomes during specific immunotherapy. J Allergy Clin Immunol 2012;129:544-51, e1-7.

103- Guerra F, Carracedo J, Solana-Lara R, Sanchez-Guijo P, Ramirez R. TH2 lymphocytes from atopic patients treated with immunotherapy undergo rapid apoptosis after culture with specific allergens. J Allergy Clin Immunol 2001;107:647-53.

104- Tsai YG, Chien JW, Chen WL, Shieh JJ, Lin CY. Induced apoptosis of TH2 lymphocytes in asthmatic children treated with Dermatophagoides pteronyssinus immunotherapy. Pediatr Allergy Immunol 2005;16:602-8.

105- Gardner LM, O'Hehir RE, Rolland JM. High dose allergen stimulation of T cells from house dust mite-allergic subjects induces expansion of IFN-gamma1 T Cells, apoptosis of CD41L-41 T cells and T cell anergy. Int Arch Allergy Immunol 2004;133:1-13.

106- Pree I, Shamji MH, Kimber I, Valenta R, Durham SR, Niederberger V. Inhibition of CD23-dependent facilitated allergen binding to $B$ cells following vaccination with genetically modified hypoallergenic Bet v 1 molecules. Clin Exp Allergy 2010;40:1346-52. 
107- van de Veen W, Stanic B, Yaman G, et al. IgG4 production is confined to human IL-10-producing regulatory $B$ cells that suppress antigen-specific immune responses. J Allergy Clin Immunol. 2013;131(4):1204-1212.

108- van de Veen $\mathrm{W}$. The role of regulatory $B$ cells in allergen immunotherapy. Curr Opin Allergy Clin Immunol. 2017;17(6):447-452.

109- Mosges R, Koch AF, Raskopf E, et al. Lolium perenne peptide immunotherapy is well tolerated and elicits a protective B-cell response in seasonal allergic rhinitis patients. Allergy. 2018;73(6):1254-1262.

110- Ozdemir C, Kucuksezer UC, Akdis M, Akdis CA. Mechanisms of Aeroallergen Immunotherapy: Subcutaneous Immunotherapy and Sublingual Immunotherapy. Immunology and allergy clinics of North America. 2016;36(1):71-86.

111- Kucuksezer UC, Ozdemir C, Akdis M, Akdis CA. Mechanisms of immune tolerance to allergens in children. Korean journal of pediatrics. 2013;56(12):50513.

112- Sahiner UM, Durham SR. Hymenoptera Venom Allergy: How Does Venom Immunotherapy Prevent Anaphylaxis From Bee and Wasp Stings? Front Immunol. 2019 Aug 21;10:1959. doi: 10.3389/fimmu.2019.01959. PMID: 31497015; PMCID: PMC6712168.

113- Sturm GJ, Varga EM, Roberts $G$, et al. EAACl guidelines on allergen immunotherapy: Hymenoptera venom allergy. Allergy. 2018;73(4):744-764. doi:10.1111/all.13262

114- Reisman RE, Lantner R. Further observations of stopping venom immunotherapy: comparison of patients stopped because of a fall in serum venom-specific IgE to insignificant levels with patients stopped prematurely by self-choice. J Allergy Clin Immunol 1989 Jun83(6):1049-54.

115- Watanabe AS, Fonseca LA, Galvao CE, Kalil J, Castro FF (2010) Specific immunotherapy using Hymenoptera venom: systematic review. Sao Paulo Med J 128: 30-37.

116- Golden DB, Demain J, Freeman T, Graft D, Tankersley M, Tracy J, Bernstein D, Blessing-Moore J, Dinacar $C$ et al. Stinging insect hypersensitivity: a practice parameter update 2016 Ann Allergy Asthma Immunol. 2017 Jan;118(1):28-54. 
117- Graft DF, Schuberth KC, Kagey-Sobotka A, Kwiterovich KA, Niv Y, Lichtenstein LM, et al. A prospective study of the natural history of large local reactions after Hymenoptera stings in children. J Pediatr 1984; 104:664-8.

118- Mauriello PM, Barde SH, Georgitis JW, Reisman RE. Natural history of large local reactions from stinging insects. J Allergy Clin Immunol 1984; 74:4948.

119- Golden DB, Kelly D, Hamilton RG, Craig TJ. Venom immunotherapy reduces large local reactions to insect stings. J Allergy Clin Immunol 2009; 123:1371-5.

120- Rodriguez Del Rio P, Pitsios C, Tsoumani M, Pfaar O, Paraskevopoulos G, Gawlik R, et al. Physicians' experience and opinion on contraindications to allergen immunotherapy: The CONSIT survey. Ann Allergy Asthma Immunol 2017; 118:621-8.e1.

121- Sasvary T, Muller U. [Fatalities from insect stings in Switzerland 1978 to 1987]. Schweiz Med Wochenschr 1994; 124:1887-94.

122- Pitsios C, Demoly P, Bilo MB, Gerth van Wijk R, Pfaar O, Sturm GJ, et al. Clinical contraindications to allergen immunotherapy: an EAACI position paper. Allergy 2015; 70:897-909.

123- Muller UR, Haeberli G. Use of beta-blockers during immunotherapy for Hymenoptera venom allergy. J Allergy Clin Immunol 2005; 115:606-10.

124- Rueff F, Przybilla B, Bilo MB, Muller U, Scheipl F, Aberer W, et al. Predictors of side effects during the buildup phase of venom immunotherapy for Hymenoptera venom allergy: the importance of baseline serum tryptase. $J$ Allergy Clin Immunol 2010; 126:105-11 e5.

125- Stoevesandt J, Hain J, Stolze I, Kerstan A, Trautmann A. Angiotensinconverting enzyme inhibitors do not impair the safety of Hymenoptera venom immunotherapy build-up phase. Clin Exp Allergy 2014; 44:747-55.

126- Rueff F, Przybilla B, Bilo MB, Muller U, Scheipl F, Aberer W, et al. Predictors of severe systemic anaphylactic reactions in patients with Hymenoptera venom allergy: importance of baseline serum tryptase-a study of the European Academy of Allergology and Clinical Immunology Interest Group on Insect Venom Hypersensitivity. J Allergy Clin Immunol 2009; 124:1047-54. 
127- Brown SG. Clinical features and severity grading of anaphylaxis. J Allergy Clin Immunol 2004; 114:371-6.

128- Stoevesandt J, Hain J, Kerstan A, Trautmann A. Over and underestimated parameters in severe Hymenoptera venom-induced anaphylaxis: cardiovascular medication and absence of urticaria/angioedema. $J$ Allergy Clin Immunol 2012; 130:698-704 e1.

129- Arzt L, Bokanovic D, Schwarz I, Schrautzer C, Massone C, Horn M, et al. Hymenoptera stings in the head region induce impressive, but not severe sting reactions. Allergy 2016; 71:1632-4

130- Wohrl S, Kinaciyan T, Jalili A, Stingl G, Moritz KB. Malignancy and specific allergen immunotherapy: the results of a case series. Int Arch Allergy Immunol 2011; 156:313-9.

131- Pfaar O, Bachert C, Bufe A, Buhl R, Ebner C, Eng P, et al. Guideline on allergen-specific immunotherapy in IgE-mediated allergic diseases: S2k Guideline of the German Society for Allergology and Clinical Immunology (DGAKI), the Society for Pediatric Allergy and Environmental Medicine (GPA), the Medical Association of German Allergologists (AeDA), the Austrian Society for Allergy and Immunology (OGAI), the Swiss Society for Allergy and Immunology (SGAI), the German Society of Dermatology (DDG), the German Society of Oto- Rhino-Laryngology, Head and Neck Surgery (DGHNO-KHC), the German Society of Pediatrics and Adolescent Medicine (DGKJ), the Society for Pediatric Pneumology (GPP), the German Respiratory Society (DGP), the German Association of ENT Surgeons (BV-HNO), the Professional Federation of Paediatricians and Youth Doctors (BVKJ), the Federal Association of Pulmonologists (BDP) and the German Dermatologists Association (BVDD). Allergo J Int 2014; 23:282-319.

132- Livingston MG, Livingston HM. Monoamine oxidase inhibitors. An update on drug interactions. Drug Saf 1996; 14:219-27.

133- Lockey RF, Turkeltaub PC, Baird-Warren IA, Olive CA, Olive ES, Peppe BC, et al. The Hymenoptera venom study I, 1979-1982: demographics and history-sting data. J Allergy Clin Immunol 1988; 82:370-81. 
134- Stritzke Al, Eng PA. Age-dependent sting recurrence and outcome in immunotherapy-treated children with anaphylaxis to Hymenoptera venom. Clin Exp Allergy 2013; 43:950-5.

135- Metzger WJ, Turner E, Patterson R. The safety of immunotherapy during pregnancy. J Allergy Clin Immunol 1978; 61:268-72.

136- Randolph CC, Reisman RE. Evaluation of decline in serum venomspecific $\lg E$ as a criterion for stopping venom immunotherapy. J Allergy Clin Immunol 1986; 77:823-7.

137- Golden DB, Johnson K, Addison BI, Valentine MD, Kagey-Sobotka A, Lichtenstein LM. Clinical and immunologic observations in patients who stop venom immunotherapy. J Allergy Clin Immunol 1986; 77:435-42.

138- Mosbech H, Muller U. Side-effects of insect venom immunotherapy: results from an EAACI multicenter study. European Academy of Allergology and Clinical Immunology. Allergy 2000; 55:1005-10.

139- van Anrooij B, van der Veer E, de Monchy JG, van der Heide S, KluinNelemans JC, van Voorst Vader PC, et al. Higher mast cell load decreases the risk of Hymenoptera venom-induced anaphylaxis in patients with mastocytosis. J Allergy Clin Immunol 2013; 132:125-30.

140- Bonadonna P, Zanotti R, Caruso B, Castellani L, Perbellini O, Colarossi $S$, et al. Allergen specific immunotherapy is safe and effective in patients with systemic mastocytosis and Hymenoptera allergy. J Allergy Clin Immunol 2008; 121:256-7

141- Gonzalez de Olano D, Alvarez-Twose I, Esteban-Lopez MI, SanchezMunoz L, de Durana MD, Vega A, et al. Safety and effectiveness of immunotherapy in patients with indolent systemic mastocytosis presenting with Hymenoptera venom anaphylaxis. J Allergy Clin Immunol 2008; 121:519-26.

142- Bonadonna P, Gonzalez-de-Olano D, Zanotti R, Riccio A, De Ferrari L, Lombardo $\mathrm{C}$, et al. Venom immunotherapy in patients with clonal mast cell disorders: efficacy, safety, and practical considerations. J Allergy Clin Immunol Pract 2013; 1:474-8.

143- Krishna MT, Ewan PW, Diwakar L, Durham SR, Frew AJ, Leech SC, et al. Diagnosis and management of hymenoptera venom allergy: British Society 
for Allergy and Clinical Immunology (BSACl) guidelines. Clin Exp Allergy 2011; 41:1201-20.

144- Hunt KJ, Valentine MD, Sobotka AK, Benton AW, Amodio FJ, Lichtenstein LM. A controlled trial of immunotherapy in insect hypersensitivity. N Engl J Med. 1978;299:157-61.

145- Golden DBK, Valentine MD, Kagay-Sobolka A, Lichtenstein LM. Regimens of hymenoptera venom immunotherapy. Ann Int Medicine 1980;92:620-4.

146- Van der Zwan JC, Flinterrman J, Jankowski IJ, Kerckhaert JA. Hyposensitisation to wasp venom in six hours. Br Med J 1983; 287: 1329-31.

147- Goldberg A, Confi no-Cohen R. Maintenance venom immunotherapy administered at 3-month intervals is both safe and efficacious. J Allergy Clin Immunol. 2001;107:902-6.

148- Freeman TM, Hylander R, Ortiz A, Martin ME. Imported Fire Ant Immunotherapy: Effectiveness of Whole Body Extracts. J Allergy Clin Immunol. 1992 Aug;90(2):210-5. doi: 10.1016/0091-6749(92)90073-b.

149- Bilo MB, Kamberi E, Tontini C, Marinangeli L, Cognigni M, Brianzoni MF, et al. High adherence to hymenoptera venom subcutaneous immunotherapy over a 5-year follow-up: A real-life experience. J Allergy Clin Immunol Pract 2016; 4:327-9 e1.

150- Berchtold E, Maibach R, Muller U. Reduction of side effects from rushimmunotherapy with honey bee venom by pretreatment with terfenadine. Clin Exp Allergy 1992; 22:59-65.

151- Brockow K, Kiehn M, Riethmuller C, Vieluf D, Berger J, Ring J. Efficacy of antihistamine pretreatment in the prevention of adverse reactions to Hymenoptera immunotherapy: a prospective, randomized, placebo-controlled trial. J Allergy Clin Immunol 1997; 100:458-63.

152- Reimers A, Hari Y, Muller U. Reduction of side-effects from ultrarush immunotherapy with honeybee venom by pretreatment with fexofenadine: a double-blind, placebo-controlled trial. Allergy 2000; 55:484-8.

153- Muller UR, Jutel M, Reimers A, Zumkehr J, Huber C, Kriegel C, et al. Clinical and immunologic effects of $\mathrm{H} 1$ antihistamine preventive medication 
during honeybee venom immunotherapy. J Allergy Clin Immunol 2008; 122:1001-7 e4.

154- Muller U, Hari Y, Berchtold E. Premedication with antihistamines may enhance efficacy of specific-allergen immunotherapy. J Allergy Clin Immunol 2001; 107:81-6.

155- Kontou-Fili K. High omalizumab dose controls recurrent reactions to venom immunotherapy in indolent systemic mastocytosis. Allergy 2008; 63:3768.

156- Schulze J, Rose M, Zielen S. Beekeepers anaphylaxis: successful immunotherapy covered by omalizumab. Allergy 2007; 62:963-4.

157- Stretz E, Oppel EM, Räwer HC, Chatelain R, Mastnik S, Przybilla B, et al. Overcoming severe adverse reactions to venom immunotherapy by using antiIgE antibodies in combination with a high maintenance dose. Clin Exp Allergy 2017.

158- Randolph CC, Reisman RE. Evaluation of decline in serum venomspecific IgE as a criterion for stopping venom immunotherapy. J Allergy Clin Immunol 1986; 77:823-7.

159- Reisman RE. Duration of venom immunotherapy: relationship to the severity of symptoms of initial insect sting anaphylaxis. J Allergy Clin Immunol 1993; 92:831-6.

160- Freeman TM, Hyghlander R, Ortiz A, Martin ME. Imported fire ant immunotherapy: effectiveness of whole-body extracts. J Allergy Clin Immunol 1992;90:210-5. (Ila).

161- Lockey RF, Turkeltaub PC, Olive ES, Hubbard JM, Baird-Warren IA, Bukantz SC. The Hymenoptera venom study. III: Safety of venom immunotherapy. J Allergy Clin Immunol 1990; 86:775-80.

162- Sturm G, Kranke B, Rudolph C, Aberer W. Rush Hymenoptera venom immunotherapy: a safe and practical protocol for high-risk patients. J Allergy Clin Immunol 2002; 110:928-33.

163- Roumana A, Pitsios C, Vartholomaios S, Kompoti E, Kontou-Fili K. The safety of initiating Hymenoptera immunotherapy at 1 microg of venom extract. $J$ Allergy Clin Immunol 2009; 124:379-81. 
164- Korosec P, Ziberna K, Silar M, Dezman M, Celesnik Smodis N, Rijavec $\mathrm{M}$, et al. Immunological and clinical factors associated with adverse systemic reactions during the build-up phase of honeybee venom immunotherapy. Clin Exp Allergy 2015; 45:1579-89.

165- Bonadonna P, Perbellini O, Passalacqua G, et al. Clonal mast cell disorders in patients with systemic reactions to Hymenoptera stings and increased serum tryptase levels. J Allergy Clin Immunol . 2009;123:680-686.

166- Muller UR, Haeberli G. Use of beta-blockers during immunotherapy for Hymenoptera venom allergy. J Allergy Clin Immunol 2005; 115:606-10.

167- Shamji MH, Kappen JH, Akdis M, et al. Biomarkers for monitoring clinical efficacy of allergen immunotherapy for allergic rhinoconjunctivitis and allergic asthma: an EAACI Position Paper. Allergy. 2017;72(8):1156-1173.

168- Keating MU, Kagey-Sobotka A, Hamilton RG, Yunginger JW. Clinical and immunologic follow-up of patients who stop venom immunotherapy. J Allergy Clin Immunol. 1991;88:339-348.

169- Erzen R, Kosnik M, Silar M, Korosec P. Basophil response and the induction of a tolerance in venom immunotherapy: a long-term sting challenge study. Allergy. 2012;67:822-830.

170- Rueff F, Przybilla B, Muller U, Mosbech $H$. The sting challenge test in Hymenoptera venom allergy. Position paper of the Subcommittee on Insect Venom Allergy of the European Academy of Allergology and Clinical Immunology. Allergy. 1996;51:216-225.

171- Lichtenstein LM, Valentine MD, Sobotka AK. Insect allergy: the state of the art. J Allergy Clin Immunol. 1979;64:5-12.

172- Lessof MH, Sobotka AK, Lichtenstein LM. Effects of passive antibody in bee venom anaphylaxis. Johns Hopkins Med J 1978;142:1-7.

173- James LK, Shamji MH, Walker SM, Wilson DR, Wachholz PA, Francis $\mathrm{JN}$, et al. Long-term tolerance after allergen immunotherapy is accompanied by selective persistence of blocking antibodies. J Allergy Clin Immunol 2011;127:509-16, e1-5.

174- Brydon MJ. Skin prick testing in general practice. J Adv Nurs, 1998. 27(2): p. 442-4. 
175- Mota A, Kalil J, Barros MT. Testes cutâneos. Rev bras alerg imunopatol 2005,28(2):73-83.

176- Tripolt P, Arzt-Gradwohl L, Čerpes U, Laipold K, Binder B, Sturm GJ. Large local reactions and systemic reactions to insect stings: Similarities and differences. PLoS One. 2020;15(4):e0231747. Published 2020 Apr 16. doi:10.1371/journal.pone.0231747

177- Koterba AP, Greenberger PA. Chapter 4: Stinging insect allergy and venom immunotherapy. Allergy Asthma Proc. 2012;33 Suppl 1:12-14. doi:10.2500/aap.2012.33.3534.

178- Cox L, Larenas-Linnemann D, Lockey RF, Passalacqua G. Speaking the same language: The World Allergy Organization Subcutaneous Immunotherapy Systemic Reaction Grading System. The Journal of allergy and clinical immunology. 2010;125(3):569-74, 74.e1-74.e7.

179- Cox LS, Sanchez-Borges M, Lockey RF. World Allergy Organization Systemic Allergic Reaction Grading System: Is a Modification Needed? The journal of allergy and clinical immunology In practice. 2017;5(1):58-62.e5.

180- Tankersley MS, Butler KK, Butler WK, Goetz DW. Local reactions during allergen immunotherapy do not require dose adjustment. J Allergy Clin Immunol. 2000, Vol. 106, 840-3.

181- JM., Kelso. The rate of systemic reactions to immunotherapy injectons is the same whether or not the dose is reduced after a local reaction. Ann Allergy Asthma Immunol. 2004, Vol. 92, 225-7.

182- Roy SR, Sigmon JR, Olivier J, Moffitt JE, Brown DA, Marshall GD. Increased frequency of large local reactions among systemic reactors during subcutaneous allergen immunotherapy. Ann Allergy Asthma Immunol. 2007, Vol. 99, 82-6.

183- Stablein JJ, Lackey RF. Adverse reactions to ant stings. Clin Rev Allergy 1987;5:161.

184- Fehr D, Micaletto S, Moehr T, Schmid-Grendelmeier P. Risk factors for severe systemic sting reactions in wasp (Vespula spp.) and honeybee (Apis mellifera) venom allergic patients. Clin Transl Allergy. 2019 Oct 11;9:54. doi: 10.1186/s13601-019-0292-5. eCollection 2019. 
185- Simons FE, Ardusso LR, Bilo MB, El-Gamal YM, Ledford DK, Ring J, et al. World Allergy Organization anaphylaxis guidelines: summary. J Allergy Clin Immunol. 2011;127(3):587-93 e1-22.

186- Shaker MS, Wallace DV, Golden DBK, Oppenheimer J, Bernstein JA, Campbell RL, Dinakar C, Ellis A, Greenhawt M, Khan DA, Lang DM, Lang ES, Lieberman JA, Portnoy J et al. Anaphylaxis-a 2020 practice parameter update, systematic review, and Grading of Recommendations, Assessment, Development and Evaluation (GRADE) analysis. J Allergy Clin Immunol. 2020 Jan 28. pii: S0091-6749(20)30105-6. doi: 10.1016/j.jaci.2020.01.017. [Epub ahead of print]

187- Simons FE, Ardusso LR, Bilò MB, Cardona V, Ebisawa M, El-Gamal YM, Lieberman P, Lockey RF, Muraro A, Roberts G, Sanchez-Borges M, Sheikh A, Shek LP, Wallace DV, Worm M. International consensus on (ICON) anaphylaxis. World Allergy Organ J. 2014 May 30;7(1):9. doi: 10.1186/19394551-7-9. PMID: 24920969; PMCID: PMC4038846.

188- Fernandez J, Soriano V, Mayorga L, Mayor M. Natural history of Hymenoptera venom allergy in Eastern Spain. Clin Exp Allergy. 2005 Feb;35(2):179-85.

189- Golden DBK, Kagey-Sobotka A, Norman PS, et al. Outcomes of allergy to insect stings in children with and without venom immunotherapy. $\mathrm{N}$ Engl $J$ Med. 2004;351:668e674.

190- Graft DF, Schubert KC, Kagey-Sobotka A, et al. A prospective study of the natural history of large local reactions after Hymenoptera stings in children. J Pediatr. 1984;104:664e668.

191- Sturm GJ, Kranzelbinder B, Schuster C, Sturm EM, Bokanovic D, Vollmann J, et al. Sensitization to Hymenoptera venoms is common, but systemic sting reactions are rare. J Allergy Clin Immunol. 2014;133(6):1635-43. 192- Warrington R. Lack of Correlation between Severity of Clinical Symptoms, Skin Test Reactivity, and Radioallergosorbent Test Results in Venom Allergic Patients. Allergy Asthma Clin Immunol. 2006;2(2):62-7.

193- Sturm GJ, Heinemann A, Schuster C, Wiednig M, Groselj-Strele A, Sturm $E M$, et al. Influence of total $\lg E$ levels on the severity of sting reactions in Hymenoptera venom allergy. Allergy. 2007;62(8):884-9. 
194- Urbanek R, Kemeny DM, Richards D. Sub-class of IgG anti-bee venom antibody produced during bee venom immunotherapy and its relationship to long-term protection from bee stings and following termination of venom immunotherapy. Clin Allergy. 1986;16:317-322.

195- Rueff F, Wolf H, Schnitker J, Ring J, Przybilla B. Specific immunotherapy in honeybee venom allergy: a comparative study using aqueous and aluminium hydroxide adsorbed preparations. Allergy. 2004;59:589-595.

196- van Halteren HK, van der Linden PW, Burgers JA, Bartelink AK. Discontinuation of yellow jacket venom immunotherapy: follow-up of 75 patients by means of deliberate sting challenge. J Allergy Clin Immunol. 1997;100:767770.

197- Ewan PW, Deighton J, Wilson AB, Lachmann PJ. Venom-specific IgG antibodies in bee and wasp allergy: lack of correlation with protection from stings. Clin Exp Allergy. 1993;23:647-660.

198- Golden DB, Lawrence ID, Hamilton RH, Kagey-Sobotka A, Valentine MD, Lichtenstein LM. Clinical correlation of the venom-specific IgG antibody level during maintenance venom immunotherapy. J Allergy Clin Immunol. 1992;90:386-393.

199- Wilson AB, Deighton J, Lachmann PJ, Ewan PW. A comparative study of IgG subclass antibodies in patients allergic to wasp or bee venom. Allergy. 1994;49:272-280.

200- Eich-Wanger C, Muller UR. Bee sting allergy in beekeepers. Clin Exp Allergy. 1998;28:1292-1298.

201- Chliva C, Aggelides X, Makris M, Katoulis A, Rigopoulos D, Tiligada E. Comparable profiles of serum histamine and IgG4 levels in allergic beekeepers. Allergy. 2015;70:457-460.

202- Hayashi $Y$, Hirata $H$, Watanabe $M$, et al. Usefulness of specific-lgG4 to Hymenoptera venom in the natural history of hymenoptera stings. J Investig Allergol Clin Immunol. 2014;24:192-194.

203- Wurtzen PA, Lund G, Lund K, Arvidsson M, Rak S, Ipsen H. A doubleblind placebo-controlled birch allergy vaccination study II: correlation between inhibition of IgE binding, histamine release and facilitated allergen presentation. Clin Exp Allergy 2008;38:1290-301. 
204- Ejrnaes AM, Svenson M, Lund G, Larsen JN, Jacobi H. Inhibition of rBet v 1 -induced basophil histamine release with specific immunotherapy-induced serum immunoglobulin G: no evidence that FcgammaRIIB signalling is important. Clin Exp Allergy 2006;36:273-82.

205- Blum S, Gunzinger A, Muller UR, Helbling A. Influence of total and specific $\operatorname{lgE}$, serum tryptase, and age on severity of allergic reactions to Hymenoptera stings. Allergy 2011;66:222-228

206- Bilò MB, Antonicelli L, Bonifazi F. Purified vs. non-purified venom immunotherapy. Curr Opin Allergy Clin Immunol 2010;(10):330-336. doi:10.1097/ACl.0b013e328339f2d1.

207- Bilò MB, Severino M, Cilia M, Pio A, Casino G, Ferrarini E, et al. The VISYT trial: Venom Immunotherapy Safety and Tolerability with purified vs nonpurified extracts. Ann Allergy Asthma Immunol 2009; (103):57-61. doi:10.1016/S1081-1206(10)60144-5.

208- Bilò MB, Cinti B, Brianzoni MF, Braschi MC, Bonifazi M, Antonicelli L. Honeybee venom immunotherapy: a comparative study using purified and nonpurified aqueous extracts in patients with normal Basal serum tryptase concentrations. J Allergy (Cairo) 2012; (2012):869243. doi:10.1155/2012/869243.

209- Wenzel J, Meissner-Kraemer M, Bauer R, et al. Safety of rush insect venom immunotherapy. The results of a retrospective study in 178 patients. Allergy 2003; 58:1176-1179.

210- Haeberli G, Bronnimann M, Hunziker T, Mu“ Iler U. Elevated basal serum tryptase and hymenoptera venom allergy: relation to severity of sting reactions and to safety and efficacy of venom immunotherapy. Clin Exp Allergy 2003;33:1216-1220.

211- Golden DBK, Kagey-Sobotka A, Valentine MD, Lichtenstein LM. Dose dependence of Hymenoptera venom immunotherapy. J Allergy Clin Immunol 1981; 67:370-374.

212- Urbanek R, Forster J, Kuhn W, Ziupa J. Discontinuation of bee venom immunotherapy in children and adolescents. J Pediatr 1985; 107:367-371. 
